\title{
IntechOpen
}

\section{Current Treatment of Cleft Lip and Palate}

\author{
Edited by Ayşe Gülsen
}





\section{Current Treatment of Cleft Lip and Palate Edited by Ayşe Gülşen}



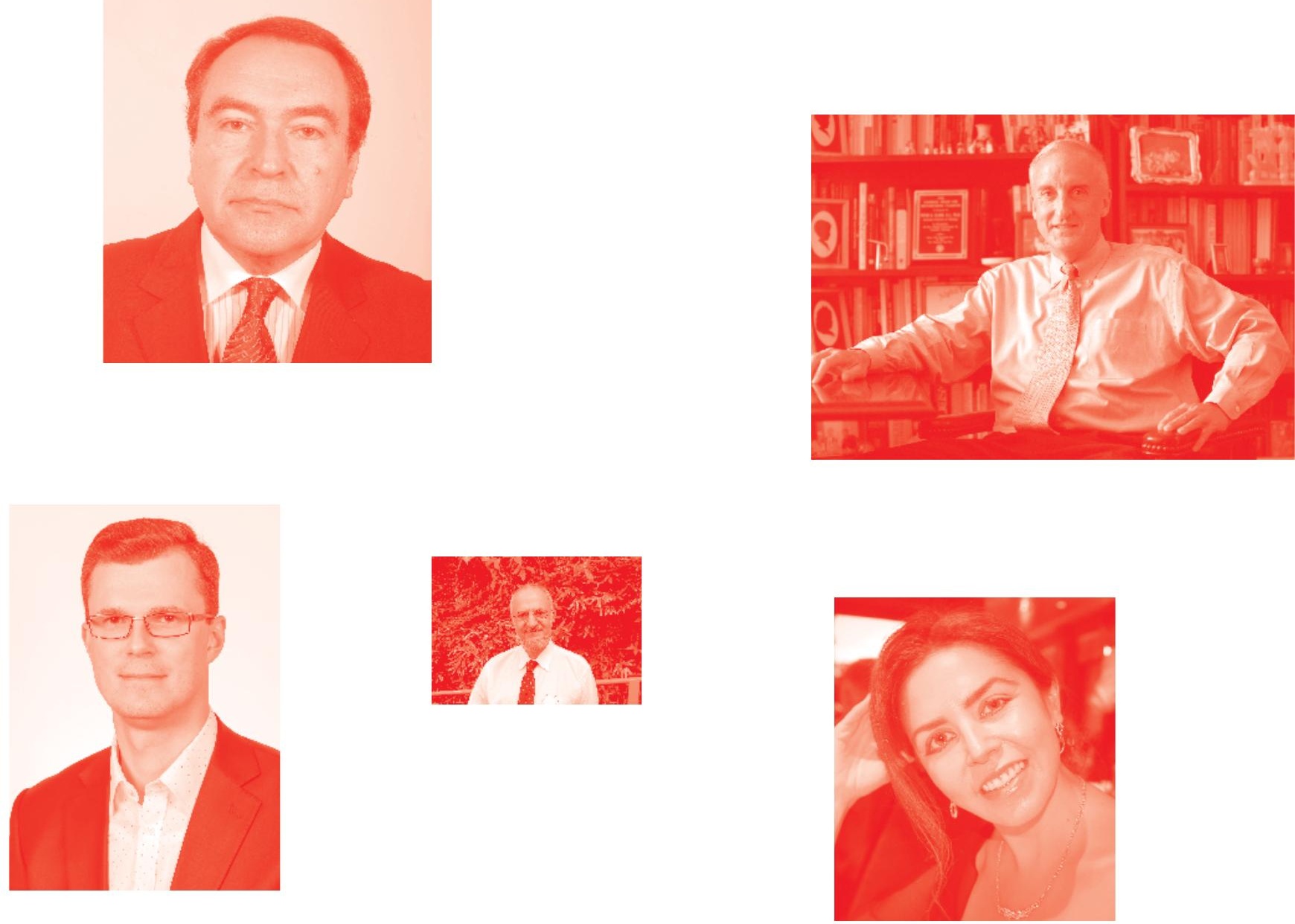

Supporting open minds since 2005
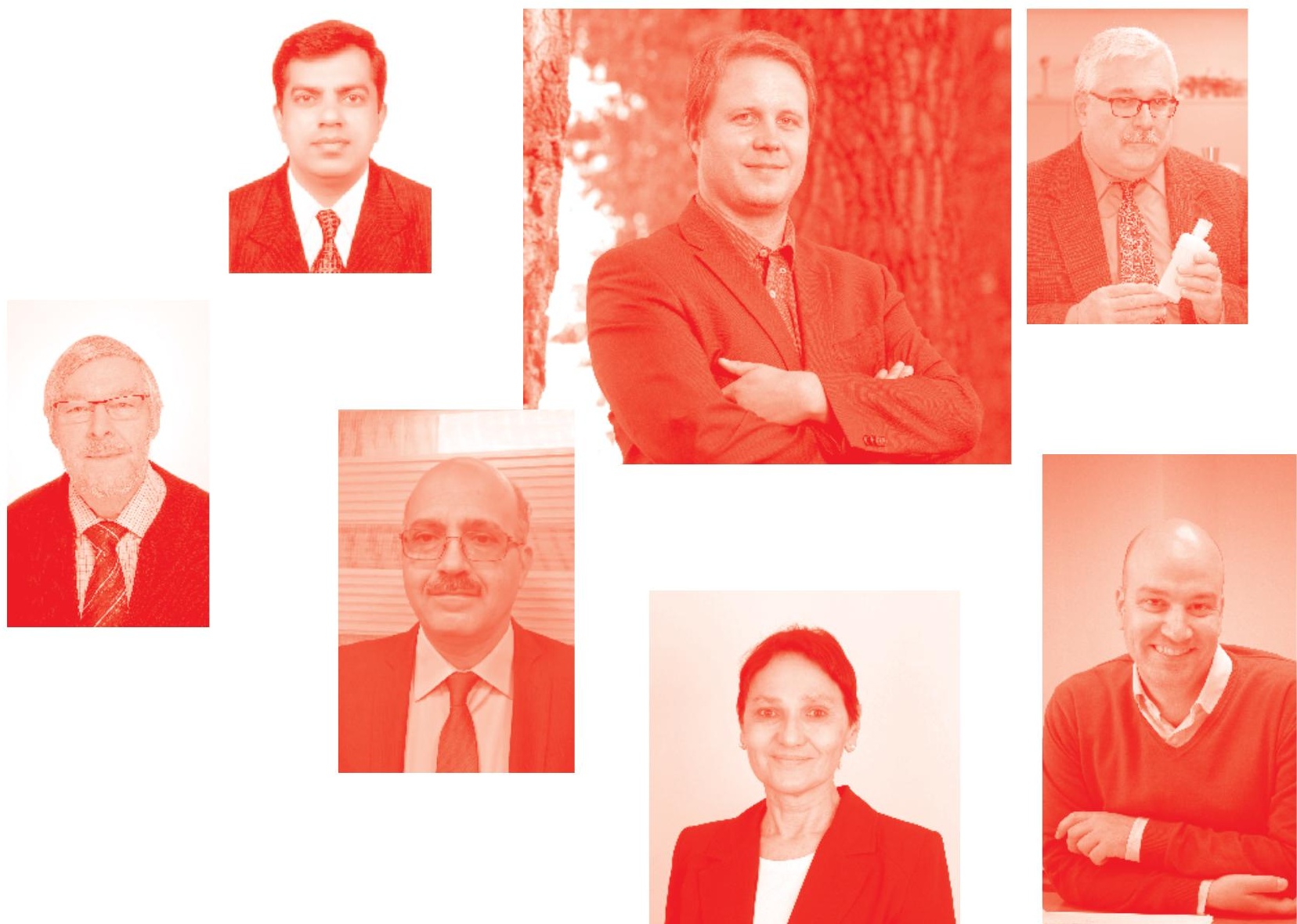
Current Treatment of Cleft Lip and Palate

http: //dx. doi. org/10.5772/intechopen. 77803

Edited by Ayșe Gülşen

\section{Contributors}

Eugene Park, Alex Campbell, Gaurav Deshpande, Bjorn Schonmeyr, Carolina Restrepo, Elaine Tan, Mimi Yow, Geetanjali Sharma, Silvia Pena-Olvera, Hakan Yilmaz, Arzu Ari Demirkaya, Latifa El Mouden, Fatima Zahra Elgasmi, Lahcen Ousehal

(-) The Editor(s) and the Author(s) 2020

The rights of the editor(s) and the author(s) have been asserted in accordance with the Copyright, Designs and Patents Act 1988. All rights to the book as a whole are reserved by INTECHOPEN LIMITED . The book as a whole (compilation) cannot be reproduced, distributed or used for commercial or non-commercial purposes without INTECHOPEN LIMITED's written permission. Enquiries concerning the use of the book should be directed to INTECHOPEN LIMITED rights and permissions department (permissions@intechopen.com).

Violations are liable to prosecution under the governing Copyright Law .

\section{(cc) BY}

Individual chapters of this publication are distributed under the terms of the Creative Commons Attribution 3.0 Unported License which permits commercial use, distribution and reproduction of the individual chapters, provided the original author(s) and source publication are appropriately acknowledged. If so indicated, certain images may not be included under the Creative Commons license. In such cases users will need to obtain permission from the license holder to reproduce the material. More details and guidelines concerning content reuse and adaptation can be found at http : //www . intechopen . com/copyright-policy. html.

\section{Notice}

Statements and opinions expressed in the chapters are these of the individual contributors and not necessarily those of the editors or publisher. No responsibility is accepted for the accuracy of information contained in the published chapters. The publisher assumes no responsibility for any damage or injury to persons or property arising out of the use of any materials, instructions, methods or ideas contained in the book.

First published in London, United Kingdom, 2020 by IntechOpen IntechOpen is the global imprint of INTECHOPEN LIMITED, registered in England and Wales, registration number: 11086078 , 7th floor, 10 Lower Thames Street, London,

EC3R 6AF, United Kingdom

Printed in Croatia

British Library Cataloguing-in-Publication Data

A catalogue record for this book is available from the British Library

Additional hard and PDF copies can be obtained from orders@intechopen .com

Current Treatment of Cleft Lip and Palate

Edited by Ayşe Gülşen

p. cm.

Print ISBN 978-1-83880-013-0

Online ISBN 978-1-83880-014-7

eBook (PDF) ISBN 978-1-83880-480-Ø 


\section{We are IntechOpen, \\ the world's leading publisher of Open Access books}

Built by scientists, for scientists

\section{$4,700+$}

Open access books available

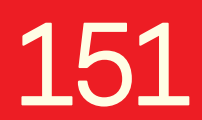

Countries delivered to

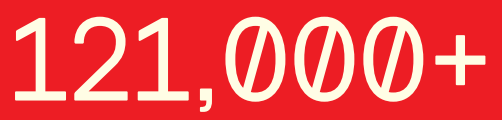

International authors and editors

Our authors are among the

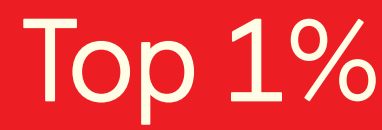

most cited scientists

Contributors from top 500 universities
40010

Downloads

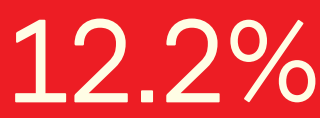

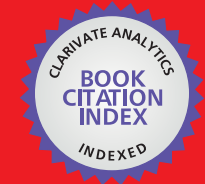

WEB OF SCIENCE ${ }^{\text {MM }}$

Selection of our books indexed in the Book Citation Index in Web of Science ${ }^{\mathrm{TM}}$ Core Collection (BKCI)

Interested in publishing with us?

Contact book.department@intechopen.com

Numbers displayed above are based on latest data collected.

For more information visit www.intechopen.com

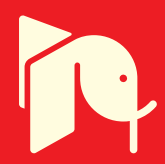





\section{Meet the editor}

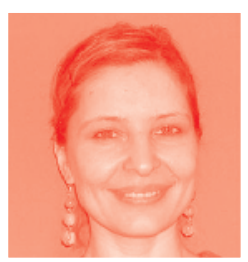

Ayşe Gülşen is an orthodontist who works as a craniofacial orthodontist in the Department of Esthetic, Plastic and Reconstructive Surgery, Faculty of Medicine, University of Gazi, Ankara Turkey. She graduated in 1990 from the Faculty of Dentistry, University of Ankara and worked as a research assistant and an assistant professor in the Department of Orthodontics, Faculty of Dentistry, University of Gazi, Ankara; Department of Orthodontics, Faculty of Dentistry, University of Ondokuz Mayss, Samsun, Turkey respectively. She has also observed cleft and craniofacial patients in the Craniofacial Department in NYU, USA (2002 and 2015) and worked as a fellowship in the Providence Hospital, Craniofacial Department, Michigan, USA (2006) and Chang Gung Memorial Hospital Craniofacial Center, Taipei, Taiwan (2017). She has authored many national and international publications, scientific abstracts, presentations, and invitation speeches. 



\section{Contents}

Preface

Section 1

Dental Development and Treatment in Clefts

Chapter 1

Dental Development and Anomalies in Cleft Lip and Palate by Elaine Li Yen Tan and Mimi Yow

Chapter 2

Orthodontic Management of Cleft Lip and Palate Patients

by Geetanjali Sharma

Section 2

Surgery in Clefts

Chapter 3

Optimizing Outcomes in Cleft Surgery

by Eugene Park, Gaurav Deshpande, Bjorn Schonmeyr, Carolina Restrepo and Alex Campbell

Chapter 4

Anesthesia Considerations in the Perioperative of Patients with Lip and Palate Length

by Silvia Peña, Claudia Paulina Reyes, Andres Felipe Beltran

and Ofelia Ham

Chapter 5

Orthognathic Surgery in Cleft Lip and Palate Patients

by Hakan Yilmaz and Arzu Ari Demirkaya

Section 3

Life Quality in Clefts

Chapter 6

Quality of Life in Adolescents with Cleft Lip and Palate

by Latifa Elmouden, Fatima Zahra Elgasmi and Lahcen Ousehal 



\section{Preface}

Non-syndromic cleft lip and palate patients have the most common congenital anomalies that affect the middle and lower part of the face, and which impair aesthetic integrity. These anomalies also affect basic functions such as hearing, speaking, chewing, and breathing. In addition to the dental, skeletal, auditory, and speech problems created by the defect itself, some other problems that may arise include midfacial retrognathie at various stages of the growth development period as a result of the restraining effect of the development of scar tissue developed secondary to the lip and palate surgery.

Treatment of patients with cleft lip and palate is not only possible with surgery, but it requires multidisciplinary teamwork. The cleft child should be followed and treated by a team of experts from different disciplines who work well together. The presence of an orthodontist, plastic, reconstructive and esthetic surgeon, maxillo facial surgeon, otolaryngologist, speech therapist, pediatric dentist, psychologist and nurse in this team affects the success of the treatment. Although cleft surgery, orthodontic treatment, and speech therapy are the main disciplines, each of the other branches is also very important. In this book, we present the reader with the experiences and knowledge of some of these disciplines. This book also includes information on the quality of life of children with this anomaly and anesthesia evaluation, which is very important for the cleft surgery. I would like to extend my sincere thanks to all the authors who have contributed, and to the valuable readers.

Ayşe Gülşen, PhD, DDS

Orthodontist,

Associate Professor, Department of Plastic Reconstructive and Esthetic Surgery, University of Gazi, Ankara, Turkey 

Section 1

\section{Dental Development and Treatment in Clefts}





\title{
Dental Development and Anomalies in Cleft Lip and Palate
}

\author{
Elaine Li Yen Tan and Mimi Yow
}

\begin{abstract}
Cleft lip and/or palate is a birth defect with heterogeneous clinical presentations. Prevalence and cleft-types differ by gender, ethnic groups and geographic locations. Published literature indicates high frequencies of cleft-associated dental anomalies, commonly variations in tooth-number, shape and size. Delayed dental development is also reported with catch-up growth at a later age. In the unilateral cleft phenotype, delayed development can occur on the cleft-side of the maxilla. Dental anomalies present frequently in the spectrum of cleft defects. Heterogeneity of defects is wide-ranging and may represent different aetiological origins of cleft phenotypes and sub-types due to: genetic mutations with altered ectomesenchymal growth; iatrogenesis from disrupted blood supply during early postnatal surgery; and maldevelopment or mistimed development. Orofacial clefting and odontogenesis may share critical pathways.
\end{abstract}

Keywords: dental anomalies, dental development, cleft lip, cleft palate

\section{Introduction}

Cleft lip and/or palate (CLP) is a birth defect with heterogeneous clinical presentations [1]. Prevalence and cleft-types differ by gender, ethnic groups and geographic locations [2]. It has been widely reported that dental anomalies (delayed dental development and eruption, hypodontia, supernumeraries, hypoplasia and abnormalities in tooth size and shape) in CLP are commonly associated with the presence of the cleft [3].

\section{Dental development and eruption in CLP patients}

\subsection{Methods in assessing dental development}

There are several methods that have been devised for assessing dental development or calculating dental age [4-12]. Essentially, tooth development is observed from radiographs and compared with the formation stages in each system. Some systems allow dental age to be calculated after ascertaining the teeth formation stages.

Of the various systems available, the method proposed by Demirjian et al. [9] and Demirjian and Goldstein [12] has been well researched and was found to be highly accurate and precise for estimation of dental age, particularly during early childhood $[13,14]$. For any method of age estimation, it is best established within population-specific groups to reduce confounders [15]. 


\subsubsection{Demirjian's method}

According to the criteria, the maturity of the seven mandibular teeth on the left side (excluding the third molar) was determined by comparing their radiographic appearances with a sequence of reference radiographs and diagrams, and description of formation stages. If any of the mandibular left teeth was missing, or its image was unclear, the contra-lateral tooth was used [9].

Each tooth was divided into eight formative stages (A to $\mathrm{H}$ ), and each stage was allocated a score depending on the gender. The scores for all seven teeth were then added to give the maturity score which can be converted directly into dental age by reading off a percentile curve the age at which the 50th centile attains the maturity score value, or by using a table which had been constructed.

\subsection{Delayed dental development}

Several investigators reported on delayed formation of the permanent teeth in CLP patients and the delay was observed to vary from 0.3 to 0.9 year [16-22].

Bailit and coworkers found that tooth formation in 39 children with cleft palate was significantly retarded by about 0.7 year when compared with 36 normal controls [16]. Ranta in his earlier study compared 258 CLP Finnish children with 1162 noncleft children and reported a delay in tooth formation of 0.5 year in the maxilla and 0.4 year in the mandible, but the difference was not statistically significant [18].

\subsubsection{Cleft severity and delayed dental development}

Ranta went on further to conduct other investigations and revealed that the delay in tooth formation increased from 0.3 to 0.7 year with increasing severity of the cleft deformity. No significant difference was found in the tooth formation of subgroups with and without hypodontia [23]. However, in his later study on children with isolated CP only, he found that the dental development was delayed longer in the cleft subgroup with hypodontia ( 0.7 year) than in the subgroup without hypodontia ( 0.4 year), and a somewhat longer delay in tooth formation was observed with increasing number of missing teeth per child [24].

\subsubsection{Age and delayed dental development}

Harris and Hullings studied 54 CLP children and reported an overall delay in dental development of 0.9 year. They also noted that teeth formed during the early postnatal period were most affected, while the later forming teeth were less delayed [19].

Other authors [25-28] found that the delay in dental development begins to decrease from the age of 8 to 9.5 years old, suggestive of some form of catch-up growth $[29,30]$. This is in contrast to the findings of Ranta who noted that the delay in dental development was significantly longer in the older age group of 9 to 12 years old (1.1 years) than in the younger age group of 6-9 years old (0.6 year) [3].

A study by Borodkin et al. found an overall delay in dental development of 0.52 year, but was found to be statistically significant only in male cleft subjects [21]. The most commonly delayed permanent teeth were the maxillary first and second premolars and maxillary second molars. No statistically significant differences in dental development were found between the various cleft types and severity of cleft deformities. 
In another investigation, Lai et al. based their study on 231 southern Chinese CLP children from Hong Kong and compared them with a non-CLP control sample of the same size [20]. Similarly, they found an overall delay in tooth formation of Chinese CLP children ( 0.4 year) with the earlier formed permanent teeth being more delayed in development than those formed later. In accordance to the findings of Ranta [23], CLP children with more severe hypodontia were also more delayed in dental development.

Tan et al. found that UCLP children at 5-9 years old had more delayed dental maturation of 0.55 year when compared to controls [28]. The delay in dental maturation attenuated as they grew older and no difference in dental maturation were found in the UCLP children and controls at 9-13 years old. Several postulations may account for this phenomenon. Firstly, there could be some form of catch-up growth in the patients with CLP as they mature, as described by some authors [27, 29-32]. Secondly, the accuracy and precision of Demirjian's method [9] have been shown to decrease with age $[13,26,33]$. This is because the tooth developmental stages occurring earlier in life are generally of shorter duration than the stages occurring later, and the stages of short duration are more easily discerned with distinctive changes over a shorter period than smaller increments over a longer duration [13]. In addition, at an older age, the assessment of dental age is based on fewer teeth with roots that are not fully formed. For example, at the age of eleven, there may only be two teeth (usually the second premolar and second molar) with incomplete root formation, and the assessment of dental age would be based entirely on these two teeth. Any measurement error will, thus, have a profound effect on the dental age determination. Hence, there is a tendency to overestimate the dental age in the older age group, and this could reduce the discrepancy in dental age delay between the group with UCLP and without CLP. Furthermore, the roots of the teeth in patients with CLP are reported to be shorter than average [34], and this may further complicate the assessment of dental age. Thirdly, only the incisors and first molars are affected by environmental factors during gestation and early prenatal period [35]. As the formation of these teeth plays a big part in determining the dental age in the younger age group, their effects on the length of dental age delay would be significant. Root formation of the incisors and first molars would have been already completed in the older group of subjects; hence, they no longer have an impact on the dental age determination.

\subsubsection{Hypodontia and delayed dental development}

Tan et al. found that the presence and extent of hypodontia in CLP patients did not influence the dental development [28]. This contrasted with earlier studies [20, 24 ] that found a bigger delay in dental development in clefts with hypodontia than without hypodontia, and the more severe the hypodontia, the bigger the delay. However, these studies had several confounding factors. Ranta's study only included patients with isolated cleft palate [24], while the study of Lai et al. included various cleft types [20].

\subsubsection{Gender and delayed dental development}

The evidence for any gender association has been weak, with some studies suggesting that the delay was more pronounced in boys compared to girls [20, 21, 27], and other studies showing no significant gender differences [18, 23, 24, 26, 28, 36]. 


\subsection{Asymmetric tooth formation}

\subsubsection{Definition}

A pair of teeth is regarded as developing asymmetrically when the crown or root development of one of the teeth deviated from that of the antimeric tooth by at least one developmental stage. Ranta was one of the earliest authors to report on asymmetric tooth formation [18]. Studies have found that children with CLP had asymmetrical tooth formation that was 3-4 times more common than those of the control group $[20,21,23]$. The only study that did not report such a finding was by Borodkin et al. [21].

\subsubsection{Teeth involved}

When considering individual teeth, some teeth seem to display a greater propensity for asymmetric formation. Ranta reported that asymmetric tooth development occurred most frequently in the upper central incisors followed by the upper and lower premolars, without taking into account peg-shaped teeth and third molars $[19,38]$. Harris and Hullings found that second premolars and third molars were more likely candidates for asymmetric formation and these teeth were also more likely to be congenitally missing, with the incisors being excluded in their study [19]. Tan et al. found that the most commonly delayed tooth in the maxilla is the cleft-sided lateral incisors $(73.3 \%)$, followed by the cleft-sided central incisors $(37.3 \%)$, while the cleft-sided canines and first premolars were the most frequently affected (21.7\%) in the mandible [22].

\subsubsection{Cleft vs. non-cleft side}

Several authors concur that in both the maxilla and mandible, the cleft side has a significantly higher risk of delayed development of teeth than non-cleft side $[18,20,22]$.

\subsubsection{Maxilla vs. mandible}

Ranta also investigated the difference in incidence of asymmetric tooth development between both jaws. In the cleft palate group, asymmetry occurs with equal frequency in both jaws. However in the cleft lip and alveolus group and the CLP group, asymmetry occurs more frequently in the maxilla $[18,37]$. Asymmetric development of teeth was also found to decrease as growth of the crowns and roots progresses [38].

\subsection{Delayed dental eruption}

Tooth eruption occurs at a precise stage of root development and hence, any delay or asymmetric tooth formation would likely affect the timing and pattern of tooth eruption.

Peterka et al. reported that the deciduous and permanent lateral incisors in the maxillary quadrant with cleft showed the greatest retardation [39]. He also noted delayed eruption of the canine, first and second premolars in the maxillary quadrant with cleft. This coincides with the findings of Carrara et al. who found retarded eruption of the maxillary lateral incisor, cuspid and second premolar on the cleft side [40]. 


\subsection{Aetiology of asymmetric tooth formation and eruption}

Eerens et al. compared 54 children with cleft, 63 children in the sibling group without cleft as well as 250 normal children in the non-sibling control group and found that the cleft group and sibling group showed a significantly higher frequency of asymmetric tooth formation compared to the control group, hence suggesting some common genetic factors for delayed tooth formation and clefting [41].

Another possible reason for asymmetric tooth formation and delayed eruption in CLP patients has also been proposed. The effects of surgical cleft repair could result in damage to the tooth bud, or fibrosis and reduced blood supply to the cleft area [18]. Other etiological factors include lack of space in the cleft area [39] and growth attenuation due to improper nutrition as a result of feeding problems [18].

\section{Dental anomalies in CLP patients}

\subsection{Lateral incisor in the cleft area}

The permanent maxillary lateral incisor in CLP patients is a tooth of much interest and has been widely researched on, due to its proximity to the cleft and hence vulnerability to maldevelopment and injury. Disrupted development at the site of the cleft could also be due to altered neurovascular anatomy that could affect the developing tooth germ [42].

Some primary maxillary lateral incisors were found to be macrodonts whereas the permanent lateral incisors were microdonts or peg-shaped [43]. It has been reported as the most commonly missing tooth in CLP patients with a frequency ranging from $19.2-39.3 \%$ [3, 17, 44-47].

\subsubsection{Position of cleft-sided lateral incisor}

When the permanent maxillary lateral incisor is present in CLP patients, it is usually located on the distal side of the cleft [17, 44, 47-50] and is often reported to be delayed in formation and eruption when compared to the antimeric lateral incisor on the non-cleft side [17, 20, 22, 36, 47, 51].

Tsai et al. reported on the discrepancy in distribution patterns of the cleftsided maxillary lateral incisors in the primary and permanent dentition [46]. In the primary dentition, the lateral incisor was located most commonly on the distal side of the alveolar cleft (82.4\%), followed by missing cleft-sided maxillary lateral incisor $(9.9 \%)$, one tooth present on each side of the alveolar cleft $(5.5 \%)$, and lastly, the lateral incisor was located mesial to the alveolar cleft (2.2\%). However, in the permanent dentition, the most predominant pattern was the missing cleftsided maxillary lateral incisor $(51.8 \%)$, followed by the lateral incisor positioned distal to the alveolar cleft (46\%), lateral incisor positioned mesial to the alveolar cleft $(1.5 \%)$ and the least common finding of one tooth present on each side of the alveolar cleft $(0.7 \%)$. Due to the difference in the distribution patterns between the primary and permanent dentition, the authors proposed that there may be two odontogenic origins (maxillary and medial nasal process) for the maxillary lateral incisors. Failure of fusion between the two processes could have resulted in unequal mesenchymal mass in each of the segment, hence giving rise to different distribution patterns. 


\subsubsection{Malformed cleft-sided lateral incisor}

The permanent lateral incisor located on the cleft side is also the most malformed tooth in the entire permanent dentition, often presenting with some degree of deformity in size and shape [45, 52]. It is frequently found to be microdontic or peg-shaped [44, 47, 50, 53]. Suzuki et al. found the majority of cleft-sided permanent lateral incisors to be of conical type [49]. Other less common variations include T-shaped lateral incisor or presence of a palatal cusp $[44,53,54]$.

Some authors have proposed that malformed or missing lateral incisors are possible microforms of cleft lip and/or palate [55-57] but this proposal has also been disputed by others [58-60] who found the frequency of lateral incisor anomaly to be the same in cleft families and non-cleft families.

\subsection{Hypodontia}

\subsubsection{Teeth involved}

Another common dental anomaly found in CLP patients is an increased prevalence of congenitally missing teeth occurring near and away from the cleft area. Apart from the commonly missing lateral incisor as mentioned previously, other teeth frequently involved are the upper and lower second premolars $[17,19,41$, $44-46,61,62]$, with the maxillary second premolar being the more frequently missing tooth $[45,61]$.

\subsubsection{Prevalence}

The prevalence of hypodontia in CLP sample has been reported to range from $31.6-77 \%$ [50, 62-64]. In addition, the prevalence of hypodontia also increases with severity of the cleft $[3,44,61,65]$.

Ranta found that in complete cleft cases, almost every fourth (24\%) of the upper second premolar was found to be missing [61].

However, other authors found that the maxillary lateral incisor was the most commonly missing tooth $(41.7 \%)$, followed by the maxillary second premolar $(18.3 \%)[50,62]$. Due to its proximity to the cleft defect, the cleft-sided maxillary lateral incisor is the most vulnerable to maldevelopment and iatrogenic injury, hence explaining its high frequency of being missing [66]. It was similarly reported as the most commonly missing tooth in CLP patients with a frequency ranging from 19.2-39.3\% [3, 17, 44-47].

In a non-cleft population, Brook (1984) reported that the prevalence of hypodontia in British school children was 4.4\%; the most commonly missing tooth was the mandibular second premolar [67]. The lower second premolar was the most commonly missing tooth in $26.1 \%$ of the Singapore Chinese orthodontic population with hypodontia. The lower incisor was the next most commonly missing tooth in $21.6 \%$, followed by the upper lateral incisor in $20.5 \%$ of the population [68]. In Caucasians, the next most commonly missing tooth would be the maxillary lateral incisors, followed by the maxillary second premolar [69].

\subsubsection{Primary vs. permanent dentition}

Hypodontia, in contrast to supernumerary teeth, is found to be more prevalent in the permanent dentition than primary dentition in CLP patients [43, 44, 52, 61]. 


\subsubsection{Aetiology}

One hypothesis for hypodontia which explains these findings is the Butler's field theory (1939) that postulated teeth were not individual structures but constituted a series of different morphological classes with the most stable tooth at the mesial end. The distal tooth in each class was evolutionarily less stable [70].

Eerens et al. also demonstrated a higher occurrence of hypodontia in the cleft group and sibling group as compared to the normal, non-cleft control group, hence suggesting some relationship between the genetic factors controlling clefting and hypodontia [41].

Among the genetic factors involved in craniofacial development are members of the $M s x$ homeobox gene family [71] and till date, $M s x 1$ has shown good evidence of involvement in human orofacial clefting and tooth agenesis [71-76]. A missense mutation resulting in an arginine to proline substitution within the homeodomain of $M s x 1$ causes selective tooth agenesis in humans, an autosomal dominant phenotype affecting the second premolars and third molars of the secondary dentition [72].

\subsection{Supernumerary teeth}

\subsubsection{Prevalence}

CLP patients present with a higher prevalence of supernumeraries, more commonly found at the lateral incisor region adjacent to the cleft $[17,44,46,50,54$, 77-79]. The prevalence of a supernumerary lateral incisor in CLP patients ranged from $5.1 \%-22.1 \%[47,50,52,61,62]$.

In contrast, a lower prevalence of supernumeraries is found in normal children, ranging from $0.46-3.4 \%$ across all nationalities [80-82]. In a local study carried out on 408 normal Singaporean Chinese patients, the prevalence of hyperdontia was found to be $7.1 \%$, with most of the supernumeraries found in the premaxilla area [83].

\subsubsection{Primary vs. permanent dentition}

It has also been reported that supernumeraries occur more frequently in the primary dentition than in the permanent dentition in CLP patients $[44,46,47,49$, 61]. However, this finding was disputed in the study by Vichi and Franchi which noted a higher prevalence of supernumerary lateral incisors in the permanent dentition $(22.1 \%)$ than in the primary dentition (19.5\%) [52].

\subsubsection{Aetiology}

Some authors attribute this finding of higher prevalence of supernumerary lateral incisor in CLP patients to the close proximity of the lateral incisor tooth bud to the cleft, hence a higher susceptibility to division or modification of the tooth bud or separation of the epithelial remnants, resulting in a supernumerary tooth forming $[76,77]$.

Tsai et al. proposed that there could be two odontogenic origins for the maxillary lateral incisors, one from the maxillary process and one from medial nasal process. The two processes are unable to fuse due to the cleft, resulting in two separate odontogenic regions having the potential to develop lateral incisors [46]. 


\subsection{Enamel hypoplasia}

A high incidence of enamel hypoplasia is found to occur more frequently in CLP patients compared with non-cleft populations, especially involving the maxillary incisors $[1,52,62]$.

Dixon suggested that lip repair could cause enamel hypoplasia in deciduous incisors and tips of permanent incisor crowns related to the surgical area; whereas the palatal repair could cause some defects in the crowns of the permanent incisors [1].

\subsection{Abnormalities in shape and size of permanent teeth}

\subsubsection{Crown abnormalities}

CLP patients commonly present with anomalies in shape and size of permanent teeth, especially at the maxillary anterior region. The malformations frequently exhibit as microdontia or macrodontia [47, 50, 52, 62].

Other dental anomalies associated with CLP patients include thick curved maxillary central incisors [53,54], addition of paralabial tubercles on the central incisor and canine, missing cusp or altered cusp patterns of the maxillary molars and mandibular bicuspids [53] and smaller mesial-distal width of central incisors on the cleft side $[44,84]$. Interactive compensations with dental variations in size have been reported to occur within tooth classes [85]. In non-cleft oligodontia with multiple missing teeth, the dentition was found to be reduced in size. However, in dentition with isolated tooth agenesis, tooth-size was larger compared to those of fully dentate individuals without hypodontia [86]. The premise of an odontogenic interactive compensatory mechanism was suggested in that a size reduction of a lateral incisor was a localised response to a large adjacent central incisor [87].

\subsubsection{Root abnormalities}

Taurodontism [65, 88], root dilacerations [62], fusion, germination and concrescence [81] have also been associated with CLP patients.

\subsection{Abnormalities in position of permanent teeth}

\subsubsection{Rotated cleft-sided central incisors}

Cleft sided central incisors are often found to be rotated, with a prevalence of $68.6 \%$ to $86.17[48,50,89]$ reported. This has been attributed to the lack of space at the end of the alveolar segment [90].

\subsubsection{Impacted canines}

The canines on the cleft side are often palatally impacted. It has been suggested that the impaction may be due to the palatal collapse of the maxillary lateral segment [89] or related to the genetic factor responsible for CLP [91].

Lai et al. suggested that when the lateral incisor is located distal to the cleft, it can provide guidance for the eruption of the adjacent canine [47].

\subsubsection{Ectopic eruption}

Ectopic eruption of teeth, including transposition has also been reported in patients with CLP $[62,90,92,93]$. 


\subsection{Aetiology of dental anomalies}

\subsubsection{Cleft defect and surgical trauma}

Since a high prevalence of dental anomalies was found at the region of the cleft, these anomalies may be attributed to the cleft itself or to the early surgical correction of the defects. The severity of these anomalies also appears to be related to the severity of the cleft.

\subsubsection{Genetic factors}

As the increased prevalence of dental anomalies was also found in the noncleft region, it was postulated that dental anomalies in CLP patients were affected by common developmental mechanisms that involved non-fusion of orofacial processes and the persistence of orofacial clefts during embryonic and foetal formation. Extensive studies on orofacial clefting have linked genetic susceptibility, signalling pathways and transcription factors in the regulation of -lip, palate and dentition development [94-97].

Multiple disruptions in development of a number of body tissues including the dental lamina result in frequent occurrences of dental anomalies together with and several other visceral and skeletal anomalies in CLP children [41, 98, 99].

This has led to several studies investigating the presence of dental anomalies in parents and siblings of CLP children, of which, the results have been conflicting to date. Both Jordan et al. [53] and Schroeder and Green [54] reported a higher than normal frequency of occurrence of dental anomalies in the siblings of affected CLP individuals than in the general population. More recently, Eerens et al. reported significantly higher frequency of hypodontia and asymmetric tooth formation in both cleft and unaffected sibling groups compared with normal controls [41].

On the other hand, Woolf et al. observed that the incidence of maxillary lateral incisor abnormalities in parents' dentition was similar to non-cleft controls [58]. Mills et al. demonstrated no significant differences in the oral and facial defects between cleft and non-cleft families [59].

Anderson and Moss similarly found no evidence to suggest that parents of CLP children have a higher incidence of dental abnormalities than the general population and suggested that the genes carried by the non-cleft parents of CLP cases do not produce dental manifestations [60]. This could be because the genetics of odontogenesis is complex and is influenced by many factors, genes, epigenetics, and environmental factors $[60,100,101]$.

\section{Conclusion}

It has been well-documented in the literature that CLP patients often present with delayed dental development and tooth eruption, asymmetric tooth formation and dental anomalies like hypodontia, supernumerary teeth, malformed or missing lateral incisor at the cleft region. However, there are minor controversies regarding gender differences, teeth most commonly affected, and differences in the development of maxillary and mandibular teeth.

The coming together of genetic, epigenetic and environmental factors seem to play an important role in the sequential pathway of orofacial and dental formation. Cell differentiation, proliferation and migration, as well as timing and fusion impact on the development of the lip, palate and dentition. Perturbations in the highly orchestrated mechanisms result in orofacial, dental and systemic organ defects. 
Further studies are needed to link the dental characteristics of relatives of CLP patients as well as the molecular network that define and regulate orofacial and dental development. With new knowledge from research to bridge these gaps, effective strategies can be derived to prevent or rescue cleft defects and associated multi-system maldevelopment.

\section{Acknowledgements}

National Dental Centre of Singapore for the financial support in open access publication fees.

\section{Conflict of interest}

There is no conflict of interest related to individual authors' commitments and any project support.

\section{Author details}

Elaine Li Yen Tan* and Mimi Yow

Department of Orthodontics, National Dental Centre, Singapore

*Address all correspondence to: elaine.tan.l.y@singhealth.com.sg

\section{IntechOpen}

(C) 2019 The Author(s). Licensee IntechOpen. This chapter is distributed under the terms of the Creative Commons Attribution License (http://creativecommons.org/licenses/ by/3.0), which permits unrestricted use, distribution, and reproduction in any medium, provided the original work is properly cited. (cc) BY 


\section{References}

[1] Dixon MJ, Marazita ML, Beaty TH, Murray JC. Cleft lip and palate: Synthesizing genetic and environmental influences. Nature Reviews Genetics. 2011;12:167-178

[2] IPDTOC Working Group. Prevalence at birth of cleft lip with or without cleft palate: Data from the international perinatal database of typical oral clefts (IPDTOC). The Cleft PalateCraniofacial Journal. 2011;48:66-81

[3] Ranta R. A review of tooth formation in children with cleft lip/palate.

American Journal of Orthodontics and Dentofacial Orthopedics. 1986;90:11-18

[4] Gleiser I, Hunt EE Jr. The permanent mandibular first molar: Its calcification, eruption and decay. American Journal of Physical Anthropology. 1955;13:253-283

[5] Hayes RL, Mantel N. Procedures for computing the mean age of eruption of human teeth. Journal of Dental Research. 1958;37:938-947

[6] Nolla C. The development of the permanent teeth. Journal of Dentistry for Children. 1960;49:197-199

[7] Moorrees CF, Fanning EA, Hunt EE Jr. Age variation of formation stages for ten permanent teeth. Journal of Dental Research. 1963;42:1490-1502

[8] Liliequist B, Lundberg M. Skeletal and tooth development. A methodologic investigation. Acta Radiologica: Diagnosis. 1971;11:97-112

[9] Demirjian A, Goldstein H, Tanner JM. A new system of dental age assessment. Human Biology. 1973;45:211-227

[10] Gustafson G, Koch G. Age estimation up to 16 years of age based on dental development. Odontologisk Revy. 1974;25:297-306
[11] Haavikko K. Tooth formation age estimated on a few selected teeth. A simple method for clinical use. Proceedings of the Finnish Dental Society. 1974;70:15-19

[12] Demirjian A, Goldstein H. New systems for dental maturity based on seven and four teeth. Annals of Human Biology. 1976;3:411-421

[13] Hagg U, Matsson L. Dental maturity as an indicator of chronological age: The accuracy and precision of three methods. European Journal of Orthodontics. 1985;7:25-34

[14] Maber M, Liversidge HM, Hector MP. Accuracy of age estimation of radiographic methods using developing teeth. Forensic Science International. 2006;159(Suppl. 1):S68-S73

[15] Esan TA, Yengopal V, Schepartz LA. The Demirjian versus the Willems method for dental age estimation in different populations: A meta-analysis of published studies. PLoS One. 2017;12(11):e0186682. DOI: 10.1371/ journal.pone.0186682

[16] Bailit H, Doykos JD, Swanson LT. Dental development in children with cleft palates. Journal of Dental Research. 1968;47:664

[17] Fishman LS. Factors related to tooth number, eruption time, and tooth position in cleft palate individuals. ASDC Journal of Dentistry for Children. 1970;37:303-306

[18] Ranta R. A comparative study of tooth formation in the permanent dentition of Finnish children with cleft lip and palate. An orthopantomographic study. Proceedings of the Finnish Dental Society. 1972;68:58-66

[19] Harris EF, Hullings JG. Delayed dental development in children with 
isolated cleft lip and palate. Archives of Oral Biology. 1990;35:469-473

[20] Lai MC, King NM, Wong HM. Dental development of Chinese children with cleft lip and palate. The Cleft Palate-Craniofacial Journal. 2008;45:289-296

[21] Borodkin AF, Feigal RJ, Beiraghi S, Moller KT, Hodges JS. Permanent tooth development in children with cleft lip and palate. Pediatric Dentistry. 2008;30:408-413

[22] Tan EL, Yow M, Kuek MC, Wong HC. Dental maturation of unilateral cleft lip and palate. Annals of Maxillofacial Surgery. 2012;2:158-162

[23] Ranta R. Comparison of tooth formation in noncleft and cleft-affected children with and without hypodontia. ASDC Journal of Dentistry for Children. 1982;49:197-199

[24] Ranta R. Associations of some variables to tooth formation in children with isolated cleft palate. Scandinavian Journal of Dental Research. 1984;92(6):496-502

[25] Prahl-Andersen B. The dental development in patients with cleft lip and palate. Transactions of European Orthodontic Society. 1976;52:155-160

[26] Poyry M, Nystrom M, Ranta R. Tooth development in children with cleft lip and palate: A longitudinal study from birth to adolescence. European Journal of Orthodontics. 1989;11:125-130

[27] Heidbuchel KL, Kuijpers-Jagtman AM, Ophof R, van Hooft RJ. Dental maturity in children with a complete bilateral cleft lip and palate. The Cleft Palate-Craniofacial Journal. 2002;39:509-512

[28] Tan ELY, Kuek MC, Wong HC, Yow M. Longitudinal dental maturation of children with complete unilateral cleft lip and palate: A case-control cohort study. Orthodontics \& Craniofacial Research. 2017;20:189-195

[29] Tanner JM. The regulation of human growth. Child Development. 1963;34:817-847

[30] Krogman WM, Mazaheri M, Harding RL, Ishiguro K, Bariana G, Meier J, et al. A longitudinal study of the craniofacial growth pattern in children with clefts as compared to normal, birth to six years. The Cleft Palate Journal. 1975;12:59-84

[31] Seow WK. A study of the development of the permanent dentition in very low birthweight children. Pediatric Dentistry. 1996;18:379-384

[32] Solis A, Figueroa AA, Cohen M, Polley JW, Evans CA. Maxillary dental development in complete unilateral alveolar clefts. The Cleft PalateCraniofacial Journal. 1998;35:320-328

[33] Davis PJ, Hagg U. The accuracy and precision of the "Demirjian system" when used for age determination in Chinese children. Swedish Dental Journal. 1994;18(3):113-116

[34] Hunter WS. The effects of clefting on crown-root length, eruption, height and weight in twins discordant for cleft of lip and/or palate. The Cleft Palate Journal. 1975;12:222-228

[35] Heikkinen T, Alvesalo L, Osborne $\mathrm{RH}$, Tienari J. Maternal smoking and tooth formation in the foetus. II. Tooth crown size in the permanent dentition. Early Human Development. 1994;40:73-86

[36] Pioto NR, Costa B, Gomide M. Dental development of the permanent lateral incisor in patients with incomplete and complete unilateral 
cleft lip. The Cleft Palate-Craniofacial Journal. 2005;42:517-520

[37] Ranta R. Asymmetric tooth formation in the permanent dentition of cleft-affected children. An orthopantomographic study. Scandinavian Journal of Plastic and Reconstructive Surgery. 1973;7:59-63

[38] Ranta R. Development of asymmetric tooth pairs in the permanent dentition of cleft-affected children. Proceedings of the Finnish Dental Society. 1973;69:71-75

[39] Peterka M, Tvrdek M, Mullerova Z. Tooth eruption in patients with cleft lip and palate. Acta Chirurgiae Plasticae. 1993;35:154-158

[40] Carrara CFC, Lima JEO, Carrara $\mathrm{CE}$, Gonzalez VB. Chronology and sequence of eruption of the permanent teeth in patients with complete unilateral cleft lip and palate. The Cleft Palate-Craniofacial Journal. 2004;41:642-645

[41] Eerens K, Vlietinck R, Heidbuchel K, Van Olmen A, Derom C, Willems G, et al. Hypodontia and tooth formation in groups of children with cleft, siblings without cleft, and nonrelated controls. The Cleft Palate-Craniofacial Journal. 2001;38:374-378

[42] Kjaer I, Kocsis G, Nodal M, Christensen LR. Aetiological aspects of mandibular tooth agenesis — focusing on the role of nerve, oral mucosa, and supporting tissues. European Journal of Orthodontics. 1994;16:371-375

[43] Pegelow M, Alqadi N, Karsten A. The prevalence of various dental characteristics in the primary and mixed dentition in patients born with non-syndromic unilateral cleft lip with or without cleft palate. The European Journal of Orthodontics. 2012;34(5):561-570
[44] Boehn A. Dental anomalies in harelip and cleft palate. Acta Odontologica Scandinavica. 1963;21(Suppl. 38):1-109

[45] Olin WH. Dental anomalies in cleft lip and palate patients. The Angle Orthodontist. 1964;34:119-123

[46] Tsai TP, Huang CS, Huang CC, See LC. Distribution patterns of primary and permanent dentition in children with unilateral complete cleft lip and palate. The Cleft Palate-Craniofacial Journal. 1998;35:154-160

[47] Lai MC, King NM, Wong H. Abnormalities of maxillary anterior teeth in Chinese children with cleft lip and palate. The Cleft Palate-Craniofacial Journal. 2009;46:58-64

[48] Keith A. Three demonstrations ON CONGENITAL MALFORMATIONS OF PALATE, FACE, AND NECK: Given at the royal college of surgeons, England. British Medical Journal. 1909;2:438-441

[49] Suzuki A, Watanabe M, Nakano M, Takahama Y. Maxillary lateral incisors of subjects with cleft lip and/or palate: Part 2. The Cleft Palate-Craniofacial Journal. 1992;29:380-384

[50] Tan ELY, Kuek MC, Wong HC, Ong SAK, Yow M. Secondary dentition characteristics in children with nonsyndromic unilateral cleft lip and palate: A retrospective study. The Cleft Palate-Craniofacial Journal. 2018;55:582-589

[51] Ribeiro LL, das Neves LT, Costa B, Gomide M. Dental development of permanent lateral incisor in complete unilateral cleft lip and palate. The Cleft Palate-Craniofacial Journal. 2002;39:193-196

[52] Vichi M, Franchi L. Abnormalities of the maxillary incisors in children with cleft lip and palate. ASDC 
Journal of Dentistry for Children. 1995;62:412-417

[53] Jordan RE, Kraus BS, Neptune CM. Dental abnormalities associated with cleft lip and/or palate. The Cleft Palate Journal. 1966;3:22-55

[54] Schroeder DC, Green L. Frequency of dental trait anomalies in cleft, sibling, and noncleft groups. Journal of Dental Research. 1975;54:802-807

[55] Fukuhara T, Saito S. Possible carrier status of hereditary cleft palate with cleft lip; report of cases. The Bulletin of Tokyo Medical and Dental University. 1963;10:333-345

[56] Meskin LH, Gorlin RJ, Isaacson RJ. Abnormal morphology of the soft palate. Ii. The genetics of cleft uvula. The Cleft Palate Journal. 1965;45:40-45

[57] Tolarova M. Microforms of cleft lip and-or cleft palate. Acta Chirurgiae Plasticae. 1969;11:96-107

[58] Woolf CM, Woolf RM, Broadbent TR. Lateral incisor anomalies. Microforms of cleft lip and palate? Plastic and Reconstructive Surgery. 1965;35:543-547

[59] Mills LF, Niswander JD, Mazaheri M, Brunelle JA. Minor oral and facial defects in relatives of oral cleft patients. The Angle Orthodontist. 1968;38:199-204

[60] Anderson PJ, Moss AL. Dental findings in parents of children with cleft lip and palate. The Cleft PalateCraniofacial Journal. 1996;33:436-439

[61] Ranta R. The development of the permanent teeth in children with complete cleft lip and palate. Proceedings of the Finnish Dental Society. 1972;68(Supl. III):6-27

[62] Al Jamal GA, Hazza’a AM, Rawashdeh MA. Prevalence of dental anomalies in a population of cleft lip and palate patients. The
Cleft Palate-Craniofacial Journal. 2010;47:413-420

[63] Da Silva AP, Costa B, de Carvalho Carrara CF. Dental anomalies of number in the permanent dentition of patients with bilateral cleft lip: Radiographic study. The Cleft Palate-Craniofacial Journal. 2008;45:473-476

[64] Shapira Y, Lubit E, Kuftinec MM. Hypodontia in children with various types of clefts. The Angle Orthodontist. 2000;70:16-21

[65] Ranta R, Stegars T, Rintala AE. Correlations of hypodontia in children with iolated cleft palate. The Cleft Palate Journal. 1983;20:163-165

[66] Dixon DA. Defects of structure and formation of the teeth in persons with cleft palate and the effect of reparative surgery on the dental tissues. Oral Surgery, Oral Medicine, and Oral Pathology. 1968;25:435-446

[67] Brook AH. A unifying aetiological explanation for anomalies of human tooth number and size. Archives of Oral Biology. 1984;29:373-378

[68] Qian L, Chew MT, Yow M, Wong HC, Foong WCK. Anomalies in tooth number in the permanent dentition of three Asian ethnicities. Australian Orthodontic Journal. 2017;33:212-219

[69] Polder BJ, Van't Hof MA, Van der Linden FP, Kuijpers-Jagtman AM. A meta-analysis of the prevalence of dental agenesis of permanent teeth. Community Dentistry and Oral Epidemiology. 2004;32:217-226

[70] Butler PM. Studies of the mammalian dentition - differentiation of the postcanine dentition. Proceedings of the Zoological Society of London. 1939;B109:1-36

[71] Alappat S, Zhang ZY, Chen YP. Msx homeobox gene family and craniofacial 
development. Cell Research. 2003;13:429-442

[72] Vastardis H, Karimbux N, Guthua SW, Seidman JG, Seidman CE. A human MSX1 homeodomain missense mutation causes selective tooth agenesis. Nature Genetics. 1996;13:417-421

[73] Lidral AC, Romitti PA, Basart AM, Doetschman T, Leysens NJ, DaackHirsch S, et al. Association of MSX1 and TGFB3 with nonsyndromic clefting in humans. American Journal of Human Genetics. 1998;63:557-568

[74] van den Boogaard MJ, Dorland M, Beemer FA, van Amstel HK. MSX1 mutation is associated with orofacial clefting and tooth agenesis in humans. Nature Genetics. 2000;24:342-343

[75] Blanco R, Chakraborty R, Barton SA, Carreno H, Paredes M, Jara L, et al. Evidence of a sex-dependent association between the MSX1 locus and nonsyndromic cleft lip with or without cleft palate in the Chilean population. Human Biology. 2001;73:81-89

[76] Lidral AC, Reising BC. The role of MSX1 in human tooth agenesis. Journal of Dental Research. 2002;81:274-278

[77] Millhon J, Stafne EC. Incidence of supernumerary and congenitally missing incisor teeth in eighty-one cases of harelip and cleft palate. American Journal of Orthodontics and Oral Surgery. 1941;27:599-604

[78] Nagai I, Fujiki Y, Fuchihata H, Yoshimoto T. Supernumerary tooth associated with cleft lip and palate. Journal of the American Dental Association (1939). 1965;70:642-647

[79] Schulze C. Anomalies of the deciduous teeth with special reference to anomalies associated with cleft palate. Stoma. 1953;6:201-221

[80] Niswander JD, Sujaku C. Congenital anomalies of teeth in Japanese children. American Journal of Physical Anthropology. 1963;21:569-574

[81] Buenviaje TM, Rapp R. Dental anomalies in children: A clinical and radiographic survey. ASDC Journal of Dentistry for Children. 1984;51:42-46

[82] Davis P. Hypodontia and hyperdontia of permanent teeth in Hong Kong schoolchildren. Community Dentistry and Oral Epidemiology. 1987;15:218-220

[83] Ho KK, Mok YY. Hypodontia and hyperdontia of permanent teeth in 12-14 year old Singaporean Chinese: A preliminary study. Singapore Dental Journal. 1991;16:16-19

[84] Zilberman Y. Observations on the dentition and face in clefts of the alveolar process. The Cleft Palate Journal. 1973;10:230-238

[85] Bishara SE, Jakobsen JR. Compensatory developmental interactions in the size of permanent teeth in three contemporary populations from Egypt, Mexico, and the United States. Angle Orthodontist. 1989;59(2):107-112

[86] Yamada H, Kondo S, Hanamura H. Tooth size in individuals with congenitally missing teeth: A study of Japanese males. Anthropological Science. 2010;118(2):87-93

[87] Kondo S, Hanamura H. Does a maxillary lateral incisor reduce to compensate for a large central incisor? Aichi Gakuin Journal of Dental Science. 2010;48(3):215-227

[88] Laatikainen T, Ranta R.

Taurodontism in twins with cleft lip and/or palate. European Journal of Oral Sciences. 1996;104:82-86

[89] Ranta R. On the development of central incisors and canines situated adjacent to the cleft in unilateral total 
cleft cases. An orthopantomographic and clinical study. Suomen Hammaslääkäriseuran Toimituksia. 1971;67:345-349

[90] Smahel Z, Tomanova M, Mullerova Z. Position of upper permanent central incisors prior to eruption in unilateral cleft lip and palate. The Cleft PalateCraniofacial Journal. 1996;33:219-224

[91] Takahama Y, Aiyama Y. Maxillary canine impaction as a possible microform of cleft lip and palate. European Journal of Orthodontics. 1982;4:275-277

[92] Larson M, Hellquist R, Jakobsson OP. Dental abnormalities and ectopic eruption in patients with isolated cleft palate. Scandinavian Journal of Plastic and Reconstructive Surgery and Hand Surgery. 1998;32:203-212

[93] Ranta R. Tooth germ transposition: Report of cases. ASDC Journal of Dentistry for Children. 1989;56:366-370

[94] Menezes R, Letra A, Kim AH, Küchler EC, Day A, Tannure PN, et al. Studies with Wnt genes and nonsyndromic cleft lip and palate. Birth Defects Research. Part A, Clinical and Molecular Teratology. 2010;88(11):995-1000

[95] Lan Y, Jia S, Jiang R. Molecular patterning of the mammalian dentition. Seminars in Cell \& Developmental Biology. 2014;25-26:61-70

[96] Kwon HE, Jia S, Lan Y, Liu H, Jiang R. Activin and Bmp4 signaling converge on Wnt activation during odontogenesis. Journal of Dental Research. 2017;96(10):1145-1152

[97] Reynolds K, Kumari P, Sepulveda Rincon L, Gu R, Ji Y, Kumar S, et al. Wnt signaling in orofacial clefts: Crosstalk, pathogenesis and models. Disease Models \& Mechanisms. 2019;12(2):dmm037051
[98] Kraus BS, Kitamura H, Ooe T. Malformations associated with cleft lip and palate in human embryos and fetuses. American Journal of Obstetrics and Gynecology. 1963;86:321-328

[99] Kitamura H, Kraus BS. Visceral variations and defects associated with cleft lip and palate in human fetusess macroscopic description. The Cleft Palate Journal. 1964;16:99-115

[100] Sperber GH. Genetic mechanisms and anomalies in odontogenesis. Journal of the Canadian Dental Association. 1967;33:433-442

[101] Howe LJ, Richardson TG, Arathimos R, Alvizi L, Passos-Bueno $\mathrm{MR}$, Stanier $\mathrm{P}$, et al. Evidence for DNA methylation mediating genetic liability to non-syndromic cleft lip/palate. Epigenomics. Feb 2019;11(2):133-145 


\title{
Orthodontic Management of Cleft Lip and Palate Patients
}

\author{
Geetanjali Sharma
}

\begin{abstract}
Patients with a cleft palate and or lip often require complex long-term orthodontic treatment, often in combination with a number of other specialists including maxillofacial surgery in order to produce a good facial appearance, with an esthetic, functional and stable occlusion. This chapter will specifically introduce the role of the orthodontic consultant in the management of the cleft lip and palate patient at multiple stages of their dental development and growth. The orthodontic burden of care for these patients is high and the duration of treatment will depend on the diagnosis and pattern of jaw growth and need for orthognathic surgery.
\end{abstract}

Keywords: orthodontist, role, cleft lip, cleft palate, management

\section{Introduction}

The orthodontic burden of care for patients with cleft lip and/or palate is significant as patients will often present with numerous variations and complications in their skeletal, dental and medical/behavioral presentation compared to the non-cleft patient.

\subsection{Skeletal presentation}

There are well established differences in growth patterns and dimensions among cleft patients. The growth and form of the maxillary arch may be affected in the vertical, antero-posterior and transverse dimensions leading to a dental malocclusion as a result of the severity of the initial cleft deformity and the growth response to the primary surgery [1].

Antero-posterior sagittal problems: the cleft lip and palate patient will often present with a Skeletal III base owing to maxillary hypoplasia as a consequence of scar tissue which can restrict the growth of the maxilla in the forwards and downwards direction.

Transverse problems: a narrow maxilla is a common finding in affected patients owing to a lack of boney development. Scar tissue from previous palate repair can also constrict the growth of the maxilla in the transverse plane.

Vertical problems: vertical deficiency is a common finding and can be coupled with an occlusal cant in the palatal plane, excessive freeway space and altered mandibular posture. 


\subsection{Dental presentation}

About 94\% of cleft patients have at least one dental anomaly [2] and can present with one or more of the following features:

- congenitally missing teeth especially the upper laterals (50\%);

- presence of natal/neonatal teeth;

- presence of supernumerary teeth (20\%);

- ectopic eruption or impaction of teeth;

- delayed dental eruption;

- anomalies in tooth morphology, e.g. fused teeth;

- anomalies in tooth size, e.g. microdontia;

- enamel hypoplasia;

- poor oral hygiene leading to caries and periodontal disease;

- posterior and anterior cross bites;

- deep overbite/openbite;

- centerline discrepancies; and

- dentoalveolar disproportion, e.g. crowding/spacing.

\subsection{Medical/behavioral presentation}

Cleft lip and palate patients may present with numerous behavioral/ medical conditions that can influence orthodontic management. Unfavorable behavioral characteristics can lead to poor oral hygiene and co-operation with orthodontic treatment. Medically, patients may also exhibit neuromuscular anomalies, mental retardation, frequent upper respiratory infections and enlarged adenoids/tonsils. Cleft lip and palate patients may also present with associating syndromes. Associating syndromes with autosomal dominant inheritance include Van der Woude syndrome, Apert syndrome, Treacher Collins syndrome, Cleidocranial syndrome, Ectodermal dysplasia, Pierre Robin sequence and Stickler's syndrome. Roberts syndrome, Christian syndrome and Meckel syndrome are also examples of syndromes with autosomal recessive inheritance patterns.

As a consequence of the above, cleft patients are seen multiple times by an orthodontist from a young age to monitor their dental development and jaw growth. The majority of patients will require orthodontic intervention at various stages extending from presurgical nasoalveolar molding as a baby to orthodontic preparation before alveolar bone grafting in the mixed dentition to alignment of the upper arch once the permanent dentition is established. Patients may undergo a second course of orthodontic treatment on cessation of jaw growth to either camouflage an underlying skeletal discrepancy or in preparation for orthognathic surgery. 


\section{Integrated care pathway}

Management of the cleft lip and or palate patient is a multi-disciplinary approach involving a number of health care professionals illustrated in Figure 1.

All members of the multi-disciplinary team are deemed to be equally important and it is prudent that they all work in tandem with each other to ultimately improve a patient's appearance, speech and function.

The orthodontist is involved in the management pathway at a number of different stages:

\subsection{Ante/post-natal stage}

Occasionally, an orthodontist is involved prior to the birth of a baby if a cleft lip and or palate is diagnosed on a 20 week scan. Ultrasonography is a noninvasive diagnostic tool which is widely used. The unexpected finding is a considerable psychological blow to parents and counseling is often necessary. In a district general hospital an orthodontist may be called to counsel the parents on the process and subsequently pass on the details to a hub cleft lip and palate Centre.

Postnatally the orthodontist may be required to continue to provide support and counseling to the parents. Additionally, the orthodontist may be involved in the identification of syndrome related conditions and congenital disorders. Cleft patients may also be born with mobile natal teeth which require assessment and possible extraction.

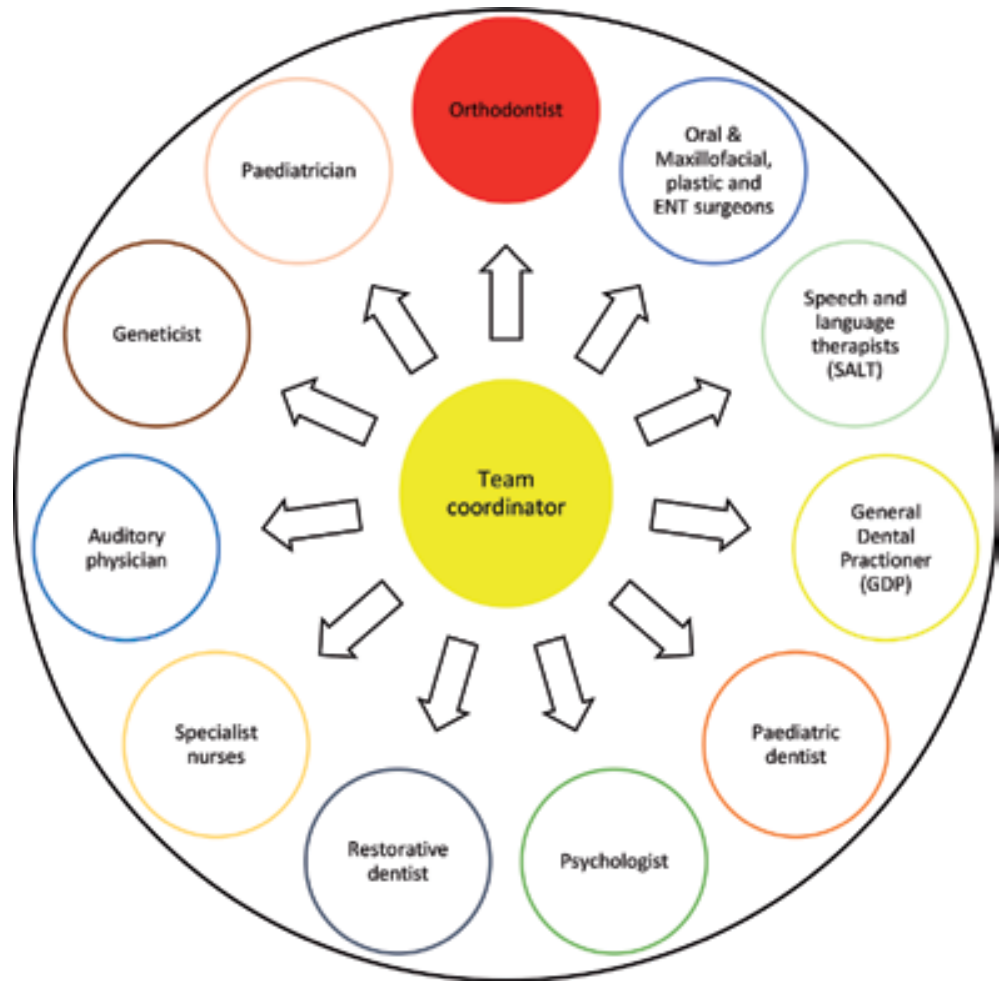

Figure 1.

Illustrative diagram of members involved in the multi-disciplinary management of cleft lip and palate patients. 


\section{$2.20-6$ months}

Between 3 and 6 months lip repair is usually carried out by the cleft surgeon. Prior to lip repair an orthodontist may be involved in a phase of oral orthopedics to align the displaced cleft segments termed presurgical orthopedic treatment. Presurgical orthopedic treatment has been used since 1950. The earlier techniques focused on elastic retraction of the premaxilla using adhesive tape binding. In 1950, McNeil introduced the use of a series of plates to actively approximate the alveolar segments into the desired position which was developed by Burston who popularized the technique [3]. Thereafter, Georgiade and Latham introduced a pin retained active appliance to retract the premaxilla and simultaneously expand the posterior segments over several days [4]. Another example of an active appliance includes the DiBiase plate which uses an active coffin spring. Passive appliances aim to allow the segments to grow without the tongue being in the way. The use of passive orthopedic plates to align the cleft segments was described by Hotz in 1987 in response to controversy associated with active retraction of the premaxilla [5].

Fabrication of molding plates involves taking a heavy bodied silicone impression within the first week of birth. The impression is taken by inserting the impression tray whilst the infant is held upside down. This technique minimizes blockage of the airway by the tongue, impression material and oral fluids [6]. A dental stone model is then fabricated after which, the laboratory technician then obturates the cleft space and blocks out the undercuts with wax. Laboratory technicians may use a variety of methods to construct the molding plates. One technique involves approximating the segments on the model before an active plate is fabricated over this. In the case of a passive appliance the impression is taken and plastered out but the model is not cut prior to fabricating the passive plate over this. The molding plates usually have a minimum thickness of $2 \mathrm{~mm}$, and should be relived in the region of the frenum, suitably adjusted distally and smooth around the edges. An emergency airway hole of approximately $6 \mathrm{~mm}$ in diameter is made on the palatal surface of the molding plate and positioned $8 \mathrm{~mm}$ from the posterior border to assure a patent airway in the instance of plate dislodgement. Retention buttons/arms are then added and positioned at the junction of the cleft segments and vertically at the junction of where the upper and lower lip rests. Appliances are secured extra orally to the cheeks and bilaterally by surgical tapes. Approximately 100 grams of force can be applied to an active plate through a combination of screws and or elastics that are extended from the retention arms/buttons and stretched approximately two times their resting diameter for an appropriate activation force. Active appliances should be reviewed weekly to modify the acrylic plate and gradually approximate the alveolar segments and reduce the size of the cleft. This is often achieved by removing acrylic resin in areas where alveolar segments are to move and application of soft liner in areas where alveolar bone is to be reduced. Following a few visits, parents are often instructed to place tapes to approximate cleft lip segments to the base of the nose extending from the non-cleft side to the cleft side [7]. It is important to note that lip strapping is seldom done in the UK and only considered for wide bilateral clefts. Objectives include elongation of the columella, expansion of the cleft nasal mucosa and improvement of nasal tip symmetry.

Occasionally, a nasal stent component is incorporated into the plate once the width of the alveolar gap is reduced to around $5 \mathrm{~mm}$. The stent is made up of 0.36 inch round stainless steel wire and adopts the shape of a 'Swan neck'. The stent is attached to the labial flange of the molding plate. It extends forward and then curves backwards entering 3-4 mm past the nostril aperture where the stent is curved back on itself to create a small loop for retention. Hard acrylic is applied to the wire armature followed by soft acrylic to create a bi-lobed structure. In the case 
of bilateral cleft lip and palate cases there will be two retention arms and two stents. Following the addition of nasal stents nonsurgical lengthening of the columella can be commenced by introducing a horizontal band of soft denture material which joins the left and right lower lobes of the stents and spans the base of the columella. Tape is then attached to the prolabium under the horizontal lip tape and stretches downward to engage the retention arms with elastics. The vertical pull works in the opposite direction to the upward force applied to the nasal tip by the stent and helps to lengthen the columella [7].

The benefits of presurgical nasoalveolar molding (PNAM) have been debated but Scott's cartilaginous theory and Moss functional matrix theory suggests that by creating a normal functioning environment for normal growth it in turn:

- allows better feeding;

- allows the segments to grow without tension;

- postures the tongue away from the palatal shelves;

- allows the lip and nose repair to heal without pressure;

- facilitates better speech;

- reduces likelihood of choking; and

- yields psychological benefit for the parents.

Reported disadvantages/complications include:

- interference with growth;

- delaying surgery;

- risk of infection;

- occlusion of the airway;

- risk of ulceration/candida infection under a plate; and

- development of skin sores from the tape.

The evidence for PNAM with plates is not conclusive due to limited long term results with some studies indicating that nasoalveolar molding is efficient at reducing cleft width and improving nasal shape and symmetry in uni- and bilateral clefts [8]. A randomized control trial (RCT) which looked at the effects of passive plates on feeding, archform, maternal satisfaction and cost effectiveness found no difference with any of the above [9]. A study by Maserai also found no difference in unilateral cleft lip palate cases [10]. Shaw et al., conducted a RCT and found no effect on feeding and the trial was stopped midway [11]. Most surgeons however, would agree that their chance of achieving a finer surgical scar, good nasal tip projection, and more symmetrical and precisely defined nasolabial complex would be better in an infant who presents with a smaller cleft deformity. Therefore, PNAM can be an adjunct to facilitate surgical repair in infants with cleft lip and palate. 


\subsection{Early mixed dentition}

It is not uncommon for patients to develop a crossbite as the incisors start to erupt. If it is associated with displacement of the lower jaw, tooth wear / fremitus of the opposing dentition than an orthodontist can fabricate a simple upper removable appliance to procline the upper incisors and push them out of an anterior crossbite. Alternatively, a sectional fixed appliance can be used. Care must be taken to ensure that incisors positioned close to the cleft site are not moved out of the alveolar bone as there is typically very thin bone covering these teeth on the cleft side.

If a dental cross bite is not related to a mandibular shift, it is advisable not to perform any palatal expansion at this early stage due to:

- risks of widening a pre-existing oro-nasal communication;

- high risk of relapse due to palatal scarring; and

- long retention period that that will be required which can burn patients compliance and impede oral hygiene.

Patients should be seen on a regular basis, usually on a 6 monthly basis to monitor dental development, continue to motivate the family, reinforce oral hygiene and dietary advice and generate a good relationship and rapport with the patient and family. Orthodontic dental records including radiographs, photos and study models should be taken regularly after the eruption of the upper permanent incisors to detect teeth that may be positioned in the cleft area and to ascertain whether there is congenital absence of the lateral incisor.

\subsection{Late mixed dentition}

At this stage a patient may require an autogenous alveolar bone graft which offers a number of benefits:

1. additional bone support for unerupted teeth and teeth adjacent to the cleft which will improve their periodontal support;

2. closure of oronasal fistulae;

3. support and elevation of the alar base on the cleft side which will help to achieve nasal and lip symmetry;

4. construction of a continuous arch form and alveolar ridge which in turn will allow the orthodontist to move teeth bodily and upright roots on the cleft side. Additionally, a more continuous archform will enable a prosthodontist/ surgeon to provide a more esthetic and hygienic prosthesis when teeth are missing; and

5. stabilization and or repositioning of the premaxilla in patients with a bilateral cleft.

The timing of a secondary alveolar bone graft largely depends on dental development than chronologic age. This usually takes place prior to the eruption of the upper permanent canine tooth when its root is approximately two-thirds formed. 
This generally occurs between 9 and 10 years of age. On rare occasions a graft may be placed at an earlier age to improve the prognosis of a lateral incisor.

Most cleft patients will present with a narrow V-shaped upper archform hence, prior to receiving an alveolar bone graft expansion of the segments that make up the upper archform may be required by the orthodontist to improve access for surgery to allow maximum boney infill. Prior to starting active expansion an upper anterior standard occlusal radiograph, long cone periapical radiograph or CBCT of the cleft site should be considered to assess the volume of bone. There is no universal protocol for maxillary expansion prior to secondary alveolar bone grafting and a number of methods can be used to achieve expansion which include:

1. removable appliances - these can be used to correct an anterior cross bite and simultaneously expand and correct a posterior cross bite but are less popular for cleft patients as removable appliances can impede existing speech problems;

2. rapid maxillary expansion appliances-a number of designs can be used pending the type and amount of expansion that is required. The Hyrax appliance is useful when parallel expansion is required. Fan expansion screws can be used when larger expansion is required anteriorly; and

3. a fixed quad-helix/tri-helix appliance-these appliances provide controlled force application.

The expansion once commenced, should be monitored closely. The cleft surgeon and orthodontist must work in tandem to determine the anatomical limits of presurgical maxillary expansion. This is prudent to avoid overexpansion and development of an oronasal fistula that is beyond the limits of surgical closure. An upper anterior standard occlusal radiograph should be taken and reviewed by the orthodontist and cleft surgeon to assess whether enough expansion has taken place (Figure 2). Thereafter, the archform should be maintained with a simple upper removable appliance or trans-palatal arch. It is important to note that any primary teeth in line of the cleft should usually be removed a minimum of 3 months in advance of any planned alveolar bone graft to allow repair of the soft tissues. Supernumerary teeth can be extracted closer to the time of alveolar bone graft.

Three to six months post ABG, a postoperative CBCT or upper anterior standard occlusal radiograph should be obtained to confirm the outcome of the surgery which is generally considered satisfactory when sufficient volume of remodeled bone tissue is present. The orthodontist should monitor the developing dentition and eruption of the canine for a minimum of 3-6 months before moving teeth into the new bone.

\subsection{Early permanent dentition}

Orthodontic treatment at this stage may be conducted to:

- relieve crowding;

- facilitate the eruption of the canine tooth with or without surgical exposure and bonding of the tooth if it has failed to erupt through the alveolar bone graft after a minimum of 6 months;

- attempt correction of a developing Skeletal III relationship; 


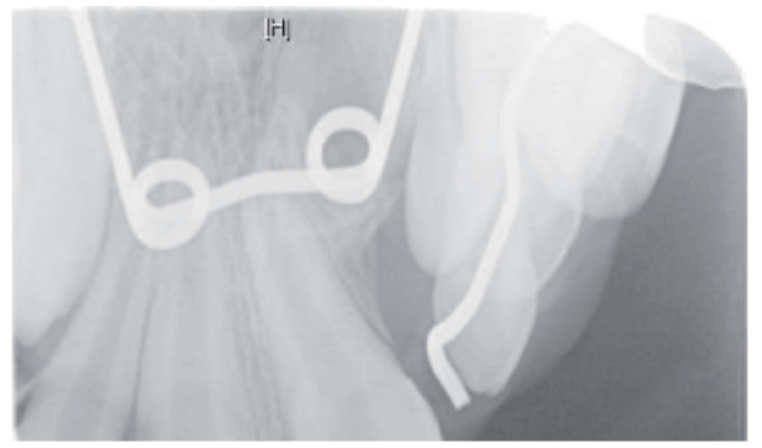

(a)

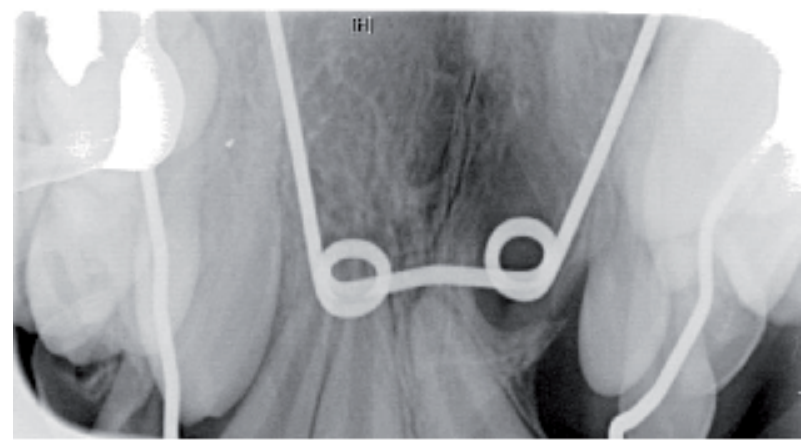

(b)

Figure 2.

(a) Pre-and (b) post-expansion upper anterior standard occlusal radiographs demonstrating successful expansion prior to a planned alveolar bone graft.

- align the dentition;

- dental centre-line correction; and

- space closure.

Comprehensive correction of the malocclusion via orthodontic camouflage will be dictated by the extent of the underlying skeletal discrepancy and the likely effect of any future lower jaw growth. In cleft lip and palate patients the mandible is often unaffected and will grow normally, however, growth of the maxilla is often restricted in the forwards and downwards direction compared to the non-cleft patient [12]. Scar tissue from previous hard palate repair is thought to disturb growth of the maxilla leading to a short/hypoplastic maxilla and a Class III malocclusion [13]. Fibrosis can strip the periosteum and also affects antero-posterior, vertical and transverse growth. One option is to consider orthopedic correction during the early mixed dentition at $7-9$ years of age. This treatment option is generally limited to patients with a maximum negative overjet of $4-5 \mathrm{~mm}$ [14]. Orthopedic correction of a short maxilla in the cleft lip and palate patient would involve the use of protraction facemask therapy with forces in the range of 300-500 grams per side over 10-12 hours/day. Stability of this treatment is questionable due to counter pressure of a tight lip on the maxilla and scarring in pterygomaxillary region after extensive tissue mobilization for palatal closure. Reported success of this treatment varies with one study reporting an average of only $1.3 \mathrm{~mm}$ of maxillary protraction in Class III patients with unilateral cleft lip and palate [15]. Success rates reduce as 
the patient ages. Long term results of early protraction appear to be only temporary which often have to be readdressed during late adolescence with retreatment [16]. To that end, if the patient is growing unfavorably and developing a significant class III incisor relationship and skeletal pattern then fixed appliance treatment should also be delayed until the patient has completed their jaw growth to coincide with any planned orthognathic surgery. However, fixed appliance orthodontic treatment can be carried out and limited to the upper arch to relieve crowding, align the dentition, dental center-line correction and or facilitate the eruption of canine teeth whilst lower jaw growth is monitored, and in attempting to achieve the above objectives extraction of a maxillary premolar or lateral incisor on the non-cleft side may be indicated.

\subsection{Late permanent dentition}

Once the patient reaches adulthood the cleft patient should be reassessed with full diagnostic records. At this stage the outcome of previous orthodontic, hard or soft tissue surgery and speech therapy should be examined. If a cleft patient in the permanent dentition presents with no skeletal deformity then management of the dental malocclusion is not dissimilar from that of a non-cleft patient. For example patients with isolated clefts of the lip and alveolus or clefts of the soft palate may be amenable to fixed orthodontic treatment alone. The dental malocclusion may be limited to mild anterior or posterior crossbites, rotated teeth and missing lateral incisors in the cleft site. Mild crossbites can be managed through archwire expansion/quadhelix appliance. Where a patient presents with missing lateral incisors a decision needs to be made with a prosthodontist to either close the spacing or redistribute space for a future prosthetic replacement. This decision is usually based on patient wishes, esthetics, position of the molar teeth and dental centerline and financial considerations. If a decision is made to open space, during active orthodontic treatment the space can be maintained with the use of a pontic tooth that contains a bracket and is ligated to the archwire. Once facial growth is complete, a single tooth implant can be placed. If space closure is planned the permanent canine will need recountering on the incisal, labial, mesial, distal and lingual surfaces either during or after active orthodontic treatment. A lateral incisor bracket should be bonded on the canine tooth more gingivally, to bring the gingival margin down and level to the adjacent incisor. Additionally, the first premolar which will adopt the canine position will also need recountering.

Patients presenting with mild skeletal discrepancies, minimal concerns about facial esthetics and no strong family history of mandibular excess can also be treated via orthodontic dental compensation. However, patients should be warned that any correction may be compromised if the patient continues to exhibit mandibular growth.

Most patients will present with a moderate to significant Class III incisor and skeletal relationship due to maxillary hypoplasia however, the need for orthognathic surgery will depend on patient wishes/concerns as well as function and esthetics. Patients who are happy to consider orthognathic treatment should be planned for carefully with an Oral and maxillofacial surgeon or plastic reconstructive surgeon. Timing is crucial. A restorative specialist may be involved to examine the need for implants, crown or bridgework as part of the overall plan as with the cleft patient who is treated via orthodontic camouflage.

Presurgical fixed appliance treatment is carried out by the consultant orthodontist to decompensate the labial segments, level and align the arches and coordinate the dental arches for a stable occlusal outcome. Where multiple segment maxillary 
osteotomies are planned bracket positions should be altered for teeth adjacent to the osteotomy site. A careful evaluation of the cleft site should be made prior to presurgical orthodontics. Snap impressions should be taken periodically to assess whether the presurgical aims have been achieved prior to definitive surgical planning with the maxillofacial/cleft surgeons. The severity of the skeletal pattern will dictate whether a patient will only require a maxillary Le Fort I advancement or bimaxillary surgery. It is important that patients undergo special investigations to determine the effects of any maxillary advancement on the patient's speech prior to planned surgery. Where maxillary advancement is expected to exceed $6 \mathrm{~mm}$, bimaxillary surgery may need to be considered to minimize the risk of developing complications related to speech, maintenance of a vascular supply and development of oronasal fistulas [17]. Alternatively, an orthodontist may be required to carry out internal or external distraction osteogenesis to reduce the impact on speech if big surgical movements are deemed necessary in patients with marked maxillary hypoplasia. Since distraction osteogenesis and midface advancement usually takes place at a rate of $1 \mathrm{~mm} /$ day, changes in velopharyngeal competence can be monitored during the advancement. Distraction can be carried out with internal distraction devices or via the use of a rigid adjustable external distractor which was described in 1997 by Polley and Figueroa [18] Compliance with internal distraction devices are better but are limited in their use. External devices allow the clinician to change the vector of skeletal correction during active distraction. The general principles of distraction involve a period of latency of 5-6 days after a Le Fort I osteotomy is performed after which the appliance is activated at the rate of $1 \mathrm{~mm}$ /day. The patient should be monitored closely until the desired outcome is achieved. Inter-arch elastics can be incorporated to help direct the correction. Once the desired correction has been achieved with the distraction device a consolidation period of approximately 8 weeks is required to allow bone healing prior to carrying out post distraction orthodontics.

Postoperatively, the orthodontist should see the patient weekly to support the surgical treatment via the use of inter-maxillary elastics and settling archwires. Relapse of the surgical correction is more common in the cleft lip and palate patient and is important to monitor post operatively. Surgical techniques such as over correction, complete mobilization of the maxilla followed by rigid fixation, use of bone grafts and or a tension free advancement can help minimize relapse of the corrected position.

On completion of orthodontic treatment all patients should have a retention regime prescribed and should be reviewed for a prolonged period of time since patients may continue to require revision surgery for their soft tissues, pharyngoplasty and complex restorative treatment including bridge, crown or implant treatment. Scarring from previous cleft palate surgery can affect the stability of the corrected malocclusion therefore, if the patients' oral hygiene permits a fixed retainer may be deemed most appropriate coupled with removable Hawley style retainers to help maintain any transverse expansion and general alignment of the dentition.

In patients that present with associating craniofacial syndromes the general principles of combined orthodontic and orthognathic surgery still apply. These patients can also be intercepted at an early stage for the provision of a functional appliance/distraction osteogenesis.

\section{Conclusion}

This chapter has focused on the orthodontic aspect of cleft lip palate (CLP) treatment. However, it should be noted that management is multi-disciplinary involving a number of specialists including the oral and maxillofacial surgeons, 
cleft surgeons, ENT surgery, restorative and pediatric dentists, plastic surgeons, psychologists and speech therapists, etc. It is important for the orthodontist to communicate well with all these specialists in the management of CLP patients to allow for timely management. Additionally, it is prudent that the parents and patient are motivated for complex and elongated orthodontic management and maintenance of a high standard of dental health throughout treatment.

\section{Conflict of interest}

The author declares no conflict of interest.

\section{Author details}

Geetanjali Sharma

Frimley Health NHS Foundation Trust, Wexham Park Hospital, Slough,

United Kingdom

*Address all correspondence to: geetanjali.sharma1@nhs.net

\section{IntechOpen}

(C) 2020 The Author(s). Licensee IntechOpen. This chapter is distributed under the terms of the Creative Commons Attribution License (http://creativecommons.org/licenses/ by/3.0), which permits unrestricted use, distribution, and reproduction in any medium, provided the original work is properly cited. (cc) BY 


\section{References}

[1] Gregory SA, Bryan DT, David MF. Preoperative cleft lip measurements and maxillary growth in patients with unilateral cleft lip and palate. The Cleft Palate-Craniofacial Journal. 2016;53(6):198-207

[2] Nicholls W. Dental anomalies in children with cleft lip and palate in Western Australia. European Journal of Dentistry. 2016;10(2):254

[3] Burston WR. The early orthodontic treatment of cleft palate conditions. Dental Practice. 1958;9:41

[4] Georgiade NG, Latham RA. Maxillary arch alignment in the bilateral cleft lip and palate infant, using pinned coaxial screw appliance. Plastic and Reconstructive Surgery. 1975;56:52-60

[5] Hotz M, Perko M, Gnoinski W. Early orthopaedic stabilization of the premaxilla in complete bilateral cleft lip and palate in combination with the Celesnik lip repair. Scandinavian Journal of Plastic and Reconstructive Surgery and Hand Surgery. 1987;21:45-51

[6] Loeffelbein DJ, Rau A, Wolff KD. Impression technique for monitoring and virtual treatment planning in nasoalveolar molding. The British Journal of Oral and Maxillofacial Surgery. 2013;51(8):902-907

[7] Grayson BH, Maull D. Nasoalveolar molding for infants born with clefts of the lip, alveolus, and palate. Seminars in Plastic Surgery. 2005;19(4):294-301

[8] Rau A, Ritschl LM, Mucke T, Wolff KD, Loeffelbein DJ. Nasoalveolar molding in cleft care- experience in 40 patients from a single centre in Germany. PLoS One. 2015;10(3):e0118103. Aviable from: https://doi.org/10.1371/journal. pone. 0118103

[9] Catharina AMB, Anne MK, Martin AV, Birte PA. The effect of infant orthopedics on the occlusion of the deciduous dentition in children with complete unilateral cleft lip and palate (Dutchcleft). The Cleft Palate-Craniofacial Journal. 2004;41(6):633-641

[10] Masarei AG, Wade A, Mars M, Sommerlad BC, Sell D. A randomized control trial investigating the effect of presurgical orthopedics on feeding in infants with cleft lip and/or palate. Cleft Palate-Craniofacial Journal. 2007;44(2):182-193

[11] Shaw WC, Bannister RP, Roberts CT. Assisted feeding is more reliable for infants with clefts-A randomized trial. Cleft Palate-Craniofacial Journal. 1999;36(3):262-268

[12] Vargervik K. Growth characteristics of the premaxilla and orthodontic treatment principles in bilateral cleft lip and palate. Cleft Palate-Craniofacial Journal. 1983;20:289-302

[13] Arosarena OA. Cleft lip and palate. Otolaryngologic Clinics of North America. 2007;40:27-60

[14] Williams MD, Sarver DM, Sadowsky PL, Bradley E. Combined rapid maxillary expansion and protraction facemask in the treatment of class III malocclusions in growing children: A prospective long-term study. Seminars in Orthodontics. 1997;3:265-275

[15] So LL. Effects of reverse headgear treatment on sagittal correction in girls born with unilateral complete cleft lip and cleft palate-skeletal and dental changes. American Journal of Orthodontics and Dentofacial Orthopedics. 1996;109:140-147

[16] Tindlund RS. Orthopedic protraction of the midface in the deciduous dentition. Results covering 
Orthodontic Management of Cleft Lip and Palate Patients

DOI: http://dx.doi.org/10.5772/intechopen.90076

3 years out of treatment. Journal

of Cranio-Maxillo-Facial Surgery.

1989;17(Suppl 1):17-19

[17] Epker BN, Stella JP, Fish LC.

Dentofacial deformities associated with cleft lip and palate. In: Dentofacial

Deformities: Integrated Orthodontic and Surgical Correction, III. 2nd ed.

St Louis: Mosby; 1998. pp. 1571-1708

[18] Polley JW, Figueroa AA.

Management of severe maxillary deficiency in childhood and adolescence through distraction osteogenesis with an external, adjustable, rigid distraction device. The Journal of Craniofacial

Surgery. 1997;8:181-185 

Section 2

Surgery in Clefts 



\title{
Optimizing Outcomes in Cleft Surgery
}

\author{
Eugene Park, Gaurav Deshpande, Bjorn Schonmeyr, \\ Carolina Restrepo and Alex Campbell
}

\begin{abstract}
Children born with cleft lip and palate in low- and middle-income countries (LMICs) have limited access to surgical care and suffer substantial morbidity as a result of delayed treatment. Charitable organizations have sought to tackle this problem through high-volume surgical missions, but these efforts have been fraught with high rates of complications and variable esthetic results. Over the past decade, Operation Smile (OS) has placed considerable emphasis on improving the quality of care delivered to patients in LMICs. By establishing an outcome evaluation program among other interventions, OS has achieved measurable improvements in complication rates and post-operative follow-up. The founding of the Guwahati Comprehensive Cleft Care Center in India has been pivotal to the success of OS's work in this field and is the evidence of the impact that an optimized model of care delivery can make. Here we describe OS's efforts to improve the quality of care delivered to patients in LMICs with a focus on the organization's work in India.
\end{abstract}

Keywords: cleft lip and palate, low and middle-income countries, global surgery, models of health care delivery, quality improvement

\section{Introduction}

Clefts of the lip and palate are among the most common congenital deformities, occurring in about 1 in 500 to 1 in 1000 births worldwide [1]. In many areas of the world, the number of patients with clefts far exceeds the capacity of the healthcare system to treat them. Consequently, only a fraction of the affected population receives treatment, resulting in a global backlog of over 600,000 untreated patients, with 72,000 in India alone [2]. Clefts of the lip and palate can have devastating consequences. Children with cleft palate have difficulty with speech and feeding, which can lead to malnourishment and developmental delay $[3,4]$. Children with cleft lip face social stigma and often have lower levels of education and greater unemployment compared to their peers, despite having normal intellectual capacity [5-7].

The global response to this problem over the past several decades has been immense. Charitable organizations have provided more than 1 million free cleft repair surgeries and trained local surgeons to perform these procedures [8]. Historically, the success of these outreach efforts has been measured by the number of patients served, and little emphasis has been placed on the quality of care delivered. Research related to surgical missions is needed but seldom performed, often due to limited funding, manpower, and time $[9,10]$. The logistical challenges of 
locating former patients, varying degrees of patient compliance, and coordinating follow-up with local providers have also been noted as barriers [11, 12].

What little data that exists indicates that cleft mission work in low and middleincome countries (LMICs) has at times been associated with poor outcomes [8]. Complication rates following cleft palate repair in these settings often approach $30 \%$ and follow up rates are understandably much lower than at tertiary care centers in developed nations $[13,14]$. In order to bridge this gap, thoughtfully designed quality improvement measures must be implemented, and outcomes must be tracked over time to prove the efficacy of these interventions. Recently, various groups have contributed to a growing body of literature related to such efforts, and some substantial improvements have been reported $[13,15,16]$.

In this chapter, we discuss Operation Smile's quality improvement efforts in global cleft care during the past decade and review their impact on measured outcomes. Operation Smile (OS) is an international not-for-profit organization that has provided hundreds of thousands of free cleft lip and palate surgeries to patients in LMICs since 1982. The organization has placed an emphasis on optimizing patient care through research and maintains electronic medical records and photo documentation for all treated patients. By analyzing data collected from missions and cleft centers, OS has been able to implement standardized protocols and quality control mechanisms that have resulted in decreased complications and increased access to cleft care in LMICs.

\section{Models of cleft care delivery}

Charitable foundations have supported cleft missions to LMICs since the late 1960s. Early efforts followed a vertical model of care delivery in which teams are sent to underserved regions for short-periods of time to provide surgical care. This model has often been criticized for its emphasis on patient volume over quality, and for its inherently limited provision for post-surgical follow up [8]. Other criticisms include the marginalization of local providers whose welfare may be threatened by foreign aid, and the use of missions as a training ground for surgeons with little experience in cleft lip and palate repair [17]. Despite these criticisms, cleft missions have been an impactful mean to serve a large number of untreated patients and are essential in parts of the world where cleft care is otherwise nonexistent.

A horizontal model of care delivery focuses solely on building local capacity by partnering with area institutions and equipping them to become autonomous centers for comprehensive cleft care. This is accomplished through long-term financial commitments and by providing training to local surgeons, with the goal of ultimately making foundational support obsolete. The horizontal model has been effective in many LMICs, with substantial disability-adjusted life years (DALYs) averted in a cost-effective manner $[18,19]$. However, the success of this model hinges on extended periods of investment from charitable organizations, as well as from individual providers, and this limits the scope of this strategy. Additionally, a horizontal program can only be initiated in regions where a care system already exists. Thus, in the most remote areas of the world, surgical missions are still a necessity.

A broadly applicable yet effective strategy for cleft care in LMICs should mobilize surgical missions while simultaneously working to increase the capacity of the local healthcare system, and this has been termed the diagonal model of healthcare delivery (Figure 1) [20]. In the state of Assam, India, this model has been utilized to develop a sustainable, high-volume cleft care center that emphasizes empowerment of local providers and continuous quality improvement. 


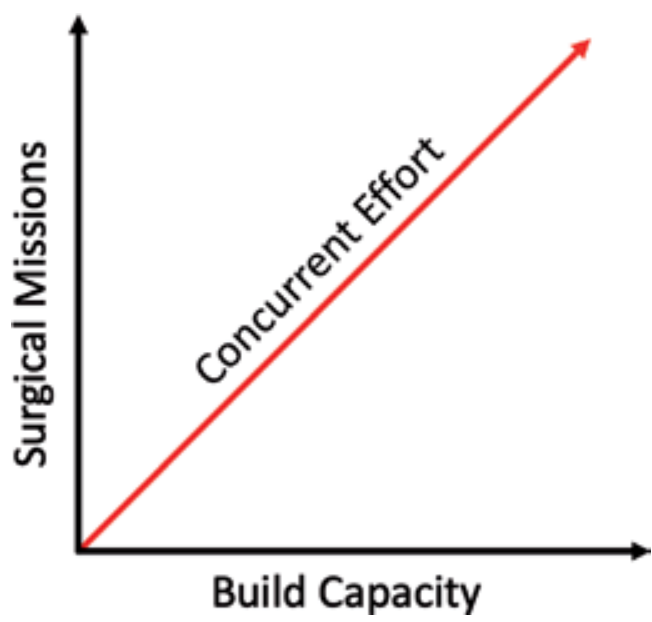

Figure 1.

In the diagonal model of cleft care delivery, surgical missions are mobilized while simultaneously initiating efforts to increase local capacity. Missions serve as a bridge to the ultimate goal of transitioning care to local surgeons.

In 2009, OS began missions to Guwahati, a large city in the state of Assam in India. After seeing the outsized burden of untreated clefts in this region, OS partnered with the state government of Assam and with Indian charitable foundations to establish the Guwahati Comprehensive Cleft Care Center (GCCCC) [21]. GCCCC is a surgical specialty hospital dedicated to providing the full spectrum of cleft care to patients who otherwise would not have access to it [22]. Since its opening in 2011, GCCCC has treated over 16,000 patients, while providing a center of operations for follow up and outcomes evaluation [23]. One of the initial goals of GCCCC was to provide training to local providers, and the center is now led entirely by local staff representing plastic surgery, oral surgery, orthodontics, speech pathology, psychology, and nutrition.

Two large missions were held in Guwahati prior to the opening of GCCCC, and this period of transition provides a unique opportunity to compare outcomes between a mission-based model of care delivery and a center-based model. In order to evaluate differences in complications, we performed a retrospective review of 3419 consecutive patients who underwent cleft lip repair and 1728 consecutive patients who underwent cleft palate repair with OS over a 4-year period (2010-2014) [13]. Our results show that early complication rates decreased for both cleft lip and cleft palate repairs with the transition to center-based care at GCCCC $(\mathrm{p}<0.05)$ (Table 1). For cleft lip repairs, complication rates (infection, wound dehiscence) decreased three-fold from the initial mission, and for cleft palate repairs, complication rates (bleeding, flap necrosis, dehiscence, fistula formation)

\begin{tabular}{lcccc}
\hline & Dec 2010 mission & Jan 2011 mission & GCCCC & $\boldsymbol{p}$ \\
\hline No. cleft lip repairs & 298 & 356 & 2765 & \\
\hline Cleft lip complications & $13.2 \%$ & $6.7 \%$ & $4 \%$ & $<0.05$ \\
\hline No. cleft palate repairs & 120 & 116 & 1491 & \\
\hline Cleft palate complications & $28 \%$ & $30 \%$ & $15.8 \%$ & $<0.05$ \\
\hline
\end{tabular}

Table 1.

Early complication rates after cleft lip and cleft palate repair in Guwahati during the transition from missionbased care to center-based care. 
were halved. These changes are attributable to multiple factors, including the presence of a permanent facility to provide systemized and chronological care, standardized protocols, training of permanent staff in all disciplines, and evolution of techniques over high volumes of cases.

GCCCC was designed from the outset to provide the highest level of care to the people it would serve while integrating the local community into its operations. As the center evolved, various quality metrics began to improve, and this is discussed below. The success in Guwahati highlights the effectiveness of the diagonal model of cleft care delivery, in which surgical missions are initiated with a concomitant effort to build local capacity.

\section{Patient-centered care}

An effective model of care delivery emphasizes patient-specific needs, and an essential component of such patient-centered care is an intimate understanding of the socioeconomic environment and cultural background of patients' communities. India represents one of the most apparent examples of the growing dichotomy between the rich and the poor. India has the world's 7th largest gross domestic product but ranks 129th in the world with regards to overall standard of living [24, 25]. As of 2018, the per capita income in India was $\$ 2036$, and severe disparities exist in terms of income, literacy rates, life expectancy, and living conditions [24]. Access to health care and health care literacy naturally succumb to the same disparities, and this posed a substantial challenge to initial work in Guwahati.

OS conducted two cleft missions to Guwahati in December 2010 and January 2011. During the first mission, it became apparent that there was widespread patient and parent misunderstanding of post-operative instructions. Instructions were given at the discretion of individual surgeons and pediatricians, and patient understanding could not always be confirmed. In response, a standardized, culturally-focused patient education program was initiated during the second mission. Nurses provided individual and group teaching sessions to patients and their parents, going over specific wound care, diet, and hygiene instructions. Additionally, a standardized post-operative instruction sheet was provided to all patients. The instructions were written in Assamese, the local language, and dietary instructions pertained to specific foods that were common in the region. The form also included easy-to-comprehend pictographs for illiterate patients (Figure 2).

Of the 220 patients who presented for early follow-up after the first mission, $3.7 \%$ had developed lip wound infection and $9.6 \%$ developed lip dehiscence. Of the 252 patients who presented for follow up after the second mission, $0.4 \%$ had infections and 6.4\% developed dehiscence [26]. Logistic regression revealed that patient education was the only covariate that contributed significantly to the decrease in wound infection rates. This demonstrates the powerful impact of addressing disparities in literacy and providing patient-centered care that accounts for community-specific beliefs and practices.

Patient-centered care was also a cornerstone for the design of GCCCC. The center was purpose-built to provide consistent and easy access to multi-disciplinary care for patients with cleft lip and palate. The state-of-the-art facility includes a modern operating suite with an open layout, sophisticated anesthesia and monitoring capabilities, central medical gases, and sterilization facilities (Figure 3). Inpatient units were also designed to provide focused pediatric care, education, and rehabilitation. The full breadth of cleft-relevant medical specialties is available 

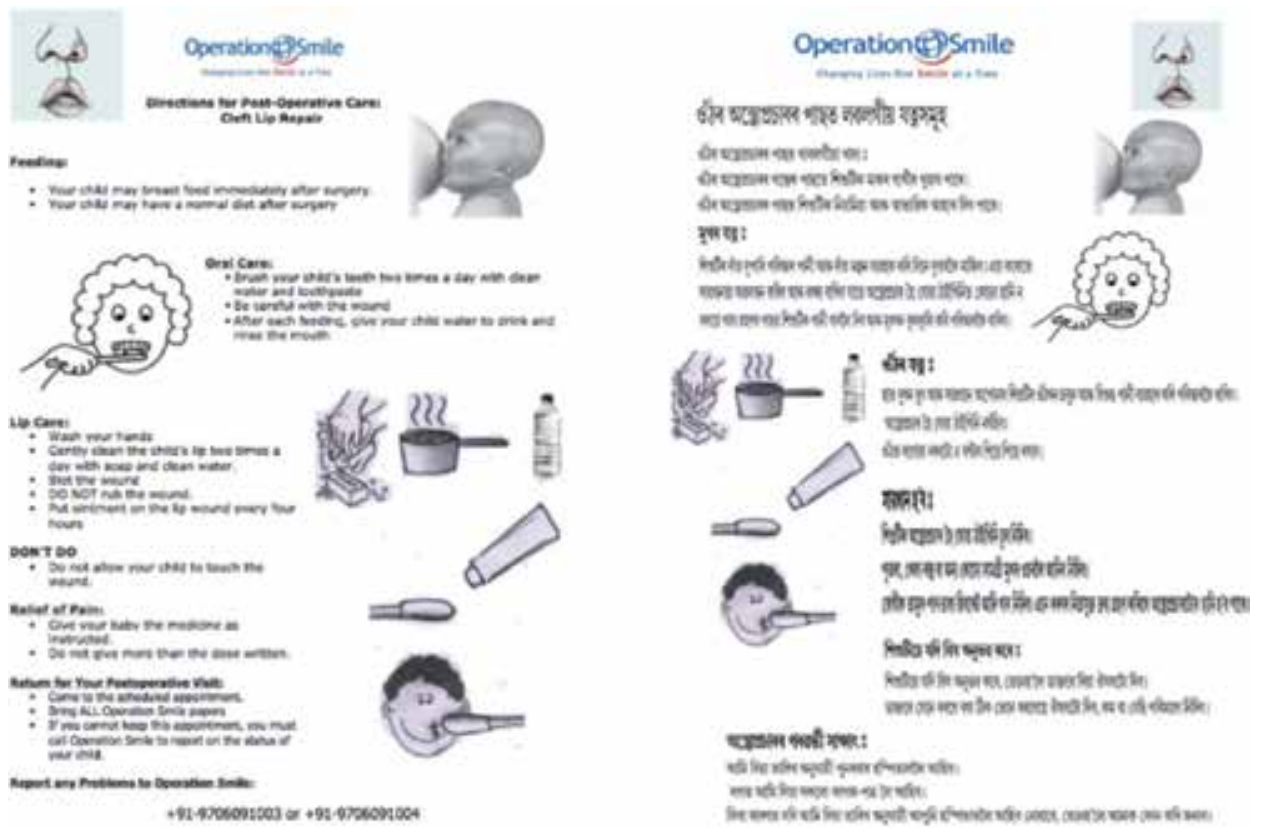

Figure 2.

Standardized post-operative instructions were printed and provided to patients in the local language, Assamese. Easy-to-understand pictographs were also included for illiterate patients.

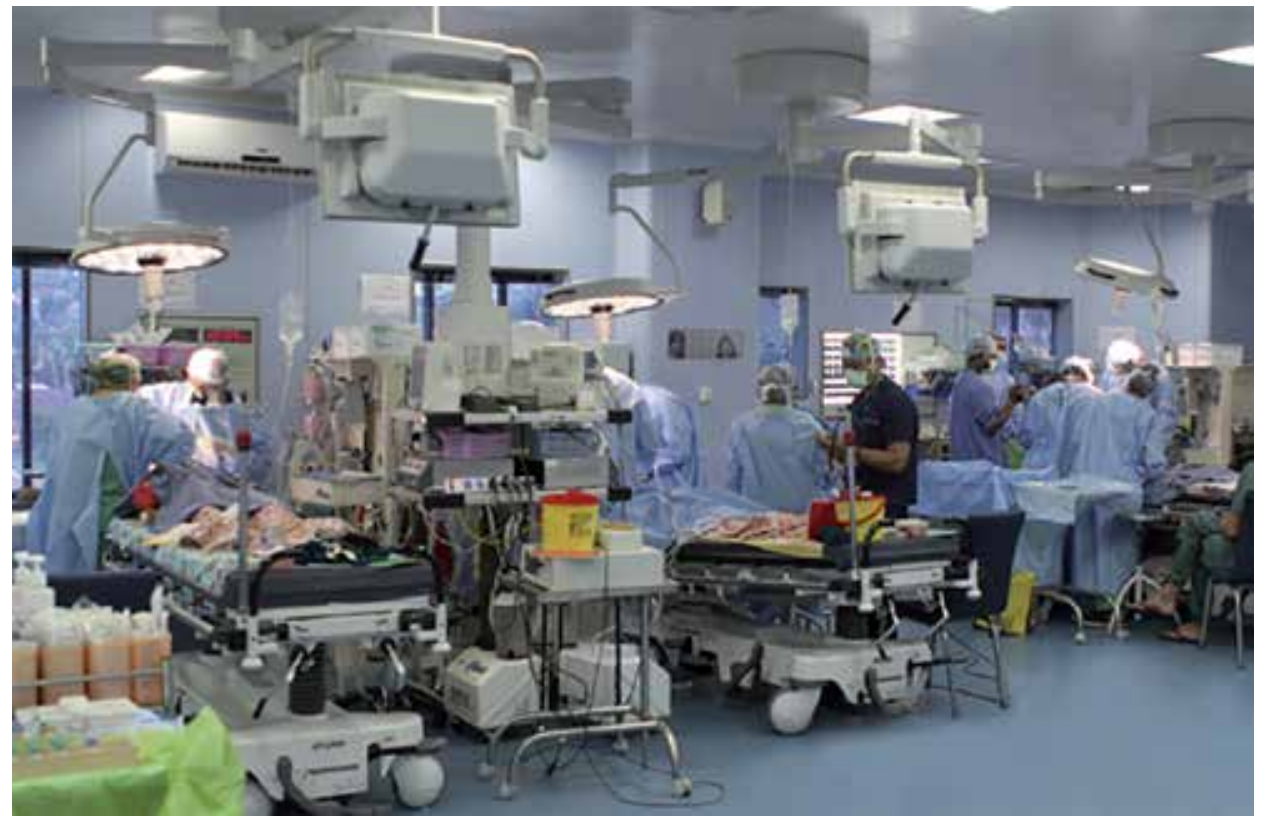

Figure 3.

The Guwahati comprehensive cleft care Center was designed with a modern operating suite with an open layout. This layout facilitates collaboration and teaching among the surgical team.

within the building, facilitating efficient interdisciplinary care for patients. Due to the restraints of providing care in a resource-limited environment, patients undergoing cleft lip repair at GCCCC do not receive preoperative orthodontics. However, post-operative care is provided in all specialties in a longitudinal manner. 


\section{Operative and perioperative protocols}

In-depth analyses of outcomes from cases completed during the first few years of operation at GCCCC helped establish standardized protocols for the peri-operative and operative care of cleft patients, which is more widely applicable in India and other LMICs. The cumulative effect of these protocols has been to decrease rates of early complications following cleft lip and palate repair as reported in our comparison of mission-based and center-based care. Protocols are supported by a retrospective analysis of outcomes from a consecutive cohort of patients. Our group analyzed rates of early surgical complications from 2062 patients who presented for early follow up after primary cleft lip repair at GCCCC between 2011 and 2013 [27]. All patients received a single pre-operative dose of intravenous cefuroxime, and all patients and families underwent an educational program for post-operative care. Surgical technique was also standardized for the majority of cases (Mohler rotationadvancement technique for unilateral cleft lip and Millard-Mulliken technique for bilateral cleft lip). Malnourished patients were enrolled in a nutrition program and were not operated on until they were considered fit for surgery. Overall, $4.4 \%$ of patients developed an early complication (wound dehiscence and/or infection), which represents a three-fold improvement from OS's initial mission to Guwahati. Logistic regression revealed that dehiscence was significantly associated with visiting surgeons (surgeons who were at GCCCC for less than 6 months) (OR 2.64; 95\% CI 1.61 to 4.33; $\mathrm{p}<0.001$ ), complete clefts (OR 1.83; 95\% CI 1.07 to $3.11 ; \mathrm{p}<0.05$ ), and bilateral clefts (OR 2.01; 95\% CI 1.14 to 3.57; p > 0.05) (Figure 4). Our results indicate that center-based care and standardized perioperative protocols can improve outcomes in LMIC settings.

A separate analysis of 1408 patients who presented for early follow up after primary cleft palate repair during the same period revealed an early complication rate of $16.9 \%$ with a fistula rate of $13.6 \%$ [28]. Logistic regression identified cleft type (Veau classification) (OR 1.52; 95\% CI 1.27 to $1.81 ; \mathrm{p}<0.001$ ), visiting status of surgeon (OR 1.60; 95\% CI 1.15 to 2.21 ; $\mathrm{p}<0.01$ ), and increasing patient age (OR 1.03; 95\% CI 1.01 to 1.05 ; $\mathrm{p}<0.01$ ) as significant contributors to the development of complications (Table 2). The results of these analyses collectively indicate that complex cases should only be performed by providers with extensive experience in treating the types of pathology seen in LMICs.

A subsequent study evaluated a subset of 512 patients who underwent cleft palate repair by 6 permanent staff surgeons at GCCCC [29]. The combined fistula rate was 3.9\%. Multivariate analysis revealed that Veau IV cleft palates had significantly higher rates of early post-operative complications, but more importantly, that there were no differences in complication rates among the 6 surgeons. The staff surgeons at GCCCC were trained to follow the same foundational principles of cleft palate repair. These includes adequate tissue mobilization for tension-free repair, delicate tissue handling, and multi-layered palatal closure. The outcome of this study validates the training received by the staff surgeons and emphasizes the importance of standardization even in surgeon education.

An additional benefit of center-based care is that it provides the infrastructure necessary for controlled research. Our group performed a prospective, double-blinded, randomized, placebo-controlled study at GCCCC to evaluate the efficacy of extended post-operative antibiotics following cleft palate repair in LMICs [30]. Five hundred eighteen patients were randomized into two cohorts, one receiving 5 days of oral amoxicillin and the other receiving only one pre-operative dose of intravenous cefuroxime. The incidence of early complications was reduced in the treatment group $(8.7 \%$ vs. $13.8 \%$ ), highlighting again the importance of tailoring care to the specific communities 


\section{Dehiscence}

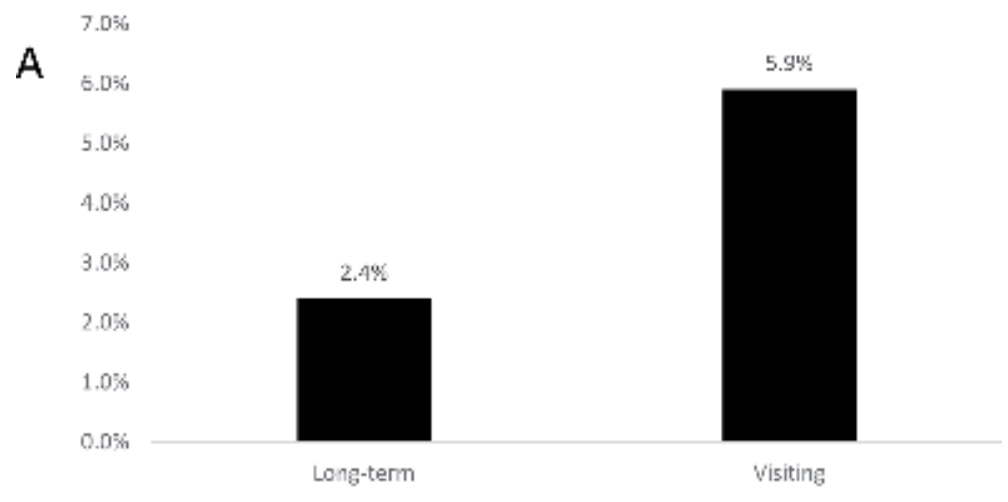

\section{Dehiscence}

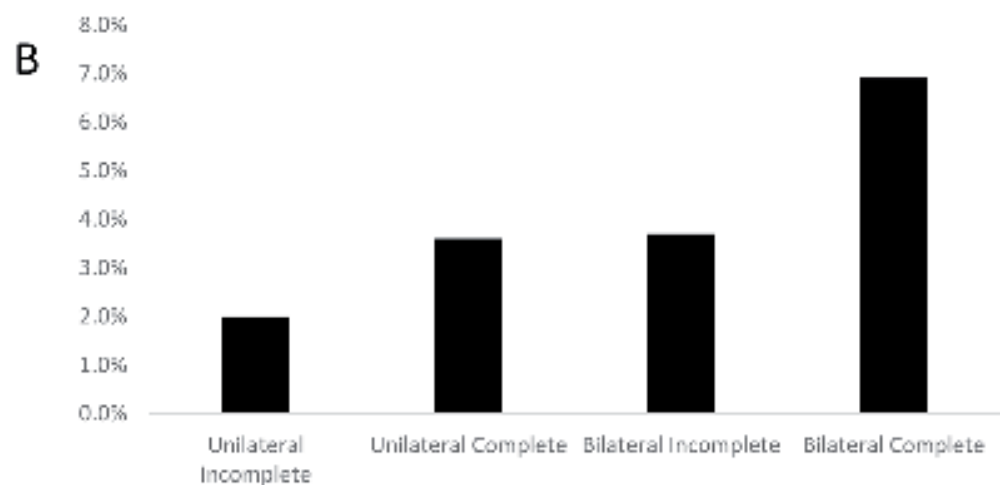

Figure 4.

Incidence of wound dehiscence after primary lip repair according to (A) surgeon status (visiting or permanent) and $(B)$ cleft type.

\begin{tabular}{lcc}
\hline Covariate & OR $(\mathbf{9 5 \%} \mathbf{C I})$ & $\mathbf{p}$ \\
\hline Cleft Type & $1.516(1.269-1.811)$ & $<0.001$ \\
\hline Age & $1.028(1.010-1.045)$ & $<0.01$ \\
\hline Surgeon & $1.599(1.154-2.214)$ & $<0.01$ \\
\hline${ }^{*}$ Visiting versus long-term $(>6$ months of service at the center $)$. & \\
\hline
\end{tabular}

Table 2.

Logistic regression analysis of factors related to postoperative complications after primary palate repair.

involved. While patients undergoing cleft palate repair in developed regions uniformly receive only one pre-operative dose of antibiotics, the results of this study show that patients in resource-poor settings with limited access to hygiene benefit from extended antibiotic coverage. This is evidence that rigorous evaluation of outcomes from specific populations helps shape best practices and ultimately improves outcomes.

Based on the data collected from these studies, OS has produced a set of evidencebased recommendations for improving outcomes in cleft surgery (Table 3). These principles continue to direct OS's efforts to improve outcomes in resource-limited areas all around the world. 
1. Implement standardized perioperative protocols for cleft lip and cleft palate.

Standardizing things means all doctors and nurses are doing the same thing and this translates into improved patient understanding and compliance.

\begin{tabular}{l}
\hline Cleft Lip [27] \\
\hline - 1 dose pre-operative intravenous antibiotic before incision \\
\hline - No post-operative antibiotics \\
\hline - No tapes over incisions or other complicated dressings \\
\hline - Oral hygiene including washing mouth after eating and brushing teeth twice a day \\
\hline - Wash wound two times a day with clean water and blot dry \\
\hline - Normal diet with soft foods, breastfeeding okay immediately \\
\hline - No chewing tobacco, pan, etc. for older patients \\
\hline Cleft Palate [28] \\
\hline 1 dose pre-operative intravenous antibiotic before incision \\
\hline - May days of oral antibiotics post-operatively [30] \\
\hline Oral hygiene including washing mouth after eating and brushing teeth twice a day \\
\hline
\end{tabular}

2. Implement standardized patient education program that is taught to nurses then to patients and families [26].

Teaching sessions are held on the ward after surgery before discharge where nurses go through all discharge instructions and provide handouts in the local language with pictographs.

3. Higher risk patients should be done by the most experienced surgeons [28].

Cases to be performed by experienced surgeons

- Complete unilateral cleft palate

- Complete bilateral cleft palate

- Older patients

4. Educate surgeons about optimal techniques for successful outcomes [29].

Complications in cleft palate surgery are very closely linked to technique. Surgeons should be taught to adequately mobilize all tissues for a tension-free repair. Delicate tissue handling is stressed.

Table 3.

Evidence-based recommendations for improving outcomes in cleft surgery.

\section{Follow up}

Post-operative follow-up is an indispensable component of any type of surgical care. It is especially critical in cleft care as speech therapy is a necessary adjunct to realizing the full benefits of palatoplasty. Additionally, longitudinal patient evaluation is important when analyzing outcomes and quality improvement interventions. Unfortunately, follow-up is also one of the most challenging aspects of patient care in LMICs due to the time and financial burden placed on patients, as well as limited access to transportation. In the early stages of operation at GCCCC, significant barriers were noted to follow-up, necessitating a rethinking of the way follow-ups were performed.

The District Outreach Follow-up and Speech Therapy (DOFAST) program was started by GCCCC with the goal of bringing the follow-up to patients instead of having them travel to the center. Small multi-disciplinary teams of providers 
were sent to outreach camps near patients living more than $200 \mathrm{~km}$ away if there were at least 20 patients to be seen. When patients were evaluated at GCCCC, the direct cost of transportation is covered by the center, but patients must still deal with the indirect costs of travel such as time off from work. These indirect costs are decreased with the DOFAST program, but the costs of staff travel, meals, and lodging had to be covered by the center.

A prospective study was launched to measure changes in follow-up rates and costs after the launch of the DOFAST program [14]. Questionnaires were also completed by 195 patients (122 at GCCCC and 73 at DOFAST camps) to evaluate expenses, time lost, and other patient-related variables. Patients who attended local follow up had fewer accompanying family members, fewer days off work, less lost income (Rs 143 vs. 367; p < 0.05) and lower direct costs (Rs 299 vs. 911; p < 0.05) compared to patients seen at GCCCC. Post-operative follow-up visits increased from 139 monthly visits (follow-up to surgery ratio of 0.722 ) to 363 monthly visits (ratio of 1.57). Additionally, the average cost to the center per patient was lower for local follow-up compared to follow-up at the center (Rs. 303 vs. 1100).

\section{Esthetic outcomes}

While complications following cleft lip repairs are widely reported in the literature, esthetic outcomes are rarely assessed. Furthermore, esthetic outcomes after cleft lip repair in LMICs are rarely, if ever, reported. The goals of any quality improvement initiative are not only to reduce complication rates, but also to help patients achieve the best possible esthetic result from their surgery. To that end, OS started the Surgical Outcomes Program (SOP) which aims to critically evaluate post-operative results after cleft lip repair using validated instruments.

The Unilateral Cleft Lip Severity Index was developed as a tool for analyzing and categorizing unilateral cleft lip deformities according to the amount of lip involved and the degree of nasal asymmetry (Figure 5) [31]. The severity index was validated in a study measuring the inter-rater reliability of the tool when used by both surgeon and laypersons. Twenty-five participants (10 surgeons and 15 laypeople) evaluated 25 sets of pre-surgical photographs of unilateral cleft lip patients. Inter-rater reliabilities for both groups were categorized as very good (ICC > 0.8). The severity index is used in conjunction with the Surgical Outcomes Evaluation Scale, which grades the esthetic outcome of a unilateral cleft lip repair based on the symmetry of the nose, cupid's bow, lateral lip, and free vermilion (Figure 6) [32]. A similar validation study was performed for the outcomes evaluation scale in which 20 participants ( 9 surgeons and 12 laypeople) evaluated 25 sets of post-operative photographs. Inter-rater reliabilities were 0.71 for surgeons and 0.82 for laypeople. The validation of these tools for use by non-medical personnel is important as they were designed to be used in resource-limited settings by mission teams composed of a few surgeons and many non-medical personnel.

The Unilateral Cleft Lip Severity Index and Surgical Outcomes Evaluation Scale are now utilized globally and provide feedback regarding outcomes to volunteer surgeons as well as OS administrators with a relatively short turn-around time. In order to aid in the interpretation of results, a retrospective study was performed applying the severity index and outcomes evaluation scale to 1823 patients who had undergone unilateral cleft lip repair by OS during missions in various countries and at GCCCC [33]. The results of this study established a normative bell curve of outcomes for each severity of unilateral cleft lip deformity (Figure 7). Based on these normative values, a surgeon can see where his or her results fall in the range of results for a given severity of cleft. Surgeons who fall on the upper end of the spectrum can 


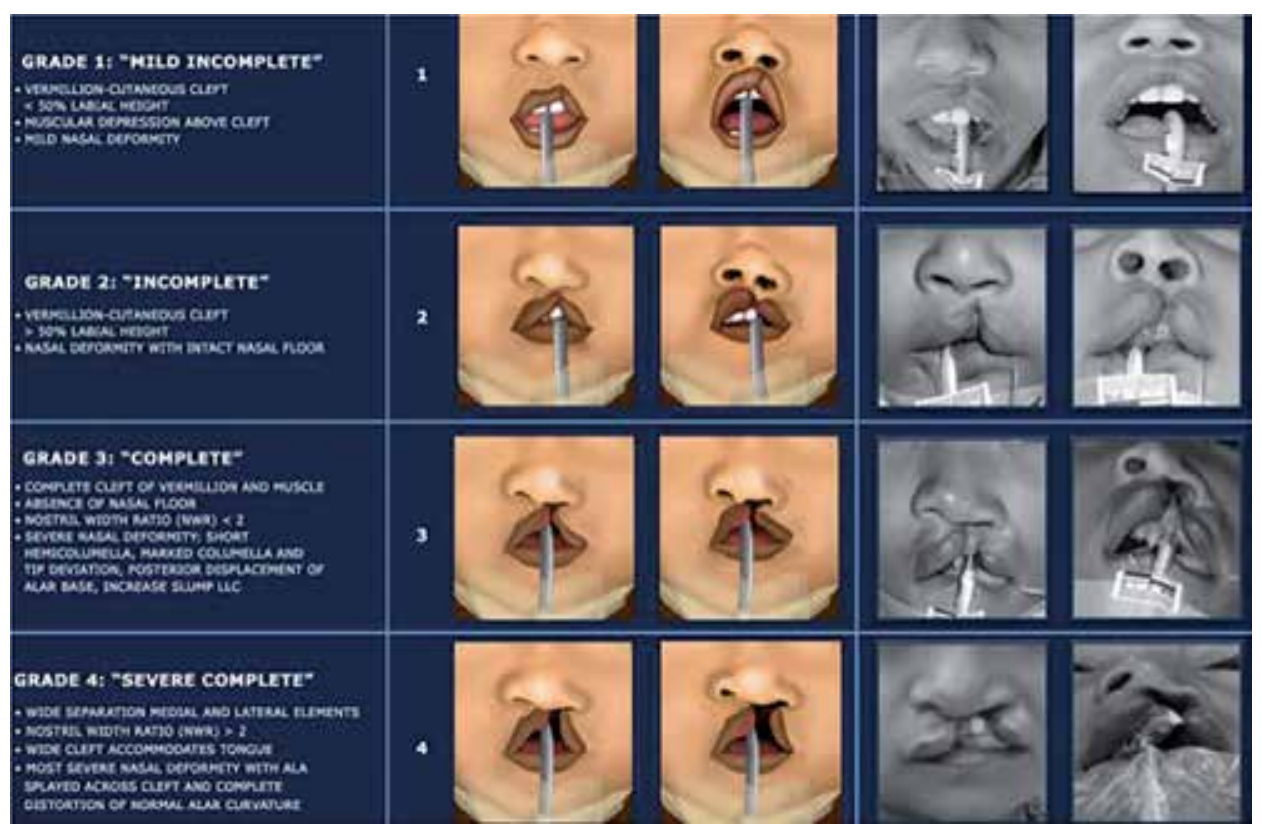

Figure 5.

Criteria and examples demonstrating each of the 4 grades of the cleft severity index.

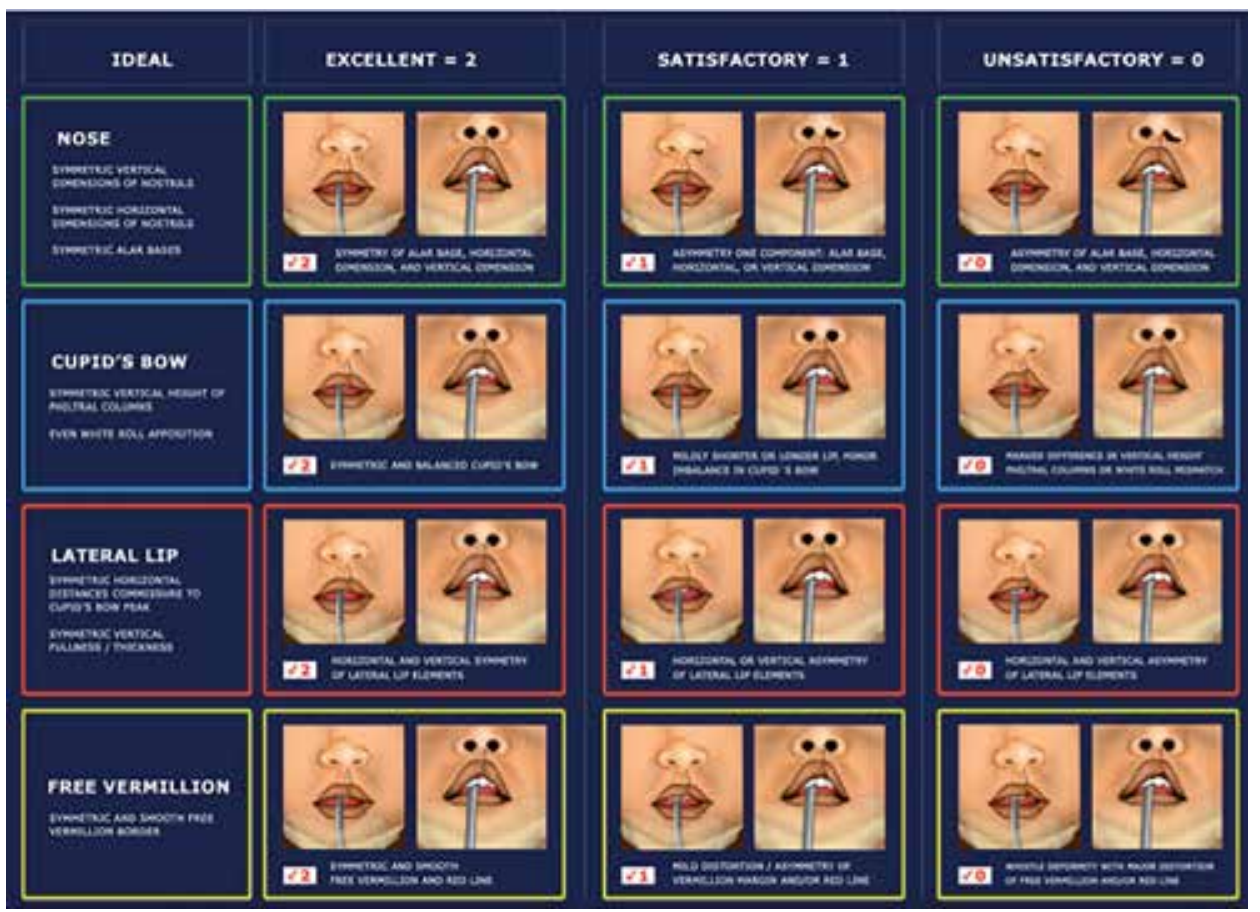

Figure 6.

Each element is scored on a 3-point scale: 2 (excellent), 1 (mild asymmetry), o (unsatisfactory). The scores of the 4 individual components are then summed for a total score of o (lowest) to 8 (highest).

provide coaching to less experienced surgeons, and results that fall below a standard deviation of the average can be investigated for root cause analyses.

The next steps in OS's mission to provide the best quality care to cleft patients in LMICs will be to use the cleft severity index and outcomes evaluation scale to study 


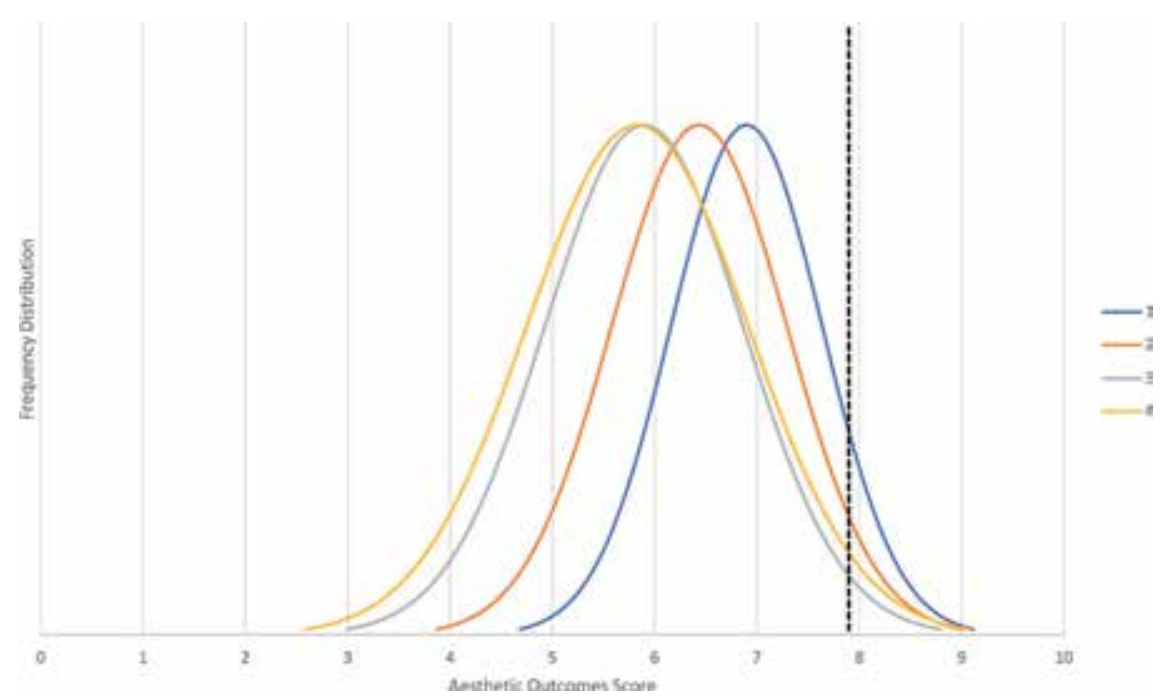

Figure 7 .

Bell curve of normative surgical outcomes evaluation scores for each of the cleft severities (1 through 4). Dotted line represents the maximum possible score.

whether certain interventions or models of care delivery improve esthetic outcomes after cleft lip repair. The routine use of these tools in OS's work around the world provides a means of quality control and ensures that patients in LMICs receive the same high level of care as patients in the developed world.

\section{Conclusion}

Cleft care in LMICs has grown tremendously over the past few decades through the work of charitable organizations and individuals. However, complication rates in this setting have historically been high, and much work is needed to improve the quality of care delivered. Through outcomes analysis and a strong focus on patientcentered care, it is possible to achieve substantial, measurable improvements in the care provided to patients. OS's work over the past decade is evidence that the diagonal model of care delivery can be effective. If charitable foundations are to improve health care equity around the globe, they must work with the intention of building capacity and transferring responsibilities to the local community. By emphasizing research and continuous quality improvement, these organizations will continue to make great strides toward making top-quality care accessible to every child born with a cleft. 


\section{Author details}

Eugene Park ${ }^{1}$, Gaurav Deshpande ${ }^{2}$, Bjorn Schonmeyr ${ }^{3}$, Carolina Restrepo ${ }^{4}$ and Alex Campbell ${ }^{4 *}$

1 Division of Plastic Surgery, Northwestern University Feinberg School of Medicine, Chicago, IL, USA

2 Maaya Cleft and Craniofacial Unit, MGM Medical College, Navi Mumbai, Maharashtra, India

3 Skane University Hospital, Malmo, Sweden

4 Operation Smile Inc., Virginia Beach, VA, USA

*Address all correspondence to: alexcampbellmd@gmail.com

\section{IntechOpen}

(C) 2019 The Author(s). Licensee IntechOpen. This chapter is distributed under the terms of the Creative Commons Attribution License (http://creativecommons.org/licenses/ by/3.0), which permits unrestricted use, distribution, and reproduction in any medium, provided the original work is properly cited. (cc) BY 


\section{References}

[1] Cooper ME, Ratay JS, Marazita ML. Asian oral-facial cleft birth prevalence. The Cleft Palate-Craniofacial Journal. 2006;43(5):580-589

[2] Carlson LC, Stewart BT, Hatcher KW, Kabetu C, VanderBurg R, Magee WP Jr. A model of the unmet need for cleft lip and palate surgery in low- and middleincome countries. World Journal of Surgery. 2016;40(12):2857-2867

[3] Schonmeyr B, Wendby L, Sharma M, Raud-Westberg L, Restrepo C, Campbell A. Limited chances of speech improvement after late cleft palate repair. The Journal of Craniofacial Surgery. 2015;26(4):1182-1185

[4] Chepla KJ, Gosain AK. Evidencebased medicine: Cleft palate. Plastic and Reconstructive Surgery. 2013;132(6):1644-1648

[5] Tapia VJ, Chang DC, Ramirez M, Gosman A. A qualitative analysis of identity and goals in patients with deformities: Preparation for an evidence-based advocacy for a vulnerable population. Annals of Plastic Surgery. 2013;70(4):457-461

[6] Weatherley-White RC, Eiserman W, Beddoe M, Vanderberg R. Perceptions, expectations, and reactions to cleft lip and palate surgery in native populations: A pilot study in rural India. The Cleft Palate-Craniofacial Journal. 2005;42(5):560-564

[7] el-Shazly M, Bakry R, Tohamy A, Ali WM, Elbakry S, Brown SE, et al. Attitudes toward children with clefts in rural Muslim and Hindu societies. Annals of Plastic Surgery. 2010;64(6):780-783

[8] Kantar RS, Cammarata MJ, Rifkin WJ, Diaz-Siso JR, Hamdan US,
Flores RL. Foundation-based cleft Care in Developing Countries. Plastic and Reconstructive Surgery. 2019;143(4):1165-1178

[9] McQueen KA, Parmar P, Kene M, Broaddus S, Casey K, Chu K, et al. Burden of surgical disease: Strategies to manage an existing public health emergency. Prehospital and Disaster Medicine. 2009;24(Suppl 2):s228-s231

[10] Yeow VK, Lee ST, Lambrecht TJ, Barnett J, Gorney M, Hardjowasito W, et al. International task force on volunteer cleft missions. The Journal of Craniofacial Surgery. 2002;13(1):18-25

[11] Butler DP, Samman N, Gollogly J. A multidisciplinary cleft palate team in the developing world: Performance and challenges. Journal of Plastic, Reconstructive \& Aesthetic Surgery. 2011;64(11):1540-1541

[12] Adetayo O, Ford R, Martin M. Africa has unique and urgent barriers to cleft care: Lessons from practitioners at the Pan-African congress on cleft lip and palate. The Pan African Medical Journal. 2012;12:15

[13] Park E, Deshpande G, Schonmeyr B, Restrepo C, Campbell A. Improved early cleft lip and palate complications at a surgery specialty Center in the Developing World. The Cleft Palate-Craniofacial Journal. 2018;55(8):1145-1152

[14] Jansen LA, Carillo L, Wendby L, Dobie H, Das J, Restrepo C, et al. Improving patient follow-up in developing regions. The Journal of Craniofacial Surgery. 2014;25(5):1640-1644

[15] Braun TL, Louis MR, Dickey RM, Buchanan EP. A sustainable and scalable approach to the provision of cleft care: A focus on safety and quality. 
Plastic and Reconstructive Surgery. 2018;142(2):463-469

[16] Yao CA, Swanson J, Chanson D, Taro TB, Gura B, Figueiredo JC, et al. Barriers to reconstructive surgery in low- and middle-income countries: A cross-sectional study of 453 cleft lip and cleft palate patients in Vietnam. Plastic and Reconstructive Surgery. 2016;138(5):887e-895e

[17] Dupuis CC. Humanitarian missions in the third world: A polite dissent. Plastic and Reconstructive Surgery. 2004;113(1):433-435

[18] Corlew DS, Alkire BC, Poenaru D, Meara JG, Shrime MG. Economic valuation of the impact of a large surgical charity using the value of lost welfare approach. BMJ Global Health. 2016;1(4):e000059

[19] Poenaru D, Lin D, Corlew S. Economic valuation of the global burden of cleft disease averted by a large cleft charity. World Journal of Surgery. 2016;40(5):1053-1059

[20] Patel PB, Hoyler M, Maine R, Hughes CD, Hagander L, Meara JG. An opportunity for diagonal development in global surgery: Cleft lip and palate care in resource-limited settings. Plastic Surgery International. 2012;2012:892437

[21] Campbell A, Restrepo C, Mackay D, Sherman R, Varma A, Ayala R, et al. Scalable, sustainable cost-effective surgical care: A model for safety and quality in the developing world, part I: Challenge and commitment. The Journal of Craniofacial Surgery. 2014;25(5):1674-1679

[22] Campbell A, Restrepo C, Mackay D, Sherman R, Varma A, Ayala R, et al. Scalable, sustainable cost-effective surgical care: A model for safety and quality in the developing world, part II: Program development and quality care.
The Journal of Craniofacial Surgery. 2014;25(5):1680-1684

[23] Campbell A, Restrepo C, Mackay D, Sherman R, Varma A, Ayala R, et al. Scalable, sustainable cost-effective surgical care: A model for safety and quality in the developing world, part III: Impact and sustainability. The Journal of Craniofacial Surgery. 2014;25(5):1685-1689

[24] World Economic Outlook Database. International Monetary Fund; 2019

[25] Datt R. Indian Economy. New Delhi: Chand Group; 2009

[26] Schonmeyr B, Restrepo C, Wendby L, Gillenwater J, Campbell A. Lessons learned from two consecutive cleft lip and palate missions and the impact of patient education. The Journal of Craniofacial Surgery. 2014;25(5):1610-1613

[27] Schonmeyr B, Wendby L, Campbell A. Early surgical complications after primary cleft lip repair: A report of 3108 consecutive cases. The Cleft Palate-Craniofacial Journal. 2015;52(6):706-710

[28] Schonmeyr B, Wendby L, Campbell A. Surgical complications in 1408 primary cleft palate repairs operated at a single Center in Guwahati, Assam, India. The Cleft Palate-

Craniofacial Journal. 2016;53(3):278-282

[29] Deshpande GS, Campbell A, Jagtap R, Restrepo C, Dobie H, Keenan HT, et al. Early complications after cleft palate repair: A multivariate statistical analysis of 709 patients. The Journal of Craniofacial Surgery. 2014;25(5):1614-1618

[30] Aznar ML, Schonmeyr B, Echaniz G, Nebeker L, Wendby L, Campbell A. Role of postoperative antimicrobials in cleft palate surgery: Prospective, double-blind, randomized, 
placebo-controlled clinical study in India. Plastic and Reconstructive Surgery. 2015;136(1):59e-66e

[31] Campbell A, Restrepo C, Deshpande G, Bernstein SM, Tredway C, Wendby L, et al. Validation of the unilateral cleft lip severity index for surgeons and laypersons. Plastic and Reconstructive Surgery. Global Open. 2017;5(9):e1479

[32] Campbell A, Restrepo C, Deshpande G, Tredway C, Bernstein SM, Patzer R, et al. Validation of a unilateral cleft lip surgical outcomes evaluation scale for surgeons and laypersons. Plastic and Reconstructive Surgery. Global Open. 2017;5(9):e1472

[33] Campbell A, Restrepo C, Park E, Navas G, Deshpande G, Swanson J, et al. Influence of severity on aesthetic outcomes of unilateral cleft lip repair in 1,823 patients. Plastic and Reconstructive Surgery. Global Open. 2019;7(1):e2083 



\title{
Anesthesia Considerations in the Perioperative of Patients with Lip and Palate Length
}

\author{
Silvia Peña, Claudia Paulina Reyes, Andres Felipe Beltran \\ and Ofelia Ham
}

\begin{abstract}
There is a high risk of adverse events during anesthetic management in the pediatric population mainly in children under 1 year of age and with greater vulnerability: those undergoing head and neck surgery for involving airway, specifically patients who enter surgical correction of the lip and cleft palate. This pathology can be related in a high percentage to isolated malformations without integrating a specific syndrome or be part of the more than 500 associated craniofacial syndromes such as sequence Pierre Robin, Treacher Collins, and Goldenhar, among others; it is also associated in up to $10 \%$ with some heart disease. Factors that are determinants for anesthetic management have been identified in corrective surgery of the lip and cleft palate related to the patient's characteristics such as age and weight, his medical history or associated comorbidities, and the surgical technique. As it is the pathology with the highest incidence in facial malformations that requires surgical treatment, it is necessary to know the anesthetic management alternatives and establish criteria in the different stages of the perioperative period from preanesthetic assessment to postanesthetic care, in order to provide planned approach within the highest safety standards that reduce the risk of adverse events.
\end{abstract}

Keywords: craniofacial anesthesia and syndromes, anesthesia and cleft lip, cleft palate anesthesia, facial clefts and anesthesia, perioperative management

\section{Introduction}

Anesthetic management in the pediatric population has a higher risk of adverse events compared to the adult population, mainly in children under 1 year of age due to the anatomical characteristics of the airway that predisposes them to difficulty in ventilation and intubation [1-3].

In order to improve the safety of patients in the perioperative period, studies have been carried out to establish risk factors. The second report of the pediatric perioperative cardiac arrest (POCA) found respiratory complications as one of the main causes of perioperative circulatory arrest [4], observing a high incidence even in the absence of active upper respiratory infection and significantly impacting the economy by increasing hospital stay and costs up to $30 \%$. Laryngospasm, hypoxemia, and bronchospasm were considered as the most common adverse events related to anesthesia $[4,5]$. 
When attempting to identify patients with high risk, greater vulnerability was observed in those undergoing head and neck surgery that involves airway and specifically those of surgical correction of the cleft lip and palate [5-7]. The cleft lip and palate is the most common craniofacial anomaly nomination in Latin America whose incidence in Mexico.

Cleft lip and palate (CLP) is the most common craniofacial anomaly in Latin America whose incidence in Mexico is 1 per 800-1000 live births registered with great medical, psychological, and social repercussions [7].

It is defined as an elongated opening due to fusion failure between the lateral and medial nasal processes with the maxillary process during the fifth to eighth week of embryonic development, the severity of which is in relation to the percentage of interruption [8-10].

There are multiple classifications of orofacial clefts; due to their location, they can be unilateral, bilateral, or midline, and by their description, they are complete, incomplete, or submucosal, and according to structures, they involved the tip of the nose, nasolabial groove, lips, gums, hard palate, soft palate, and uvula $[9,10]$.

The etiology is heterogeneous due to the interaction of genetic and environmental factors during the early stages of pregnancy such as exposure to tobacco, alcohol consumption, nutritional deficiencies, viral infections, and exposure to phenytoinlike teratogens, valproic acid, thalidomide, and herbicides $[8,11]$. Prenatal diagnosis of cleft lip can be performed reliably in the 18-20 weeks of gestation, while the cleft palate is difficult to identify before birth [10].

Bibliographic reviews based on advances in medical technology agree that although surgical repair of cleft lip and palate is not an emergency, it should be done at an early age; the objective is to favor dentition and the development of hearing and language and reduce the incidence of respiratory infections by offering better esthetic and functional results that impact on the quality of life at an individual, family, and social level, with a low morbidity rate and zero mortality [7, 9, 12]. Primary repair of cleft lip and tip of the nose is performed around 3 months of age and that of cleft and maxillary palate at 9-12 months of life $[13,14]$.

\begin{tabular}{|c|c|c|c|c|}
\hline $\begin{array}{l}\text { Patient } \\
\text { characteristics }\end{array}$ & Comorbidities & $\begin{array}{l}\text { Surgical } \\
\text { management }\end{array}$ & $\begin{array}{l}\text { Anesthetic } \\
\text { management }\end{array}$ & $\begin{array}{l}\text { Postoperative } \\
\text { management }\end{array}$ \\
\hline Age & $\begin{array}{l}\text { Associated } \\
\text { syndromes (Pierre } \\
\text { Robin, Treacher, } \\
\text { Goldenhar) }\end{array}$ & $\begin{array}{l}\text { Surgical } \\
\text { technique }\end{array}$ & $\begin{array}{l}\text { Anesthetic } \\
\text { technique }\end{array}$ & Presence of bleeding \\
\hline Weight & Pneumopathies & $\begin{array}{l}\text { Procedure } \\
\text { duration }\end{array}$ & Induction type & Pain management \\
\hline Type of defect & Heart disease & & $\begin{array}{l}\text { Airway } \\
\text { management }\end{array}$ & Airway edema \\
\hline $\begin{array}{l}\text { Recurrent } \\
\text { respiratory } \\
\text { tract infections }\end{array}$ & & & $\begin{array}{l}\text { Endotracheal } \\
\text { tube used }\end{array}$ & $\begin{array}{l}\text { Nausea and vomiting } \\
\text { postoperatively }\end{array}$ \\
\hline $\begin{array}{l}\text { Mishandling of } \\
\text { secretions }\end{array}$ & & & Maintenance & $\begin{array}{l}\text { Postoperative } \\
\text { agitation }\end{array}$ \\
\hline $\begin{array}{l}\text { Anatomical } \\
\text { predictors of } \\
\text { difficult airway }\end{array}$ & & & $\begin{array}{l}\text { Extubation } \\
\text { technique }\end{array}$ & \\
\hline
\end{tabular}

Table 1.

Factors to consider for the perioperative approach of patients with CLP. 
Surgical treatment of fissures is a challenge for the plastic or maxillofacial surgeon and for the anesthesiologist. As a historical background, the first references on the management of cleft lip and palate date back to 1847 with John Show who used chloroform as an anesthetic in the repair of lip fissures in 147 patients aged 3-6 weeks; in The Lancet magazine of 1850, the cleft lip and palate closure is mentioned in a 7-year-old male with 1-week interval between surgeries, and Magill in 1921 used a catheter for the first time endotracheal with the advent of halothane and the piece in " $\mathrm{T}$ " [13].

It is currently known that there are determining factors for anesthetic management in corrective surgery of the lip and cleft palate related to the characteristics of the patient, his medical history or associated comorbidities, and the surgical technique.

As it is the pathology with the highest incidence in facial malformations that requires surgical treatment, it is necessary to know the anesthetic management alternatives and establish criteria in the different stages of the perioperative period from preanesthetic assessment to postanesthetic care, in order to provide planned approach within the highest safety standards that reduce the risk of adverse events (Table 1).

\section{Preanesthetic assessment}

Within the preanesthetic assessment of patients with CLP, it is mandatory to know:

a. Demographic characteristics such as age, sex, and weight.

b.Variety of pathology presentation: cleft lip, cleft palate, cleft lip and palate, and cleft palate with fistula.

c. Presence of difficult airway predictors for interrogation and physical examination.

d.Presence of associated congenital anomalies or craniofacial syndromes.

e. Associated comorbidities such as heart disease, recurrent or active respiratory tract infections, poor management of oropharyngeal secretions, pneumopathies, or obstructive apnea.

The recommended age for surgical repair of cleft lip is 3-6 months, currently tends to be performed in the neonatal period with the implications of anesthetic management of this age group. Cleft palate repair is recommended at 9-12 months with reports up to 18 months $[4,10,15]$. There is evidence in the literature about a risk of complications 5 times greater during anesthetic management of children under $10 \mathrm{~kg}$ and under 10 weeks of age. A direct relationship between body weight at the time of surgery and the presence of complications has been observed; in patients weighing 4-6 kg, they occur in 54\% and in patients weighing more than $8 \mathrm{~kg}$ in $26 \%[13,16]$.

According to the characteristics of the defect, the surgical experience, and the management institutions' protocols, the surgeon will determine the age of repair and the need for a primary or sequential closure in stages with the objective of minimizing distortion in facial growth by very early repairs [10].

The male-female ratio is 2:1 in cases involving lip and 1:2 in cases involving only palate. As for laterality, the ratio is $2: 1$ left to right $[14,17]$; greater risk of difficulty in airway management and secondary adverse events has been observed in patients 
with a cleft lip with bilateral defect, and in cases of cleft palate, the difficulty in laryngoscopy and intubation is related to age, at a younger age difficulty $[3,18]$.

Patients with CLP can present various malformations without integrating a specific craniofacial syndrome; approximately $70 \%$ of cases of CLP and $50 \%$ of isolated cleft palate are considered non-syndromatic. A higher ratio of malformations has been found in patients with CLP (32\%) than $11 \%$ in isolated cleft lip or $22 \%$ in cleft palate $[13,19]$.

There are about 500 craniofacial syndromes related to the pathology that increase the probability of difficult airway (8.4\%) and the risk of perioperative adverse events; the most frequent are Treacher Collins, Goldenhar, Pierre Robin sequence, and velocardiofacial syndrome $[2,13,15]$.

As part of the comorbidities, the literature reports that $5-10 \%$ of patients have some congenital heart disease $[7,13]$. The possibility of chronic respiratory symptoms such as rhinorrhea, chronic airway obstruction, and sleep apnea $[3,19]$ is also mentioned.

Given the history of upper airway infection, it is suggested that surgery be deferred for 2 weeks and in lower airway infections for 4 weeks with the objective of reducing risks of adverse events [3].

\section{Transanesthetic management}

\subsection{Monitoring}

It is essential to have the basic monitoring for general anesthesia recommended by the current official standards; continuous electrocardiography is included in two leads, noninvasive blood pressure, pulse oximetry, capnography line, and thermal control.

Since hypothermia is one of the most frequently reported adverse events in the literature, thermal control is important throughout the entire transanesthetic $[16,18]$.

\subsection{Anesthetic technique used}

In the different bibliographic reviews, there is no consensus on an ideal anesthetic technique or with more preference; the choice will be made based on the characteristics and needs of each patient. There are reports of balanced general anesthesia without neuromuscular relaxation, balanced general anesthesia with neuromuscular relaxation, and intravenous total anesthesia with and without neuromuscular relaxation without significant differences between them [11, 20].

\subsubsection{Anesthetic induction}

Anesthetic induction is a crucial stage of anesthetic management; through pharmacological measures it provides favorable conditions for airway manipulation, reducing the neurovegetative response to intubation such as hypertension, tachycardia, and increased intraocular or intracranial pressure [21].

Specifically in patients with cleft lip and palate, the use of inhalation induction techniques with sevofluorane or intravenous with propofol is more frequently referred to.

The one made with propofol is characterized by being fast and smooth with the additional advantage of a rapid awakening; in the inhalation with sevofluorane, the advantages lie in halogenated characteristics such as the unpleasant smell, the less irritation of the respiratory tract, the lower solubility in the blood and, in a 
secondary way, the lower myocardial depression. Other intravenous inducers such as thiopental, midazolam, and ketamine are mentioned in the literature [3,22].

Within the opioids indicated for the control of the neurovegetative response, fentanyl or remifentanil use is considered without significant differences [21].

\subsubsection{Endotracheal intubation}

Endotracheal intubation is a critical moment in the anesthetic management of the pediatric and adult population, specifically in the presence of difficult airway predictors such as cleft lip and palate facial malformations due to the implicit risk of adverse events; situations of difficult laryngoscopy, difficult or failed intubation, laryngospasm, and bronchospasm are reported [21].

It is important to use a technique that provides us with rapid and safe favorable intubation conditions in an adequate time. Some authors evaluate the conditions of intubation through the Helbo-Hansen scale that emerged in 1988, which assesses aspects such as jaw relaxation (complete, tone, tense, or rigid), laryngoscopy (easy, good, difficult, or impossible), vocal cords (open, moving, closing, or closing), cough (absent, poor, moderate, or severe), and limb movements (absent, scarce, moderate, or severe); scores of 1-2 indicate favorable conditions, while scores of 3-4 are unacceptable [21, 22].

There is sufficient evidence that positions propofol as a favorable inducing agent by decreasing airway reflexes and providing adequate conditions for intubation without muscle relaxants; sevofluorane at 8 volume percent facilitates the proper position of the vocal cords in the absence of muscle relaxants, in a period of 180 seconds with low incidence of cough [22].

The use of neuromuscular blockers is controversial. It is a fact that they provide favorable conditions for endotracheal intubation, and according to literature reports, there is a lower incidence of respiratory adverse events when they are used; succinylcholine with rapid onset of action and ultra-short effect but with a risk of adverse effects in the pediatric population positions rocuronium and vecuronium non-depolarizing neuromuscular blockers as an alternative with a slower onset, prolonged effect, and great advantage of pharmacological reversal of rocuronium in a situation of unexpected difficult airway [3, 22]. In contrast, some authors recommend avoiding them due to the high incidence of retrognathia, micrognathia, and glossoptosis that make it difficult to approach the airway from ventilation with a facial mask, laryngoscopy, or endotracheal intubation, emphasizing the existence of other alternatives that offer favorable conditions of intubation such as those mentioned [22, 23].

Any of the techniques can be effective, the decision will depend on the characteristics and needs of each patient [3].

Regarding the choice of endotracheal tube (TET), there is no single criterion; the use of RAE (Ring-Adair-Elwyn) U-shaped tubes is recommended for lip surgery and reinforced tubes also known as spiral-shaped spiral wire reinforcement inside and along the tube wall to reduce your occlusion during palate surgery. Other frequently reported are Oxford or "L"-shaped tubes to avoid couplings [24, 25].

A point that should be considered is the lowest risk of accidental extubation when the TET is placed $1.5 \mathrm{~cm}$ above the carina [3].

\subsubsection{Airway management}

According to different references, the documented incidence of unexpected difficult airway in the pediatric population is low (0.08-1.35\%) compared to that of the adult; in children under 1 year of age, it can reach $3.5 \%$ and in patients with cleft 
lip and palate from 4.7 to $8.4 \%$ representing a greater risk of difficulty in airway management and adverse respiratory events [2, 26, 27].

In 2002 Bordet reported an incidence of airway-related complications of $7.87 \%$ in children under general anesthesia, varying according to the type of instrumentation used: $7.4 \%$ with endotracheal tube and $10.2 \%$ with laryngeal mask [3].

The anatomical characteristics of the airway corresponding to the age group and those of the pathology are related to difficulties in the management of the airway at any time during the perioperative period, induction (ventilation, laryngoscopy, intubation), transanesthetic, extubation, or early postanesthetic period with varying severity, requiring pediatric intensive care unit [17].

On the other hand, more than 500 related craniofacial syndromes such as Treacher Collins, Goldenhar, or Pierre Robin sequence increase the probability of difficult airway. Other related syndromes in the literature are Down syndrome, DiGeorge syndrome, and Marfan syndrome [2, 7, 13, 15].

Some researchers have established situations with a higher risk of adverse events during airway management; there is talk of difficult laryngoscopy in the presence of facial deformities such as micrognathia or bilateral complete fissures due to difficulty in positioning the laryngoscope blade altering the line of sight when falling into the left cleft. There is a greater likelihood of risks in patients with cleft lip with bilateral defects, while the difficulty in laryngoscopy and intubation in patients with cleft palate is related to age, being older at a younger age $[3,18]$.

A larger number of laryngoscopies performed increases the likelihood of adverse events such as trauma and edema of the airway, laryngospasm, and bronchospasm. Airway management in patients with CLP has been studied for more than 70 years, increasing throughout history the indirect devices and techniques for the pediatric population that favor airway manipulation such as laryngeal masks, video laryngoscopes, and fibrobronchoscopies in their different versions; however, direct laryngoscopy without stiletto remains the most widely used method [14].

\section{Transanesthetic management}

Keeping patients in hemodynamic and ventilatory stability and reducing the risks of adverse events by providing individualized anesthetic management according to the characteristics and needs of each patient are part of our responsibility as anesthesiologists. Adequate anesthetic maintenance is achieved through the use of drugs that provide analgesia, hypnosis, amnesia, neurovegetative protection, and neuromuscular block when necessary [21].

There is no single recommended technique, nor one that offers greater advantage over the others; within the general balanced anesthesia, the most reported technique is inhalation with sevofluorane, as it is considered the least pungent and the one that promotes greater hemodynamic stability. There are also reports of the use of isoflurane with or without a muscle relaxant $[3,18,20]$.

The use of anesthetics that provide stability and intra- and postoperative analgesia is recommended, reducing doses of transoperative opioids, and with a lower risk of respiratory depression in the postanesthetic care, dexmedetomidine and ketamine are indicated [28, 29].

Dexmedetomidine, a potent $\alpha 2$-specific adrenoceptor agonist with sedation, anxiolysis, and analgesia properties, has the advantages of not modifying respiratory recovery or extubation times and significantly reducing the risk of postoperative agitation [20]. 
The adverse events observed in the transanesthetic and related to the endotracheal tube are occlusion, bending or accidental removal by surgical manipulation [18].

There are no criteria already established for the optimal time of extubation; it is an issue that continues to cause controversy. In general terms, extubation is recommended with a patient fully awake and with protective airway reflexes [3, 19].

\section{Postanesthetic management}

Corrective cleft palate surgery reports an incidence of postoperative adverse events of $13 \%$, the highest in maxillofacial surgery; the main events reported are tongue edema, bleeding, pain, nausea, vomiting, bronchospasm, and agitation or delirium. Vigorous crying is frequent secondary to pain or agitation and when not treated promptly predisposes to wound dehiscence and pulmonary complications with great impact on the costs of delayed recovery and prolonged hospital stay [20,28].

In 2018, a retrospective study was conducted to identify risk factors related to common adverse events in cleft lip and palate surgery; a relationship of adverse events was found with situations such as multiple attempts at intubation, structural or functional abnormality of the airway, surgery greater than 160 minutes, inexperience of the anesthesiologist, high doses of opioids, and no reversal of the neuromuscular blockade [30].

\subsection{Pain management}

For many years the idea of immaturity of the nervous system in the pediatric population was defended, reducing the importance of acute and postoperative pain management; at present it is well-known that the structures responsible for pain transmission are formed from the 30th week of gestation [10].

Postoperative pain from cleft lip and palate surgery is considered acute, superficial, somatic, and of significant intensity that causes irritability with vigorous crying $[10$, $28,29]$. The nerve branches involved depend on the type and location of the defect [10]:

a. Cleft lip

- Intraorbital nerve, maxillary trigeminal branch, innervated upper lip, and skin between upper lip and lower eyelid

- External nasal nerve branch of the ophthalmic, innervates wing, and nasal tip

b. Cleft palate

- Branches of the maxillary trigeminal division

- Lesser palatine nerve; innervates soft palate, nostrils, and uvula

- Major palatine nerve, branch of the pterygopalatine ganglion. Inerva gums, mucous membrane, and hard palate glands

- Nasopalatine nerve, innervates palatine region

There is currently no pain management guide in patients with cleft lip and palate; each institution must, based on its experience and population needs, establish a protocol based on multimodal analgesia. This consists of the infiltration of local anesthetics, nerve blocks, opioid analgesics and non-opioid analgesics, providing sufficient analgesia with a lower risk of postoperative agitation [29]: 
a. Infiltration of local anesthetic at the surgical site. The use of long-acting bupivacaine-type AL calculated per kilogram of weight is suggested and consider the possible margin distortion when injected [11,29].

b. Nerve block. Age-related anatomical variants must be known, for example, the intraorbital stage is located very close to the eye [10, 29]. For lip surgery, the intraorbital stage with 1-2 $\mathrm{ml}$ of $0.5 \%$ bupivacaine with 1:200,000 epinephrine and $0.25 \mathrm{~mm}$ on each side of $0.25 \%$ bupivacaine with epinephrine is suggested. In palate surgery, the blockage of the major palatine, minor palatal, and nasopalatine is recommended [10].

c. Opioid analgesics. Opioids are the first option for transoperative analgesia since they favor mild emersion and extubation, reducing the possibility of crying and consequently of trauma and bleeding. Its main disadvantage is the risk of postoperative dose-dependent respiratory depression and undesirable effects such as dizziness, constipation, nausea, and vomiting [10, 29].

d.Non-opioid analgesics. Bibliographic reviews recommend the use of adjuvants such as ibuprofen and acetaminophen in any age group; there is evidence on the decrease in postoperative pain supported by the FLACC scale (pain facies, leg movement, activity, comforting crying) with the administration of acetaminophen at the beginning of anesthesia and in the immediate postoperative period. It can be used as a premedication orally at a dose of $20 \mathrm{mg} / \mathrm{kg}$ [10].

Other recommended drugs are those that reduce the risk of respiratory depression such as dexmedetomidine and ketamine [3].

The premise is to provide a state of complete patient well-being through multimodal analgesia; this technique emerged in 1997 and is based on the impact of several drugs at minimum doses on the different nociception mechanisms, with a lower risk of adverse effects. Management must be individualized considering factors such as age and degree of airway commitment [3, 10, 28, 29]

\subsection{Management of postoperative agitation}

The incidence of agitation during emersion or in the postanesthetic is high (12-13\%), with references up to $67 \%$. The mechanism that originates it is not clear and has been related to factors such as psychological vulnerability of the patient (separation anxiety, fear of the unknown), anesthetic technique with halogenates, and surgical stimulation such as the subsequent narrowing of the nasopharyngeal cavity due to closure of the palate; other possible causes are postsurgical stimulation such as pain, hypoxemia, hyponatremia, hypoglycemia, $\mathrm{CO}_{2}$ retention, urinary retention, postural discomfort, and/or a very rapid awakening.

Clinically it is characterized by alterations in the state of consciousness or behavior, inconsolable crying, bedwetting, nightmares, anxiety, irritability, uncontrollable movements of limbs, and inability to identify objects or people. Drugs with evidence in reducing agitation are fentanyl, midazolam, and dexmedetomidine infusion [31].

\section{Discussion}

Surgical correction of cleft lip and palate can be offered in various hospital settings from specialized institutions or as part of intensive care programs, so the medical staff responsible for surgical and anesthetic management is obliged to 
know the anatomical and physiological characteristics of the age group and pathology, accompanying comorbidities, the different alternatives of anesthetic management according to the needs of each patient, and the potential adverse events at different stages of the perioperative period.

\section{Conclusions}

Cleft lip and palate is the most frequent craniofacial pathology in Latin America coupled with the greater vulnerability of the pediatric population under 1 year to present perioperative adverse events; the objective of the approach will be to offer a properly planned comprehensive management within the maximum safety standards that reduce the morbidity and mortality of this population group.

\section{Author details}

Silvia Peña*, Claudia Paulina Reyes, Andres Felipe Beltran and Ofelia Ham National Institute of Pediatria, Mexico City, Mexico

*Address all correspondence to: sil75092hotmail.com

\section{IntechOpen}

(C) 2020 The Author(s). Licensee IntechOpen. This chapter is distributed under the terms of the Creative Commons Attribution License (http://creativecommons.org/licenses/ by/3.0), which permits unrestricted use, distribution, and reproduction in any medium, provided the original work is properly cited. (cc) BY 


\section{References}

[1] Takemura H, Yasumoto K, Toi T, Hosoyamada A. Correlation of cleft type with incidence of perioperative respiratory complications in infants with cleft lip and palate. Pediatric Anesthesia. 2002;12:585-588

[2] Tay C, Tan G, Ng S. Critical incidents in paediatric anaesthesia: An audit of 10,000 anaesthetics in Singapore. Pediatric Anesthesia. 2001;11:711-718

[3] Santhi M, Deepak P, Hari M, Prasad K. A Prospective Observational Study of Anesthetic Complications in Children Undergoing Primary Lip and Palate Repairs. International Journal of Scientific. 2017;5(8):35-39

[4] Ramamoorthy C, Haberkern C, Bhananker S, Domino K, Posner K, Campos J, et al. Anesthesia-related cardiac arrest in children with heart disease. Pediatric 2014; 119: 1 www.anesthesia-analgesia.org 121 Perioperative Cardiac Arrest (POCA) registry. Anesthesia \& Analgesia. 2010;110:1376-1382

[5] Von Ungern-Sternberg B, Boda K, Chambers N, Rebmann C, Johnson C, Sly P, et al. Risk assessment for respiratory complications in paediatric anaesthesia: A prospective cohort study. Lancet. 2010;376:773-783

[6] Tait A, Malviya S, Voepel-Lewis T, et al. Risk factors for perioperative adverse respiratory events in children with upper respiratory tract infections. Anesthesiology. 2001;95:299-306

[7] Alarcón A. Cleft lip and palate. Mexican Journal of Anesthesiology. 2010;33(1):S76-S78

[8] Dixon M, Marazita M, Beaty T, Murray J. Cleft lip and palate: Understanding genetic and environmental influences. Nature Reviews. Genetics. 2011;12(3):167-178
[9] Shkoukani MA, Chen M, Vong A. Cleft lip-A comprehensive review. Frontiers in Pediatrics. 2013;1(53):1-10

[10] Hussain R, Abhijit P. Postoperative analgesia for cleft lip and palate repair in children. Journal of Anaesthesiology Clinical Pharmacology. 2016;32(1):5-11

[11] Karki S, Rajbanshi L, Ariyal B, Shrestha K. Anaesthesia for cleft lip and palate surgery: Study from a hospital of Eastern Nepal. Birat Journal of Health Sciences. 2017;2(1):127-133

[12] McHeik J, Sfally P, Bondonny J, et al. Early repair for infants with cleft lip and nose. International Journal of Pediatric Otorhinolaryngology. 2006;70:1785-1790

[13] Reséndiz Y. Anesthetic management for a patient with cleft lip and palate. Reconstructive Surgery. 2015;38(1):245-246

[14] Bunsangjaro P, Thongrong C, Pannengpetch P, Somsaad S, Rojanapithayakorn N, Polsena N, et al. Anesthetic techniques and perioperative complications of cleft lip and cleft palate surgery at Srinagarind Hospital. Journal of the Medical Association of Thailand. 2015;98(S7):S158-S163

[15] De Graaff J, Sarfo M, van

Wolfswinkel L, van der Werff D, Schouten A. Anesthesia-related critical incidents in the perioperative period in children; a proposal for an anesthesiarelated reporting system for critical incidents in children. Paediatric Anaesthesia. 2015;25:621-629

[16] Fillies T, Homann C, Meyer U, Reich A, Joos U, Werkmeister R.

Perioperative complications in infant cleft repair. Head \& Face Medicine. 2007;3:9

[17] González O. Ecological study in Mexico (2003-2009) on cleft 
lip and/or palate and associated sociodemographic, socioeconomic and pollution factors. Anales de Pediatría. 2011;74(6):377-387

[18] Desalú I, Adeyemo WL, Akintimoye MO, Adepoju AAA. Airway and respiratory complications in children undergoing cleft lip and palate repair. Ghana Medical Journal. 2010;44(1):16-20

[19] Kwari D, Chinda J, Olasoji H, Adeosun O. Cleft lip and palate surgery in children: Anaesthetic considerations. African Journal of Paediatric Surgery. 2010;7(3):174-177

[20] Peng W, Zhang T. Dexmedetomidine decreases the emergence agitation in infant patients undergoing cleft palate repair surgery after general anesthesia. BMC Anesthesiology. 2015;15(145):2-7

[21] Escobar N, Olvera G, Martínez T, Silva A. Conditions of endotracheal intubation and hemodynamic effects in Mexican population with different doses of remifentanyl infusion. Mexican Journal of Anesthesiology. 2008;31(4):263-270

[22] Karanth H, Raveendra U, Shetty R, Shetty P, Thalanjeri P. Comparative evaluation between sevoflurane and propofol for endotracheal intubation without muscle relaxants in pediatric cleft surgeries. Anesthesia, Essays and Researches. 2018;12(2):434-439

[23] Rajan S, Gotluru P, Andews S, Paul J. Evaluation of endotracheal intubating conditions without the use of muscle relaxants following induction with propofol and sevoflurane in pediatric cleft lip and palate surgeries. Journal of Anaesthesiology Clinical Pharmacology. 2014;30(3):360-365

[24] Jindal P, Khurana G, Gupta D, Sharma J. A retrospective analysis of anesthetic experience in 2917 patients posted for cleft lip and palate repair.
Anesthesia, Essays and Researches. 2013;7(3):350-354

[25] Sen J, Sen B. Airway management: A comparative study in cleft lip and palate repair surgery in children. Anesthesia,

Essays and Researches. 2014;8(1):36-40

[26] Xue F, Zhang G, Li P, et al. The clinical observation of difficult laryngoscopy and difficult intubation in infants with cleft lip and palate. Pediatric Anesthesia. 2006;16:283-289

[27] Gunawardana R. Difficult laryngoscopy in cleft lip and palate surgery. British Journal of Anaesthesia. 1996;76:757-759

[28] Kayyal T, Wolfswinkel E, Weathers W, Capehart S, Monson L, Buchanan E, et al. Treatment effects of dexmedetomidine and ketamine on postoperative analgesia after cleft palate repair craniomaxillofacial trauma and reconstruction. Craniomaxillofacial Trauma and Reconstruction. 2014;7(2):131-138

[29] Carr L, Gray M, Morrow B, Brgoch M, Mackay D, Samson T. Opioid sparing in cleft palate surgery. The Cleft Palate-Craniofacial Journal. 2018;55(33):1-5

[30] Basta M, Fiadjoe J, Woo A, Peeples K, Jackson O. Predicting Adverse Perioperative Events in Patients Undergoing Primary Cleft Palate Repair. The Cleft Palate-Craniofacial Journal. 2018;20(10):1-8

[31] Xu H, Mei X, Xu L. Cause analysis, prevention, and treatment of posoperative restlessness after general anesthesia in children with cleft palate. Journal of Dental Anesthesia and Pain Medicine. 2017;17(1):13-20 



\title{
Orthognathic Surgery in Cleft Lip and Palate Patients
}

\author{
Hakan Yilmaz and Arzu Ari Demirkaya
}

\begin{abstract}
Cleft lip and palate patients often exhibit severe dentofacial deformities that necessitate orthognathic surgery. Orthognathic surgery in these patients generally includes not only maxillary advancement, but also sagittal, horizontal, and vertical movement of both jaws. Surgical planning and execution presents many difficulties, caused by the presence of extensive scar tissues from previous surgeries, tissue deficiencies, the difficulty of aligning multiple segments of bone and soft tissues. Other challenges in cleft patients are complications related to post-surgical airway, speech, velopharyngeal insufficiency, nerve damage, and infections. This review is focused on orthognathic surgery in cleft lip and palate patients, management, techniques, success, and complications.
\end{abstract}

Keywords: orthognathic surgery, cleft lip and palate, complications

\section{Introduction}

Deficiency of growth and development in the midfacial complex is a major drawback of primary CLP repair in the neonatal period of growth, well documented in the literature [1-3]. Causes are thought to be formation of scar tissue in the growth centers of the maxilla [4], mouth breathing due to obstruction of the nasal passage [5], deficiency of the alveolar process due to missing teeth [6], and a tense upper lip [7, 8]. Unrepaired bone defects on the other hand result in closer to normal maxillo-facial development $[7,8]$. Because of midfacial deficiency, orthognathic surgery becomes often indispensable at the adult ages in CLP management. Treatment of CLP with orthognathic surgery involves maxillary advancement, distraction osteogenesis, and mandibular setback, combined with orthodontic treatment [9].

\section{Timing of orthognathic surgery}

In the past, CLP-orthognathic surgery in the mixed dentition period has been discussed and discarded. It has been reported that there will usually be a need for revisions after completion of skeletal growth [10]. Risks of early orthognathic surgery include damage to permanent tooth germs and creation of fibrous tissue and calli in the osteotomy regions. Additionally, it was shown that neither Le Fort I osteotomy nor distraction osteogenesis in the mixed dentition period provides additional lateral maxillary growth $[11,12]$. Apart from cases with significant psychosocial or functional problems, risks of "early" surgery overweigh its benefits [13]. 
Orthognathic surgery for treatment of maxillomandibular deformities is usually applied after completion of growth of the maxillomandibular structure [14-16]. Transverse, sagittal, and vertical growth of the maxilla and the mandible ends at different chronological ages, usually at the ages of 14-16 for female patients and 16-18 for male patients [17]. Mandibular growth has a normal pattern in most CLP patients [13]. However, since skeletal growth is variable, hand-wrist or cephalometric radiographs may help in determining the timing of skeletal maturation [17].

\section{Preparation for orthognathic surgery}

In orthognathic surgery in cleft patients, there are some issues that need to be considered before surgery like velopharyngeal situation, speech problems, hearing problems, the situation of alveolar cleft gap, and dental problems.

Speech pathologists play a critical role in terms of assessing speech and articulation problems and determine velopharyngeal function with nasal endoscopy before the surgery $[18,19]$. The velopharyngeal sufficiency rarely remains the same after maxillary advancement surgery; more often, an insufficiency is created [20]. Surgical correction of cross-bites and open-bites and the repair of cleft-dental gaps and residual oronasal fistulae usually alleviate articulation disorders [19, 21].

Prevention and treatment of tympanic infection as well as comprehensive preventive and restorative dental care have been provided during early childhood and adolescence. Oral hygiene maintenance may be more difficult in CLP patients than in routine orthodontic treatment patients. Soft tissues may have a more retentive morphology due to scarring from previous operations: shallow buccal sulci, sometimes buccal flaps with mucosa or gingivae covering teeth. Furthermore, because of poor dental esthetics, CLP patients do not like their teeth and smile and have low motivation. Long treatment times reduce motivation further. Orthodontic preparation presents various challenges not only in terms of planning but also in terms of implementation. It may be difficult for the orthodontist to work in a narrow space with low visibility, since the elasticity of lips is low, mouth opening is limited, and the upper jaw is small and retrognathic. All surgical management of maxillo-mandibular deformities usually requires prior adjustment of the dental arches over the maxillary and mandibular basal bones via orthodontic treatment. The "surgery-first" protocol rarely applies to CLP patients. A major dilemma during

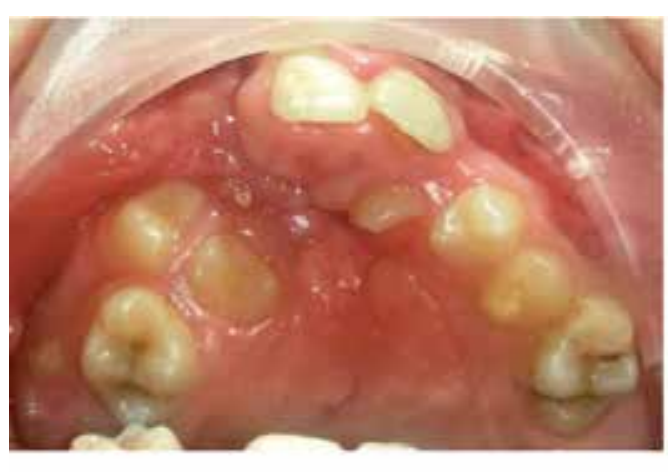

(a)

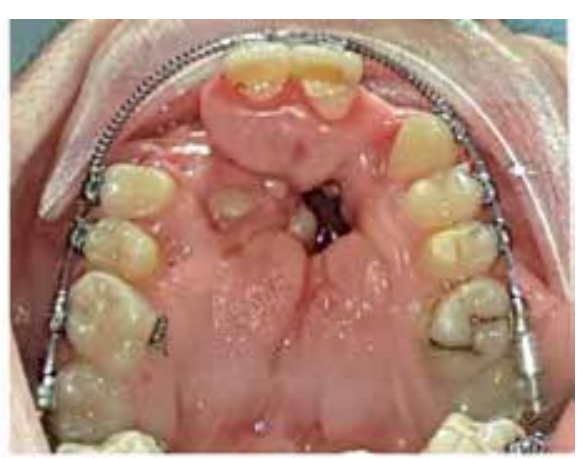

(b)

\section{Figure 1.}

Teeth erupting from the palate [25]. (a) UCLP patient, permanent dentition. Missing lateral incisors, 15 and 23 erupting palatally, and 17 erupting excessively buccally. (b) Dental arch development through orthodontic leveling, occult fistula enlarged and became visible during dental leveling, 13 is just starting to erupt after 2.5 years of orthodontic treatment. 
alignment is the decision on the management of the cleft alveolar region, where often the lateral teeth are missing [6]. Surgical correction of septal and inferior respiratory pathologies is done only in severe obstructive sleep apnoea cases before orthognathic surgery, but rather scheduled to be performed simultaneously or consecutively [22-24].

In most CLP cases, teeth are either missing, erupt late or ectopically located. Therefore, the alveolar bone base is not sufficiently developed, and this adds to the skeletal (transverse and sagittal) insufficiency. Leveling of teeth erupting in the palate usually takes a long time (Figure 1).

\section{Residual deformities in CLP patients}

Patients with Isolated Cleft Palate (ICP) have a complete alveolar ridge and generally a complete set of teeth $[13,17,26,27]$. The main deformity in unilateral cleft lip and palate (UCLP) and bilateral cleft lip and palate (BCLP) patients is maxillary hypoplasia, but oronasal fistula, bony defects, intranasal obstruction, soft tissue scarring, and velopharyngeal dysfunctions are also frequently encountered [27]. Additionally, the maxillary lateral incisor and often the second premolars in the cleft region are either congenitally missing, resulting in a cleft-dental gap [6, 28-30].

In addition to the existing deformities in UCLP and BCLP patients, nasal obstruction and sinus blockage and mandibular asymmetry and chin dysplasia are seen frequently as secondary deformities $[27,31]$. The prevalence of these deformities varies significantly based on the surgical philosophy and experience of the surgeon who repaired the first cleft [32], the individual's unique biological growth potential, and the level of care of the family/patient.

Published clinical research on individuals who were born with complete UCLP/ BCLP and treated at cleft centers showed that, despite the best efforts, the mixed dentition period would not be appropriate for grafting just before the canine tooth is erupted on the cleft side in some children $[33,34]$. Additionally, although grafted appropriately, in some individuals, additional reconstruction is needed [33]. For these reasons, repairing residual skeletal and soft tissues and managing dental deformities in patients with CLP strains the proficiency and skills of the orthognathic surgery cleft team $[26,31,35]$.

\section{Orthognathic approach on UCLP deformities}

\subsection{Prevalence}

Studies have examined the need for orthognathic surgery in UCLP patients who underwent primary lip-palate repair procedures in childhood $[3,8,36,37]$. Ross [37] stated that the midface is close to normal only in $25 \%$ of patients, and there is a need for orthognathic surgery in the remaining patients, with interventions at early stages worsening the situation. In other similar studies, the rate of orthognathic surgery needed in repaired UCLP patients was $48-59.3 \%[3,8]$.

\subsection{Orthodontic approach}

In adolescent or adult UCLP patients with maxillary hypoplasia and deficient bone grafts, there are two maxillary segments separated by the cleft. Each segment has varying degrees of dysplasia on the sagittal, vertical, and horizontal directions. 
Orthodontic treatment is carried out to both position the teeth perpendicular to the alveolar crest and level the alveolar segments using the teeth. Sometimes, it is not possible to achieve leveling of the bony segments, and it may be necessary to level the teeth into two separate segments, instead of a complete arch, and to prepare for leveling these segments by alveolar distraction osteogenesis or segmental orthognathic surgery (Figure 2).

In cases that present with sufficient bone grafting during the mixed dentition period, the maxilla is a single segment, and the orthodontist would only adapt the dental arch form to the existing basal bone.

There are substantial variations in the number of upper permanent incisors and the alveolar bone amount in the premaxilla of UCLP patients. The lateral incisor tooth on the cleft side was found normal in only 7\% of UCLP cases [6], more frequently, when present, there are shape anomalies. In the presence of a weakly formed lateral incisor tooth, these teeth might need extraction for long-term functioning and better esthetics.

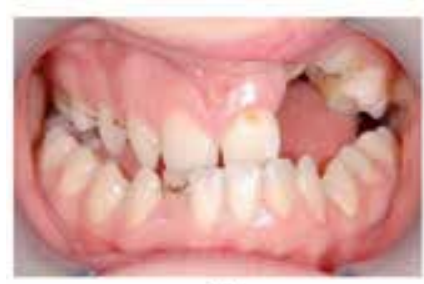

(a)

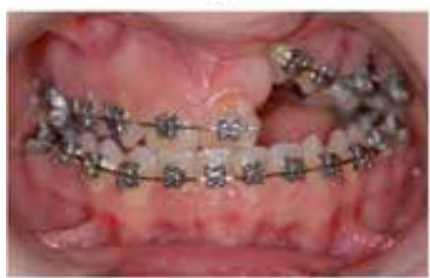

(a)

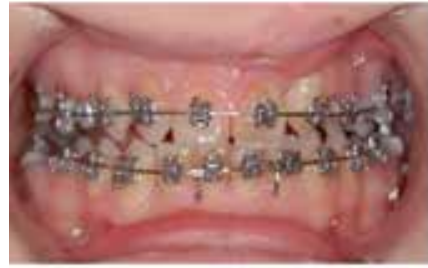

(a)

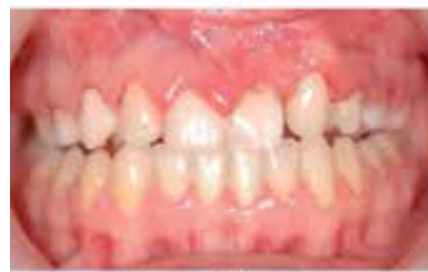

(a)

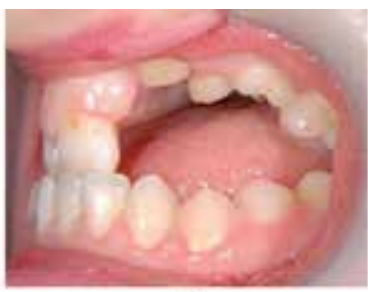

(b)

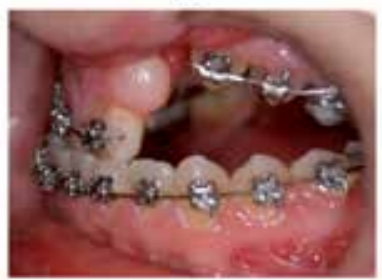

(b)

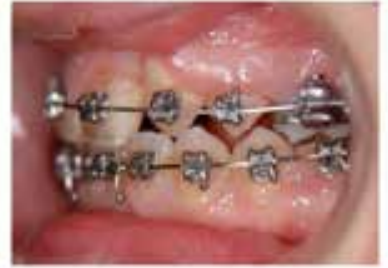

(b)

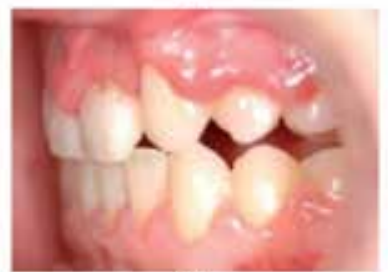

(b)

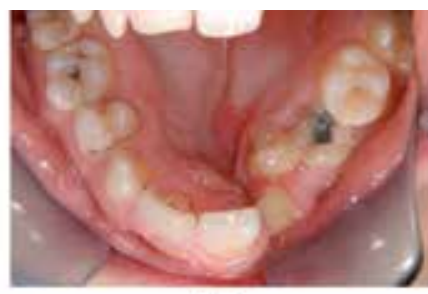

(c)

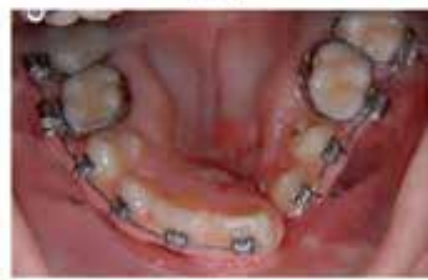

(c)

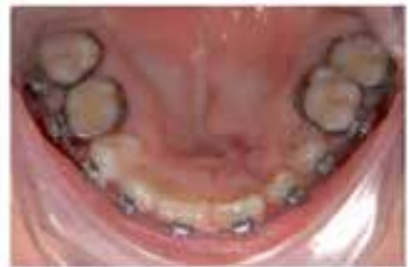

(c)

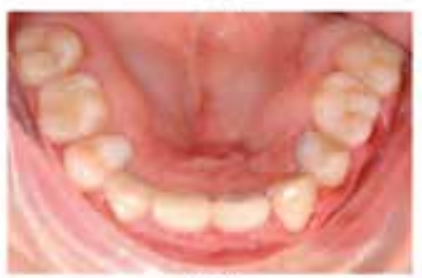

(c)

Figure 2.

UCLP patient [25]. A1-3: Before orthodontic preparation. Retrognathic and narrow maxilla, missing teeth (12, 22, 15 and 25), noticeable alveolar cleft, severe transverse and vertical dislocation of the smaller segment. B1-3: Orthodontic leveling of teeth in two separate segments. C1-3: Post-op continuous stainless-steel arch-wires. D1-3: Post-treatment vertical relapse to some extent. 
Decision to extract the first premolar, which is another tooth near the cleft, is dependent on volume and height of the alveolar bone to accommodate the root of the canine adjacent to the cleft without irreversibly weakening its periodontal support, as well as the degree of crowding. Although extractions on the mandibular arch are sometimes obligatory due to crowding, extraction is usually not necessary in the mandibular arch. The disadvantage of closing a cleft-dental gap orthodontically or surgically is the shifting of the cleft segment toward the posterior, in a way that is the opposite of what is desired (to shifting forward of the posterior region).

As mentioned above, after leveling and aligning teeth with orthodontic treatment, models prepared by digitally or by using plaster are transferred to computer software/articulators. On these models, the maxillomandibular relation and occlusion are adjusted to an ideal position, and the advancement of the maxilla, rotation/setback of the mandible and vertical and transversal dimension amounts are assessed. As a result of these arrangements, splints are fabricated to use as a guide in orthognathic surgery, and the desired effects almost completely reflected on the surgery.

\subsection{Surgical approach}

Due to the prevalence of maxillary osteotomy complications in UCLP patients [38], confusing and complicated orthognathic surgery techniques were proposed for these patients [39-41]. Moreover, as in other aspects of orthognathic surgery, Hugo Obwegeser also provided contributions that could be explained as breakthroughs for skeletally cleft reconstruction [35, 42-44]. Toward the end of 1960s, he managed to advance the cleft maxilla by up to $20 \mathrm{~mm}$ to a desired position without needing a complicated mandibular setback approach. Then, he noticed that downfracture and adequate mobilization of the maxilla, regardless of the presence or absence of a cleft, were the key in maxillary advancement [35]. The success of this approach achieved by Obwegeser was confirmed when Bell showed supply blood circulation to the down-fractured maxillae in their animal studies [45].

In the mid-1980s, Posnick used the Le Fort I techniques of Obwegeser for treatment of UCLP deformity and improved them [46]. The main issue was that the circumvestibular incision used by Obwegeser directly allowed dissection, osteotomies, disimpaction, fistula closure, septoplasty, inferior turbinate reduction, pyriform aperture recontouring, bone grafting, and application of plate and screw fixation. This was a reliable approach that did not have a circulation damage risk in smaller or larger flaps and had continuity [35]. Moreover, with the easiness of field of view provided by circumvestibular incision, it became possible to readily close the cleft-dental region by differential maxillary segmental repositioning without bone necrosis or loss of teeth. This method also closes the unoccupied space of the cleft, and at the same time, combines the labial and palatal flaps together without needing a subperiosteal undermining procedure, which allows closure of stubborn oronasal fistulae and establishment of periodontal health in the teeth adjacent to the cleft [35]. Today, although the surgical methods applied on UCLP patients differ depending on the success of grafting performed in the mixed dentition period, the main method are as follows:

\subsubsection{Standard Le fort I osteotomy}

An adolescent or adult CLP patient who has maxillary deformity but no residual fistula, in addition to an intact alveolar ridge with an adequate height in the cleft region may have been born without an alveolar cleft or had a successful grafting procedure [42]. A standard Le Fort I osteotomy may be applied on individuals who 
have sufficient alveolar ridge height and volume, a close palate and sufficient periodontal support. Segmental maxillary osteotomy may also be needed in correction of arch width, repairing vertical dimensions or preventing the need for prosthetic lateral incisors by closing the cleft-dental gap.

Unfortunately, even in the twenty-first century, alveolar defects and oronasal fistulae are encountered in many adults and adolescents who have UCLP with maxillary hypoplasia. For these patients, a modified Le Fort I osteotomy should be considered [17].

\subsubsection{Modified Le fort I osteotomy (two-segment)}

In UCLP patients, the gap of the missing lateral incisor tooth may be eliminated by advancement of the lateral alveolar bone segment, where the canine tooth is placed adjacent to the central incisor tooth. After this, the canine is formed in a similar appearance to that of the lateral incisor [47]. This method that was described by Obwegeser in cases of unilateral cleft was advanced by Posnick in 1992 and name as the modified Le Fort I osteotomy method [46].

In the technique, first, a maxillary circumvestibular incision is made labially from a zygomatic buttress to another. In the residual oronasal fistula region, vertical incisions are made to separate the mucosa on both sides of the cleft as oral and nasal. These incisions are perpendicular to the horizontal vestibular incision, and they follow the line angles of the teeth adjacent to the cleft (central and canine). If the cleft bone was not previously repaired, the segments are already in two pieces with the down-fractured maxilla. If the maxilla is intact and the arch form needs to be adjusted, by using a reciprocating saw with a short and flat tip, the maxilla is divided into two pieces by cutting from the cleft area. The parts need to be brought closer to close the cleft-dental gap. However, this may be achieved only after shaving in the distal direction of the central incisor and along the mesial part of the canine from the alveola. Attention should be paid to ensure avoiding contact with the lamina dura as it would expose the root of teeth and may result in external root resorption. The maxillary segments are then stabilized with wires and acrylic occlusal splints. Repositioning of the segments closes the cleft-dental gap, gathers the alveolar ridges together, and gets the labial and palatal mucosal tissues closer for oral-fistula closure [17].

The extent of the maxillary advancement that is carried out by the surgeon is based on previously planned occlusion, airway needs, and preoperatively determined facial esthetics. The ideal vertical dimension is achieved based on the preoperative plan, but intraoperative approaches may be considered in some cases [35]. Maxillary osteotomy regions are fixed on all zygomatic buttresses and apertures by using titanium plates and screws based on the principles described by Luhr $[48,49]$. If a graft has been used, an extra microplate is additionally applied to stabilize each interpositional cortico-cancellous (iliac) graft. For repairing facial asymmetries and secondary deformities, mandibular and jaw osteotomies are also frequently required in UCLP patients in addition to Le Fort I osteotomy.

\section{Orthognathic approach on BCLP deformities}

\subsection{Prevalence}

In the study that was carried out at Boston Pediatrics Hospital, it was stated that there was a need for maxillary advancement by orthognathic surgery in $76.5 \%$ adolescents whose BCLP had been repaired [3]. Moreover, the authors explained 
that, in addition to the severity of the cleft type, the number of previous operations and extent of cleft area also affect the need for orthognathic surgery. Another study conducted at Toronto Pediatrics Hospital stated that there was a need for orthognathic surgery in $65.1 \%$ of their own BCLP patients, while this rate was $70 \%$ for patients who were referred by other centers [8]. From the Cleft Craniofacial Unit in Adelaide, Australia, David et al. [50] followed BCLP patient groups from birth to adulthood and determined the need for orthognathic surgery. Accordingly, orthognathic repair was needed in skeletal class III malocclusion among 17 of 19 patients $(89.5 \%)$ and when they reached 18 years of age. Other previous studies also supported the findings of the aforementioned ones [51, 52].

\subsection{Orthodontic approach}

Different degrees of dysplasia in the sagittal, vertical, and horizontal directions are observed on the maxilla of patients without an ideal bone graft in the mixed dentition period that is divided into three segments. Before surgical treatment of maxillary segments, each segment is separately treated by an orthodontist. Before orthodontic treatment, cephalometric and panoramic radiography images are taken, and the angles, positions, and morphologies of teeth to soft tissues and bones are examined. In these patients, the volumes of the bones in the cleft region and the detailed position of teeth may be analyzed by additionally taking cone beam computerized tomography (CBCT) images.

BCLP patients have a broad variation in terms of the amount of dentoalveolar bone and the number of permanent teeth. Teeth that resemble lateral incisors are usually observed along the sides of the lateral segments. Due to the usually underdeveloped root structure of these teeth and their deformed crowns, extracting them is reasonable. Because of the deformed crowns and root structures of also the erupted supernumerary teeth found in the premaxilla of BCLP patients, it is usually appropriate to extract these during orthodontic treatment. In addition to this, only $7 \%$ of BCLP patients have lateral teeth with regular structure [6], and these are kept in the arch and moved to ideal position by the orthodontist.

Decision to extract the premolar teeth is dependent on the width and height of the present alveolar bone, position of canines, and the degree of crowding on the segments. In cases where inadequate bone and periodontal support remains or this support is substantially weakened after leveling and aligning the canines adjacent to the cleft, decision to extract of premolar teeth may be taken by the orthodontist. Aligning and leveling of the second molar teeth in addition to other maxillary teeth will increase the success of orthognathic surgery by improving the arch form and occlusion [35]. While extractions in the mandibular arch may be required based on the need for space on the arch and during the process of moving the incisors to an ideal angle, extraction is usually not necessary on the mandibular arch.

\subsection{Surgical approach}

Incomplete, insufficient definitions were presented by previous studies for surgical techniques used for the purpose of warning BCLP patients about possible complications regarding maxillary osteotomy and achieving reliable osteotomy operations [39, 53]. Hugo Obwegeser provided significant contributions which may be considered as milestones about cleft surgery on BCLP patients. However, at the early stages, very few clinicians adopted the methods of Obwegeser. This was because, as one of the eight patients he treated died of airway complications, and the results on the others were not reported in an appropriate manner, relevant studies criticized them [54]. In the mid-1980s, Posnick described a safe method of 
the segmental Le Fort I osteotomy technique that considers biological principles in BCLP patients with maxillomandibular deformities $[17,55,56]$. This method, for instance, emphasizes preservation of the labial soft tissue mucosal pedicle in the maxillary of patients. The significance of this flap circulation that is achieved by considering biological principles was confirmed in the study by Bell et al. that was carried out on Rhesus monkeys [38].

Mainly, in BCLP patients, clinicians encounter maxillary deformities including those that are intact on both sides (successfully grafted) with one alveolar ridge, those with two segments with one side intact (successfully grafted), and those with three segments that are failed/non-grafted, and they apply different orthognathic surgery methods for these.

\subsubsection{Standard Le fort I osteotomy}

Patients in cases of BCLP may have intact alveolar ridges on both sides, one intact alveolar ridge on only one side or alveolar clefts that have been successfully grafted during mixed dentition. In adolescents or adults with maxillomandibular deformity and intact alveolar ridges on both sides, a standard Le Fort I downfracturing technique performs to advance maxillary hypoplasia.

\subsubsection{Modified Le fort I osteotomy (two-segment)}

In an individual with BCLP, a unilaterally intact alveolar ridge (with residual alveolar cleft and oronasal fistula on the other side) shows the same anatomy as those in a UCLP patient. The surgical approach for such a patient is the same as that which is applied for a UCLP patient with separated segments. For patients who are born with BCLP and non-grafted alveolar arches, the modified Le Fort I Osteotomy (three-segment) procedure should be applied.

\subsubsection{Modified Le fort I osteotomy (three-segment)}

Unfortunately, a big part of patients who have BCLP maxillomandibular deformities are still observed to have alveolar clefts, residual oronasal fistulae, and mobile premaxilla. While carrying out a Le Fort I osteotomy procedure on a BCLP patient with non-grafted alveolar arches, accurate incisions has a critical importance for providing all three segments with blood circulation [17].

In the technique, on each side, a buccal (labiolateral) incision is made from the zygomatic buttresses (anterior and gingival levels of the parotid canal) in the depth of the vestibule extending toward the location of the residual oronasal fistula. Then, vertical incision continues according to mesial angle of the canine (or if the canine is missing, the most mesial tooth on each lateral segment). Without completely separating the premaxilla, an intermediate splint is placed to fix the lateral segments. The premaxilla is to be included to the vestibular incisions at the posterior with angular, vertical incisions in its labial direction, and to separate the oral and nasal mucosa of the fistulae even further, the incision continues downward along the distal line angle of the central incisor teeth on both sides. Attention should be paid to prevent deformation or incision of the mucosa in the premaxilla. Shavings are made from the segments to get the hard and soft tissues closer to each other. While doing this, one should be careful not to damage the lamina dura of the existing teeth. After completion of the premaxillary segment and other adjustments, the final splint is placed, and the segments are fixed with titanium plates and screws [17]. If there is grafting, an additional microplate is also needed to stabilize each cortico-cancellous (iliac) graft. To repair facial asymmetries, mandibular deformations, and secondary 
deformities, mandibular surgery may also be needed in addition to Le Fort I osteotomy in BCLP patients.

\section{Orthognathic approach on ICP deformities}

\subsection{Prevalence}

It was reported that $20 \%$ of Caucasians with ICP who receive repairs in the period of infancy would experience maxillary hypoplasia in a way that would lead to malocclusions that do not respond to a conventional or compensatory orthodontic approach by itself [36]. Chen et al. [57] reported on the horizontal maxillary growth of both children and adults with ethnic origins of Eastern China who were operated/not operated. Accordingly, as an interesting finding, the results of the individuals with ICP who were not operated in the mixed dentition period showed an almost normal horizontal growth. In the patients who were operated (repaired cleft palate) in the mixed dentition period, there was a decrease in the clockwise rotation of the maxillomandibular complex. In addition to this, it was stated that, for an individual born with ICP, the prevalence of maxillomandibular deficiency is dependent on a combination of factors such as the internal structure of the primary cleft defect, secondary hypoplasia due to surgical repair at infancy, and functional factors (e.g., muscle effects - mastication, respiratory pattern, and mandibular resting posture) [58].

\subsection{Orthodontic approach}

The main purpose of orthodontic treatment before surgery in ICP patients is to eliminate all existing dental compensations. This is because, conducting camouflage treatment in these patients threatens periodontal health and may cause to relapse and resorption in teeth. Inclination and angulation of the maxillary and mandibular teeth, crowding, gaps, and rotations are organized throughout the orthodontic treatment process. The targets related to achieving ideal arch forms and ideal occlusion may be detailed after the operation. Extractions may be needed in the maxillary arch to eliminate dental compensations. In comparison to UCLP or BCLP patients, treatment is simpler in ICP patients due to the intact nature of the alveolar bone and because all teeth are usually present.

\subsection{Surgical approach}

In general, primary maxillomandibular deformity that is seen in ICP patients is maxillary hypoplasia that is caused by the cleft deformity and surgical interventions. The normal reconstructive procedure that needs to be considered in these patients is a Le Fort I maxillary osteotomy. Obwegeser stated that complete mobilization of maxilla that are down fractured is needed to achieve an orthognathic repair during surgery and decrease skeletal relapse [35]. Bell and Levy [45] confirmed that the Obwegeser Le Fort I technique allows sufficient blood diffusion for satisfactory bone recovery without aseptic necrosis or tooth injury.

It would be difficult to close any residual palatal oronasal fistula in an ICP patient at the same time with the Le Fort I procedure during orthognathic surgery. The reason for this is that elevation of the palatal flaps that is usually needed will threaten the blood supply for the down-fractured maxilla. Moreover, it was stated that, if an impermeable closure of the nasal side can be achieved following downfracturing before fixing the maxilla to its new position, the residual mucosal gap on the palatal side will usually be recovered secondarily by fistula closure [35]. 


\section{Post-surgery clinical management}

Management of the process at the hospital and at home during the initial recovery process of the orthognathic patient is highly important for a successful outcome. Cephalometric and dental radiographies and facial and occlusal photographs should be taken at certain intervals after the surgery in order to documentation and check the patient's recovery [17].

Orthodontist should remove the splint and see the patient in the next 24 hours to replace the maxillary segmental arch wires or rigid continuous arch wires. The maxillary teeth are tied to each other to preserve the occlusion, sagittal advancement, and transversal dimension. After 2 months of surgery, active orthodontic treatment and finishing procedures can be continued. A trans-palatal appliance (wire or palatal appliance) is recommended to stabilize the new arch form. The orthodontist should closely monitor the patients throughout the 6 months following the surgery to follow up on skeletal and dental relapse and to maintain orthodontic treatment [17].

In routine and unproblematic cases, splint usage is abandoned in about 5-7 after the surgery. However, in patients with early skeletal relapse, that is, within the first 2-8 weeks, the teeth are forced in the buccolingual direction toward outside of the bone because the teeth are held in place due to splint despite the alveolar relapse, and severe gingival recessions may occur (Figure 3). Therefore, CLP patients should be observed every week, unlike other orthognathic surgical patients. It should be kept in mind that the relapse rates given in the literature are averages, and it is possible to see more of these amounts in individual cases.

Speech may be objectively assessed in 3-6 months after the surgery. A nasal endoscopy may be used for this. Exact cleft-soft tissue procedures (e.g., cleft rhinoplasty, revision of the labial scar, pharyngeal flap or flap revision) may be carried out in 6 months after the operation. After removal of orthodontic appliances, pre-planned restorative approaches may be implemented [17].

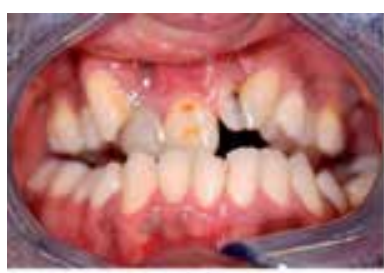

(a)

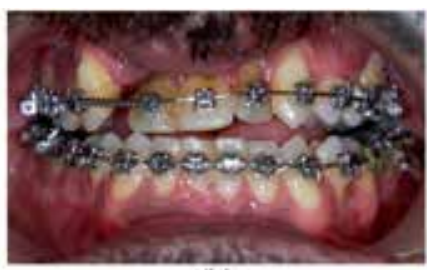

(b)

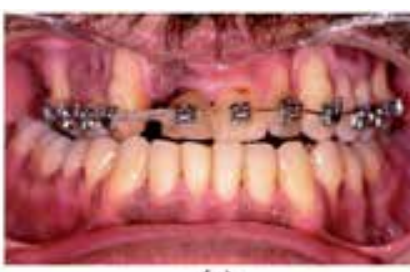

(c)

Figure 3.

Periodontal tissue loss due to relapse [25]. (a) Initial: Patient with UCLP, maxillary hypoplasia, severe crowding, missing lateral, and asymmetric arch form. (b) Pre-op: Periodontal problems after

expansion and leveling. (c) Post-op: Both transverse and sagittal skeletal relapse occur while teeth are locked within the arch-wire and surgical splint, which deteriorates the periodontal condition. The midline was surgically corrected.

\section{Success of orthognathic surgery}

After orthognathic surgery, cleft patients have a higher than normal risk of relapse due to factors such as different soft tissue-bone relations and complex mobilization vectors. Fahradyan et al. [59] reported that, in comparison to class III malocclusion patients without clefts, more relapse was encountered in those with 
clefts (1.25 mm or more on average), and there was a significant positive correlation between larger clefts and horizontal relapse. In their study, the mean relapse rate was similar among different types of clefts, and in the case of each $1 \mathrm{~mm}$ increase in maxillary advancement, horizontal relapse increased by $0.3 \mathrm{~mm}$ on average [59].

Richardson et al. [60] examined all relapse cases among individuals where more than $11 \mathrm{~mm}$ of maxillary advancement was applied, and they reported a horizontal relapse rate of $18.75 \%$. Nevertheless, Bhatia et al. [61] concluded that relapse rates stayed the same even in maxillary advancement degrees of more than $15 \mathrm{~mm}$ (mostly in cleft patients). Yamaguchi et al. [62] reported in their systematic review that the mean values of horizontal and vertical relapse were, respectively, $17.9 \%$ and $35.4 \%$ in orthodontic surgery for cleft patients. This shows us that vertical stability is lower.

Although most studies focused on horizontal maxillary stability, Park et al. [63] reported that postoperative mandibular relapse in cleft patients had a strong positive correlation with mandibular clockwise rotation and setback amounts. Wong et al. [64] could not find a significant difference between the relapse rates of individuals who received two surgical operations and those who received maxillary advancement surgery only. Some researchers used bone grafts to increase horizontal or vertical stability $[61,63,64]$. It was reported that usage of grafts has a preventive effect on horizontal maxillary stability with an average of $1.72 \mathrm{~mm}$ less relapse [61].

\section{Complications}

\subsection{Airway problems}

Treatment of cleft patients with class III malocclusion that results out of the combination of maxillary hypoplasia and intermaxillary disorder is usually achieved by maxillary advancement, mandibular setback, and clockwise rotation of the maxillomandibular complex. While maxillary advancement is associated with increased upper airway cavity, in contrast, mandibular setback is associated with reduction of airways with outcomes such as postoperative airway blockage, snoring, hypopnea (slow respiration), and obstructive sleep apnoea $[65,66]$. Additionally, a pharyngeal flap may contribute to the airway-related difficulties that are encountered during operation or in the postoperative period. When the three-dimensional (3D) pharyngeal airway cavity of cleft patients in their pre- or post-pubertal periods were compared to a control group, Karia et al. [66] found significantly smaller airway sizes in the cleft group. The total airway volume increased from the pre-pubertal to the post-pubertal periods in both groups, but the reason for this outcome in the cleft group was not anteroposterior growth as in the case of the control group, but in contrast, associated with vertical airway growth. Especially in bilateral cleft patients, significantly reduced pharyngeal airway cavity in comparison to individuals without clefts was also confirmed in a CBCT study [67].

A prospective study by Chang et al. [68] examined the airway changes in cleft patients who received maxillary advancement and mandibular setback treatments by not only CBCT but also polysomnographic examination. Regarding the airway changes after orthognathic surgery, it was found that there was no significant difference in sleep-related respiratory functions, but the snoring index was improved. 


\subsection{Speech impediment}

It is believed that maxillary advancement in cleft patients has a potential to worsen velopharyngeal function (VPF). Nevertheless, there is still no certain evidence on whether or not the amount of advancement affects velopharyngeal disorder and whether or not preoperative VPF is related to the postoperative outcome. It is most likely that improvements are seen in the articulation of patients after surgery due to the correction of dental arches [69]. In a systematic review of the complications that developed as a result of orthognathic surgery on cleft patients, Yamaguchi et al. [62] reported postoperative velopharyngeal deficiency (VPD) as $16.79 \%$.

Moran et al. [70] examined 79 cleft patients who received treatments of conventional orthognathic surgery or distraction osteogenesis, and they reported that, following maxillary advancement rates from 3 to $11 \mathrm{~mm}$, there was VPD in 5 (6.33\%) cases. These five patients were also found to have borderline VPD preoperatively. The results of their study supported those of other studies that there is no relationship between maxillary advancement and the amount of postoperative velopharyngeal disorders [71], and when orthognathic surgery and total maxillary distraction are compared in terms of speech and VPD, there is no significant difference [71-73]. Additionally, the finding that there is no correlation between postoperative speech impediment and preoperative borderline VPD was added to the literature which reported similar findings [71-73].

It is a difficult process to estimate soft tissue changes after orthognathic surgery and prevent them. This is because the adaptation of the velopharyngeal region for compensation of other regions is variable, and it is dependent on the personal characteristics of each patient and the capacity of tissues that are present or transplanted to become functional [74].

\subsection{Infection}

Infection rates following orthognathic surgery are highly variable due to reasons such as antibiotics usage styles and diagnostic differences [75, 76]. Recent studies on orthognathic surgery in individuals without clefts reported an incidence of less than $1-8 \%$ [76-78].

Miloro derived a few results by analyzing 15 previous studies on infections following orthognathic surgery: infection incidence may decrease in the case of using oral antibiotics for more than 1 day after surgery. First-generation cephalosporins are used more frequently before surgery. Mandibular osteotomy regions are where infections are seen the most. Extraction of the third molar may have a small effect on infection incidence, but this is under debate. Most infections that occur after orthognathic surgery are small, and removal of fixation plates and screws is rarely necessary [75].

In an analysis of the USA National Inpatient Samples Database (2012-2013), the rate of emergence for any kind of infectious complication following orthognathic surgery was reported as $7.4 \%$ in patients with a craniofacial anomaly and $0.6 \%$ in those without a craniofacial anomaly [78]. Recent studies reported rates of from 0to 13.92\% for infections emerging after orthognathic surgery in cleft patients without any craniofacial anomaly $[61,62,68,70]$. In the study that obtained a high rate of incidence as $13.92 \%$ despite 5 days of routine antibiotics usage, the authors emphasized the importance of oral hygiene, team collaboration, and patient cooperation [70].

\subsection{Oronasal fistula}

Segmental maxillary osteotomies may have a risk of postoperative oronasal fistulae. In a systematic review in 2017, the postoperative fistula rate was reported 
as $19.3 \%$ in segmental Le Fort I osteotomy [79]. While residual oronasal fistulae in cleft patients increase the difficult of orthognathic surgery, they may be repaired by adjusting the incision patterns during surgery. In addition to this, according to the systematic review in 2016 by Yamaguchi et al. [62], the closure deficiency of a pre-existing fistulae ( $28.57 \%$ for palatal, $10.74 \%$ for alveolar fistulae) was the most frequently encountered complication. Another study reported a residual fistulae rate of $10.53 \%$ [70]. Nevertheless, residual fistulae rates may be reduced by careful dissection, unstressed closure, delicate tissue management, and compliance with blood circulation [80].

\subsection{Nerve damage}

The neural disorders that occur as a result of orthognathic surgery mainly affect the infraorbital, inferior alveolar (mandibular), and mental and incisive nerves. Reports on facial nerve paralysis vary in the range of $0.17-0.75 \%$ [81].

The incidence of continuation of inferior alveolar nerve disorders varies between 5 and $15 \%$ depending on the age of the patient and the technique that is used (piezo-surgery or conventional) [82, 83]. A systematic review in 2017 reported that usage of piezo-surgery in orthognathic operations was associated with significant reductions of loss of blood during surgery and severe nervous disorders [84].

In orthognathic surgery on cleft patients, $70 \%$ of the patients may experience paresthesia after surgery, and a permanent sensory disorder may occur in $25 \%$ [80]. Bhatia et al. [61] stated that all $25 \%$ of patients who experienced cheek paresthesia recovered after a year. Moran et al. [70] reported that the sensory neuropathy of the infraorbital nerve was temporary in $53 \%$ of patients and permanent in $1.27 \%$. In addition to this, 3D computer-assisted planning and determination of the inferior alveolar nerve may contribute to the safety of orthognathic surgery [85].

\section{Conclusion}

Orthognathic surgery, which is the last stage of CLP treatment, is a highly important step in management of the entire process. Therefore, there should be good communication among the patient, the family, and the cleft team. There are effects of factors that are unique to individuals or clefts on the outcomes of surgery, but their extent is still under debate.

Despite the different rates reported in the literature, the rates of complications in cleft surgery are striking. Strategies should be created by focusing on causes and mechanisms to prevent or minimize these complications. 


\section{Author details}

Hakan Yilmaz* and Arzu Ari Demirkaya

Department of Orthodontics, Faculty of Dentistry, Istanbul Okan University, Istanbul, Turkey

*Address all correspondence to: hakanyilmaz90@gmail.com

\section{IntechOpen}

(c) 2019 The Author(s). Licensee IntechOpen. This chapter is distributed under the terms of the Creative Commons Attribution License (http://creativecommons.org/licenses/ by/3.0), which permits unrestricted use, distribution, and reproduction in any medium, provided the original work is properly cited. $(\mathrm{cc}) \mathrm{BY}$ 


\section{References}

[1] Broome M, Herzog G, Hohlfeld J, de Buys Roessingh A, Jaques B. Influence of the primary cleft palate closure on the future need for orthognathic surgery in unilateral cleft lip and palate patients. The Journal of Craniofacial Surgery. 2010;21(5):1615-1618

[2] Rosenstein SW, Grasseschi M, Dado DV. A long-term retrospective outcome assessment of facial growth, secondary surgical need, and maxillary lateral incisor status in a surgicalorthodontic protocol for complete clefts. Plastic and Reconstructive Surgery. 2003;111(1):1-13; discussion 4-6

[3] Good PM, Mulliken JB, Padwa BL. Frequency of Le fort I osteotomy after repaired cleft lip and palate or cleft palate. The Cleft Palate-Craniofacial Journal. 2007;44(4):396-401

[4] Filho LC, Normando ADC, Da Silva Filho OG. Isolated influences of lip and palate surgery on facial growth: Comparison of operated and unoperated male adults with UCLP. The Cleft Palate-Craniofacial Journal. 1996;33(1):51-56

[5] Astani SA, Yilmaz HN, Nevzatoglu S, Demirkaya AA, Acar ZA. Evaluation of airway volume in cleft lip and palate following nasoalveolar molding. The Journal of Craniofacial Surgery. 2018;29(8):2143-2147

[6] Cassolato SF, Ross B, Daskalogiannakis J, Noble J, TompsonB.Treatmentofdentalanomalies in children with complete unilateral cleft lip and palate at SickKids hospital, Toronto. The Cleft Palate-Craniofacial Journal. 2009;46(2):166-172

[7] McCance AM, Roberts-Harry D, Sherriff M, Mars M, Houston WJ. A study model analysis of adult unoperated Sri Lankans with unilateral cleft lip and palate. The Cleft Palate Journal. 1990;27(2):146-154
[8] Daskalogiannakis J, Mehta M. The need for orthognathic surgery in patients with repaired complete unilateral and complete bilateral cleft lip and palate. The Cleft Palate-Craniofacial Journal. 2009;46(5):498-502

[9] Swennen G, Colle F, De AM, Malevez C. Maxillary distraction in cleft lip palate patients: A review of six cases. The Journal of Craniofacial Surgery. 1999;10(2):117-122

[10] Wolford LM. Effects of orthognathic surgery on nasal form and function in the cleft patient. The Cleft Palate-Craniofacial Journal. 1992;29(6):546-555

[11] Kuo-Ting Chen P, Por Y-C, Jein-Wein Liou E, Chun-Shin Chang F. Maxillary distraction osteogenesis in the adolescent cleft patient: Three-dimensional computed tomography analysis of linear and volumetric changes over five years. The Cleft Palate-Craniofacial Journal. 2011;48(4):445-454

[12] Figueroa AA, Polley JW, Ko EW-C. Maxillary distraction for the management of cleft maxillary hypoplasia with a rigid external distraction system. Seminars in Orthodontics. 1999;5(1):46-51

[13] Posnick JC, Tiwana PS. CleftOrthognathic Surgery. In: Berkowitz S, editor. Cleft Lip and Palate. Heidelberg, Berlin: Springer; 2006. pp. 573-585

[14] Harper DC. Children's attitudes to physical differences among youth from Western and non-Western cultures. The Cleft Palate-Craniofacial Journal. 1995;32(2):114-119

[15] Jorgenson R, Shapiro S, Odinet K. Studies on facial growth and arch size in cleft lip and palate. 
Journal of Craniofacial Genetics and Developmental Biology. 1984;4(1):33-38

[16] Mccance AM, Moss JP, Fright WR, Linney AD, James DR. Three-dimensional analysis techniques-Part 1: Three-dimensional soft-tissue analysis of 24 adult cleft palate patients following Le fort I maxillary advancement: A preliminary report. The Cleft Palate-Craniofacial Journal. 1997;34(1):36-45

[17] Posnick JC. Principles and Practice of Orthognathic Surgery. London, United Kingdom: Elsevier Health Sciences; 2013

[18] Siegel-Sadewitz V, Shprintzen R. Nasopharyngoscopy of the normal velopharyngeal sphincter: An experiment of biofeedback. The Cleft Palate Journal. 1982;19(3):194-200

[19] Vallino LD, Tompson B. Perceptual characteristics of consonant errors associated with malocclusion. Journal of Oral and Maxillofacial Surgery. 1993;51(8):850-856

[20] Proffit W, editor. Orthodontic Treatment of Clefts: Yesterday, Today, and Tomorrow. Proceedings of the 48th Annual Meeting. American Cleft Palate-Craniofacial Association Hilton Head; 1991

[21] Warren DW. Perceptual characteristics of consonant errors associated with malocclusion. Journal of Oral and Maxillofacial Surgery. 1993;51(8):856

[22] Sandham A, Murray J. Nasal septal deformity in unilateral cleft lip and palate. The Cleft Palate-Craniofacial Journal. 1993;30(2):222-226

[23] Kolbenstvedt A, Aaløkken T, Arctander K, Johannessen S. CT appearances of unilateral cleft palate 20 years after bone graft surgery. Acta Radiologica. 2002;43(6):567-570
[24] Trindade IE, Yamashita RP, Suguimoto RM, Mazzottini R, Trindade AS Jr. Effects of orthognathic surgery on speech and breathing of subjects with cleft lip and palate: Acoustic and aerodynamic assessment. The Cleft Palate-Craniofacial Journal. 2003;40(1):54-64

[25] Yilmaz H, Demirkaya AA. Dudak damak yariğinda ortognatik cerrahi. Turkiye Klinikleri Orthodontics-Special Topics. 2019;5(1):34-41

[26] Stoelinga PJ, Leenen RJ, Blijdorp PA, Schoenaers JH, Team CP. The prevention of relapse after maxillary osteotomies in cleft palate patients. Journal of CranioMaxillofacial Surgery. 1987;15:326-331

[27] Posnick JC. The treatment of secondary and residual dentofacial deformities in the cleft patient. Surgical and orthodontic therapy. Clinics in Plastic Surgery. 1997;24(3):583-597

[28] Robertsson S, Mohlin B. The congenitally missing upper lateral incisor. A retrospective study of orthodontic space closure versus restorative treatment. The European Journal of Orthodontics. 2000;22(6):697-710

[29] Suzuki A, Takahama Y. Maxillary lateral incisor of subjects with cleft lip and/or palate: Part 1. The Cleft Palate-Craniofacial Journal. 1992;29(4):376-379

[30] Suzuki A, Watanabe M, Nakano M, Takahama Y. Maxillary lateral incisors of subjects with cleft lip and/or palate: Part 2. The Cleft Palate-Craniofacial Journal. 1992;29(4):380-384

[31] Laspos CP, Kyrkanides S, Tallents RH, Moss ME, Subtelny JD. Mandibular and maxillary asymmetry in individuals with unilateral cleft lip and palate. The Cleft Palate-Craniofacial Journal. 1997;34(3):232-239 
[32] Nordquist GG, McNeill RW.

Orthodontic vs. restorative treatment of the congenitally absent lateral incisorLong term periodontal and occlusal evaluation. Journal of Periodontology. 1975;46(3):139-143

[33] Felstead AM, Deacon S, Orth M, Revington PJ. The outcome for secondary alveolar bone grafting in the south West UK region post-CSAG. The Cleft Palate-Craniofacial Journal. 2010;47(4):359-362

[34] McIntyre GT, Devlin MF. Secondary alveolar bone grafting (CLEFTSiS) 2000-2004. The Cleft PalateCraniofacial Journal. 2010;47(1):66-72

[35] Posnick JC. Cleft Jaw Deformities and their Management. Cleft Lip and Palate. Heidelberg, Berlin: Springer; 2013. pp. 557-599

[36] Åbyholm FE, Bergland O, Semb G. Secondary bone grafting of alveolar clefts: A surgical/orthodontic treatment enabling a non-prosthodontic rehabilitation in cleft lip and palate patients. Scandinavian Journal of Plastic and Reconstructive Surgery. 1981;15(2):127-140

[37] Ross RB. Treatment variables affecting facial growth in complete unilateral cleft lip and palate. Part 7: An overview of treatment and facial growth. The Cleft Palate Journal. 1987;24:71-77

[38] Bell WH, You ZH, Finn RA, Fields RT. Wound healing after multisegmental Le fort I osteotomy and transection of the descending palatine vessels. Journal of Oral and Maxillofacial Surgery. 1995;53(12):1425-1433

[39] Fitzpatrick B. Mid-face osteotomy in the adolescent cleft palate patient. Australian Dental Journal. 1977;22(5):338-350
[40] James DR, Brook K. Maxillary hypoplasia in patients with cleft lip and palate deformity-The alternative surgical approach. The European Journal of Orthodontics. 1985;7(4):231-247

[41] Westbrook MT Jr, West RA, McNeill RW. Simultaneous maxillary advancement and closure of bilateral alveolar clefts and oronasal fistulas. Journal of Oral and Maxillofacial Surgery. 1983;41(4):257-260

[42] Drommer RB. The history of the "Le fort I osteotomy". Journal of Maxillofacial Surgery. 1986;14:119-122

[43] Obwegeser H, editor. Surgical Correction of Deformities of the Jaws in Adult Cleft Cases. First International Conference on Cleft Lip and Palate. Houston; 1969

[44] Obwegeser HL, editor Surgery as an Adjunct Ot Orthodontics in Normal and Cleft Palate Patients. Report of the Congress European Orthodontic Society; 1966

[45] Bell W, Levy B. Revascularization and bone healing after posterior maxillary osteotomy. Journal of Oral Surgery. 1971;29(5):313-320

[46] PosnickJC, Tompson B. Modification of the maxillary Le fort I osteotomy in cleft-orthognathic surgery: The unilateral cleft lip and palate deformity. Journal of Oral and Maxillofacial Surgery. 1992;50(7):666-675

[47] Obwegeser HL. Orthognathic surgery and a tale of how three procedures came to be: A letter to the next generations of surgeons. Clinics in Plastic Surgery. 2007;34(3):331-355

[48] Champy M. Surgical treatment of midface deformities. Head \& Neck Surgery. 1980;2(6):451-465

[49] Lund TW, Wade M. Use of osseointegrated implants to support 
a maxillary denture for a patient with repaired cleft lip and palate. The Cleft Palate-Craniofacial Journal. 1993;30(4):418-420

[50] David DJ, Anderson PJ, Schnitt DE, Nugent MA, Sells R. From birth to maturity: A group of patients who have completed their protocol management. Part II. Isolated cleft palate. Plastic and Reconstructive Surgery.

2006;117(2):515-526

[51] Friede H, Pruzansky S. Long-term effects of premaxillary setback on facial skeletal profile in complete bilateral cleft lip and palate. The Cleft Palate Journal. 1985;22(2):97-105

[52] Lisson JA, Tränkmann J.

Comparative survey of osteotomized and nonosteotomized BCLP patients. The Cleft Palate-Craniofacial Journal. 1997;34(5):430-437

[53] Poole MD, Robinson PP, Nunn ME. Maxillary advancement in cleft palate patients: A modification of the Le fort I osteotomy and preliminary results. Journal of Maxillofacial Surgery. 1986;14:123-127

[54] Willmar K. On Le fort I osteotomy; a follow-up study of 106 operated patients with maxillo-facial deformity. Scandinavian Journal of Plastic and Reconstructive Surgery. 1974;12 (suppl 12):1

[55] Posnick JC. Orthognathic surgery for the cleft lip and palate patient. Seminars in Orthodontics. 1996;2(3):205-214

[56] Posnick JC, Tompson B. Modification of the maxillary Le fort I osteotomy in cleft-orthognathic surgery: The bilateral cleft lip and palate deformity. Journal of Oral and Maxillofacial Surgery. 1993;51(1):2-11

[57] Chen Z-Q, Qian Y-F, Wang G-M, Shen G. Sagittal maxillary growth in patients with unoperated isolated cleft palate. The Cleft Palate-Craniofacial Journal. 2009;46(6):664-667

[58] Canady JW, Thompson SA, Colburn A. Craniofacial growth after latrogenic cleft palate repair in a fetal ovine model. The Cleft PalateCraniofacial Journal. 1997;34(1):69-72

[59] Fahradyan A, Wolfswinkel EM, Clarke N, Park S, Tsuha M, Urata MM, et al. Impact of the distance of maxillary advancement on horizontal relapse after orthognathic surgery. The Cleft Palate-Craniofacial Journal. 2018;55(4):546-553

[60] Richardson S, Krishna S, Khandeparker RV. A comprehensive management protocol to treat cleft maxillary hypoplasia. Journal of Cranio-Maxillofacial Surgery. 2018;46(2):356-361

[61] Bhatia S, Bocca A, Jones J, Sugar AW. Le fort I advancement osteotomies of $1 \mathrm{~cm}$ or more. How safe or stable? The British Journal of Oral \& Maxillofacial Surgery. 2016;54(3):346-350

[62] Yamaguchi K, Lonic D, Lo L-J. Complications following orthognathic surgery for patients with cleft lip/ palate: A systematic review. Journal of the Formosan Medical Association. 2016;115(4):269-277

[63] Park Y-H, Seo J-H, Yang I-H, Choi J-Y, Lee J-H, Kim M-J, et al. What are the contributing factors for postsurgical relapse after two-jaw surgery in patients with cleft lip and palate. The Journal of Craniofacial Surgery. 2017;28(4):1071-1077

[64] Wong F, Heggie A, Shand J, Schneider P. Skeletal stability of maxillary advancement with and without a mandibular reduction in the cleft lip and palate patient. International Journal of Oral 
and Maxillofacial Surgery.

2016;45(12):1501-1507

[65] Gerbino G, Gervasio FC,

Blythe J, Bianchi FA. The management of iatrogenic obstructive sleep apnoea syndrome following bimaxillary surgery in a patient with cleft lip and palate. The Journal of Craniofacial Surgery. 2016;27(5):1286-1288

[66] Karia H, Shrivastav S, Karia AK. Three-dimensional evaluation of the airway spaces in patients with and without cleft lip and palate: A digital volume tomographic study. American Journal of Orthodontics and Dentofacial Orthopedics. 2017;152(3):371-381

[67] Gandedkar NH, Chng CK, Basheer MA, Chen PY, Leng Yeow VK. Comparative evaluation of the pharyngeal airway space in unilateral and bilateral cleft lip and palate individuals with noncleft individuals: A cone beam computed tomography study. The Cleft Palate-Craniofacial Journal. 2017;54(5):509-516

[68] Chang C-S, Wallace CG, Hsiao Y-C, Hsieh Y-J, Wang Y-C, Chen N-H, et al. Airway changes after cleft orthognathic surgery evaluated by three-dimensional computed tomography and overnight polysomnographic study. Scientific Reports. 2017;7(1):12260

[69] Richardson S, Seelan NS, Selvaraj D, Khandeparker RV, Gnanamony S. Perceptual speech assessment after anterior maxillary distraction in patients with cleft maxillary hypoplasia. Journal of Oral and Maxillofacial Surgery. 2016;74(6):1239. e1-e9

[70] Moran I, Virdee S, Sharp I, Sulh J. Postoperative complications following LeFort 1 maxillary advancement surgery in cleft palate patients: A 5-year retrospective study. The Cleft Palate-Craniofacial Journal. 2018;55(2):231-237
[71] Chua H, Whitehill T, Samman N, Cheung L. Maxillary distraction versus orthognathic surgery in cleft lip and palate patients: Effects on speech and velopharyngeal function. International Journal of Oral and Maxillofacial Surgery. 2010;39(7):633-640

[72] McComb RW, Marrinan EM, Nuss RC, LaBrie RA, Mulliken JB, Padwa BL. Predictors of velopharyngeal insufficiency after Le fort I maxillary advancement in patients with cleft palate. Journal of Oral and Maxillofacial Surgery. 2011;69(8):2226-2232

[73] Phillips JH, Klaiman P, Delorey R, MacDonald DB. Predictors of velopharyngeal insufficiency in cleft palate orthognathic surgery. Plastic and Reconstructive Surgery. 2005;115(3):681-686

[74] Wu Y, Wang X, Ma L, Li Z. Velopharyngeal configuration changes following Le fort I osteotomy with maxillary advancement in patients with cleft lip and palate: A cephalometric study. The Cleft Palate-Craniofacial Journal. 2015;52(6):711-716

[75] Miloro M. Surgical site infections after orthognathic surgery. Journal of Oral and Maxillofacial Surgery. 2017;75(6):1101-1103

[76] Posnick JC, Choi E, Chavda A. Surgical site infections following bimaxillary orthognathic, osseous genioplasty, and intranasal surgery: A retrospective cohort study. Journal of Oral and Maxillofacial Surgery. 2017;75(3):584-595

[77] Davis CM, Gregoire CE, Steeves TW, Demsey A. Prevalence of surgical site infections following orthognathic surgery: A retrospective cohort analysis. Journal of Oral and Maxillofacial Surgery. 2016;74(6):1199-1206

[78] Metalwala Z, Okunseri C, Fletcher S, Allareddy V. Orthognathic 
surgical outcomes in patients with and without craniofacial anomalies. Journal of Oral and Maxillofacial Surgery. 2018;76(2):436. e1-e8

[79] Junior OH, Guijarro-Martínez R, de Sousa Gil A, da Silva Meirelles L, de Oliveira R, Hernandez-Alfaro F. Stability and surgical complications in segmental Le fort I osteotomy: A systematic review. International Journal of Oral and Maxillofacial Surgery. 2017;46(9):1071-1087

[80] Ohrmann D, Hoyte-Williams PE, Chen PK-T. Update on complications in cleft orthognathic surgery. Current Opinion in Otolaryngology \& Head and Neck Surgery. 2018;26(4):260-265

[81] Kim Y-K. Complications associated with orthognathic surgery. Journal of the Korean Association of Oral and Maxillofacial Surgeons. 2017;43(1):3-15

[82] Landes CA, Stübinger S, Rieger J, Williger B, Ha TKL, Sader R. Critical evaluation of piezoelectric osteotomy in orthognathic surgery: Operative technique, blood loss, time requirement, nerve and vessel integrity. Journal of Oral and Maxillofacial Surgery. 2008;66(4):657-674

[83] Verweij J, Mensink G, Fiocco M, van Merkesteyn J. Incidence and recovery of neurosensory disturbances after bilateral sagittal split osteotomy in different age groups: A retrospective study of 263 patients. International Journal of Oral and Maxillofacial Surgery. 2016;45(7):898-903

[84] Pagotto LEC, de Santana Santos T, de Vasconcellos SJA, Santos JS, Martins-Filho PRS. Piezoelectric versus conventional techniques for orthognathic surgery: Systematic review and meta-analysis. Journal of Cranio-Maxillofacial Surgery. 2017;45(10):1607-1613
[85] Lonic D, Pai BC-J, Yamaguchi K, Chortrakarnkij P, Lin H-H, Lo L-J. Computer-assisted orthognathic surgery for patients with cleft lip/palate: From traditional planning to three-dimensional surgical simulation. PLoS One. 2016;11(3):e0152014 
Section 3

Life Quality in Clefts 



\title{
Chapter 6
}

\section{Quality of Life in Adolescents with Cleft Lip and Palate}

\author{
Latifa Elmouden, Fatima Zahra Elgasmi and Lahcen Ousehal
}

\begin{abstract}
The cleft lip and palate (CLP) is the second most common congenital anomaly in the world; therefore, understanding the quality of life in children and adolescents with this malformation is extremely important. The study of the quality of life in this population is based on how the patient feels about his condition and how it affects his general well-being depending on the problems he may encounter concerning bone growth, phonation, speaking, facial appearance, and social relationship. As part of a descriptive survey, the aim was to assess and study the quality of life of patients with labio-palatal clefts operated and undergoing medical management, as well as the quality of life perceived by their parents to evaluate the family impact of this dysmorphia. According to the studies, teenagers had the lowest quality of life rates in the items: physical appearance and self-esteem, so the psychological support for patients and their families with multidisciplinary treatment that meets standards, are the keys to improving the quality of life of this category of patients.
\end{abstract}

Keywords: quality of life, adolescents, cleft lip and palate, self-esteem, parents

\section{Introduction}

Cleft lip and cleft palate are facial anomalies and are the most common congenital anomalies that affect the orofacial region and remain a significant public health burden [1].

Orofacial clefts (CL/P) commonly affect the lip, alveolar ridge, and hard and soft palates. Problems associated with these anomalies are dental problems, malocclusion, nasal deformity, feeding, and ear and speech difficulties [2].

Thus, any difference in those structures is noticeable and may cause some difficulties in the relationship field. In fact, the face is the front by which every human being is presented and communicates with others.

In the book "bec-du-lievre" ("harelip"): Clinical Forms-Surgery (1938) of Victor Veau, the presence of a cleft lip is stated by the absence of contacts between the external muscles and the inner verge [3]. This has the effect of destabilizing the anatomy of the nose (deformation of the alar cartilages, the nasal septum, and triangular cartilages).

Such deformation causes in humans a change in its well-being, autonomy, own world, expectations, and social insertion, which are parts of the concept of "quality of life" (QoL). 
The quality of life (QoL) is a complex multidimensional and subjective concept in permanent evolution. The study of QoL can be an instrument of evaluation of the daily impact of an individual with CL or CLP operated. It is an integral part of the evaluation of results as well as the satisfaction of the surgeon and that of the patient [4].

The issue of QoL is attracting increasing the interest from many researchers. It is a concept that groups together different areas of life and is strongly subject to individual experiences [5].

The QoL of a patient with a cranio-facial deformity is already influenced at birth by the impact of the disease on the newborn, the parents, and the family. The birth of a child with a cleft lip and palate raises controversial feelings among parents especially the mother. The relationship with the child is dominated by the notion of "who," which cannot be separated from "what we are." The abnormal child is not only the beloved child but also an unknown stranger. Once the diagnosis has been made, the child's removal can occur but also ownership [6].

The QoL of individuals with cranio-facial diseases is challenged throughout life, given the conditions themselves and the treatments needed to be done. In other words, age and time the frameworks in which optimal care and quality of life must coordinate perfectly. These children with CLP experience a number of psychosocial risks, including medical appointments and assessments, surgery, feeding difficulties, appearance differences, as well as the possibility of need for early special treatment, such as phonotherapy.

This otherness and especially the differences in appearance often involve varying degrees of facial scars, and dentition variations, such as missing teeth, limitation of speech, and language [7-9].

Several studies have described the psychological and social burden in children with CLP and reported that these patients have significantly more behavioral problems, as well as more symptoms of depression, and are less satisfied with their facial appearance.

In addition, the new concept of health proposes to measure the oral health of people in relation to general health and psychosocial well-being [7].

The judgment of the functional and esthetic results of surgery has always been traditionally performed by clinicians (surgeons, speech therapists, and orthodontists).

Quality of life brings together a number of distinct branches (appearance, speech, facial growth, and psychosocial interaction). In addition, the importance lies in how these different areas could change from the period of childish development to adulthood. As a result, a questionnaire for the cleft lip and palate population could be able to address areas of importance and be aware of any changes in quality of life aspects as the child matures [4].

There are very few studies that illustrate how patients feel after surgery and how they assess their quality of life [10].

To adequately measure the quality of life of patients with cleft lip and palate, an instrument showing the clinically significant scientific findings reported by the patient that specifically addresses quality of life issues in patients with cleft lip and palate is required. These are questionnaires that quantify QoL and/or other significant outcome variables (e.g., satisfaction, symptoms, and function) from the patient's point of view. The lack of a tool specific to this population with orofacial clefts has been identified as a major research gap that should be filled.

The objective of our study was to assess the quality of life of patients operated by a cleft lip or cleft lip and palate as well as the perception of quality of life of the patients perceived by their parents through a quality of life scale adapted to the age of the patients. 


\section{Patients and methods}

\subsection{Patients}

This study is a monocentric cross-sectional descriptive analytical survey on a sample of 40 adolescents ( 25 boys and 15 girls) aged between 12 and 16 (average age of $12.53 \pm 1.65$ years $)$ operated with a cleft lip (CL) $(n=12)$ or cleft lip and palate (CLP) $(\mathrm{n}=28)$ and their parents.

Patients operated on for cleft palate only were excluded from the sample.

The survey was conducted at the "Opération Smile" center in Casablanca (Morocco) among patients with a cleft lip and palate treated at the center over a period of 4 months, and only one interviewer was responsible for data collection.

\subsection{The questionnaire}

The questionnaire used in the study is the VSP-A (Vécu et Santé Perçue de l'Adolescent), it is a self-administered French indicator of health-related quality of life that has been developed from the perspective of healthy and sick adolescents aged 11-17.

For adolescents, nine areas were explored:

- relations with parents,

- self-esteem,

- energy and vitality,

- relationships with friends,

- leisure and activities,

- psychological well-being,

- physical well-being,

- school labor and relations with teachers, and

- relationship with the nursing staff,

Each response was rated from 1 to 5 . The points were distributed as follows: 1 point for the answer that corresponded to "ill-being," 5 points for "well-being" with all the intermediate nuances. The "no answer" and "unconcerned" questions were not included in the questionnaire administered to adolescents and therefore do not correspond to any rating.

The questions corresponding to the same field were distributed throughout the questionnaire in order to limit the response bias. The questions were in the form of multiple choice answers. Five responses were received possible: never, not at all/rarely, a little/sometimes, moderately/often, much /always, and a lot.

In the questionnaires given to "parents," in addition to the previous items, a sixth proposal appeared: not concerned. 


\subsection{Statistical analysis}

The statistical data for this study were captured, analyzed, and compared using the Microsoft Excel 2010 software; and the Spss software, Version 23.0. Armonk, NY: IBM Corp.

A test-retest was performed for a sample of 10 patients that was randomly selected to see if the questions were well assimilated by the patients. The intra-class correlation coefficient (ICC) with a 4-week interval between the two measurements with alpha level of significance alpha $=5 \%$ (corresponds to a $95 \%$ confidence). $\mathrm{P}<0.05$ value was considered significant.

\section{Results}

In order to verify the validity of the questionnaire and the reproducibility of the responses of the adolescents interviewed, we conducted a test/retest with 10 adolescents who were asked after 1 month of the first interview, giving answers, for the most part, equivalent to the first answers and therefore insignificant differences $(\mathrm{p}=0.21)$ and, therefore, we can conclude that the questionnaire was well assimilated by the patients (Table 1 ).

Our results show that the overall quality of life index for adolescents with CLP is 59.61 , while the index for parents of patients is 60.58 (Table 2). The quality of life perceived by parents is therefore close to that of their children (Figure 1). This was confirmed by the linear regression curve (Figure 2).

Parents overestimated their children's quality of life in terms of family relationships, self-esteem, education, and physical and psychological well-being. However, adolescents slightly overestimate their quality of life compared to their parents in terms of activity and leisure and relationships with friends.

The relationship with medical and nursing staff has yielded the best results for both parents and adolescents. More than $60 \%$ of adolescents reported a better quality of life in their relationships with friends, sharing their secrets and problems and expressing themselves freely.

\begin{tabular}{lcccc}
\hline Domains & $\begin{array}{c}\text { Average test } \\
\text { score }\end{array}$ & $\begin{array}{c}\text { Average retest } \\
\text { score }\end{array}$ & P-value & Significance \\
\hline Family relationship & 59.2 & 58.1 & 0.21 & NS \\
\hline Friends relationship & 58.7 & 60.2 & 0.54 & NS \\
\hline Vitality & 62.3 & 61.4 & 0.43 & NS \\
\hline Self-esteem & 55.1 & 57.2 & 0.24 & NS \\
\hline Psychological well-being & 56.7 & 58.4 & 0.19 & NS \\
\hline Physical well-being & 47.3 & 48.5 & 0.42 & NS \\
\hline $\begin{array}{l}\text { School labor and relationship with } \\
\text { teachers }\end{array}$ & 59.1 & 60.2 & 0.53 & NS \\
\hline Leisure and activities & 62.1 & 61.7 & 0.67 & NS \\
\hline Relationship with the nursing staff & 69.3 & 71.4 & 0.12 & NS \\
\hline Global Index & 58.86 & 59.67 & 0.46 & NS \\
\hline
\end{tabular}

Table 1.

Results of the test/retest patients. 
Quality of Life in Adolescents with Cleft Lip and Palate

DOI: http://dx.doi.org/10.5772/intechopen.91348

\begin{tabular}{lcc}
\hline Domains & $\begin{array}{c}\text { Average quality of life score } \\
\text { according to adolescent } \\
\text { patients }\end{array}$ & $\begin{array}{c}\text { Average score of adolescents' } \\
\text { quality of life according to } \\
\text { parents }\end{array}$ \\
\hline Family relationship & 60.2 & 65.4 \\
\hline Friends relationship & 59.6 & 62.1 \\
\hline Vitality & 61.3 & 58.2 \\
\hline Self-esteem & 54.6 & 59.6 \\
\hline Psychological well-being & 53.2 & 58.6 \\
\hline Physical well-being & 45.2 & 55.4 \\
\hline $\begin{array}{l}\text { School labor and relationship } \\
\text { with teachers }\end{array}$ & 57.4 & 60.1 \\
\hline Leisure and activities & 62.4 & 60.2 \\
\hline $\begin{array}{l}\text { Relationship with the } \\
\text { nursing staff }\end{array}$ & 70.2 & 69.3 \\
\hline Global Index & 59.61 & 60.98 \\
\hline
\end{tabular}

Table 2.

Average quality of life of adolescents and the quality of life perceived by their parents.

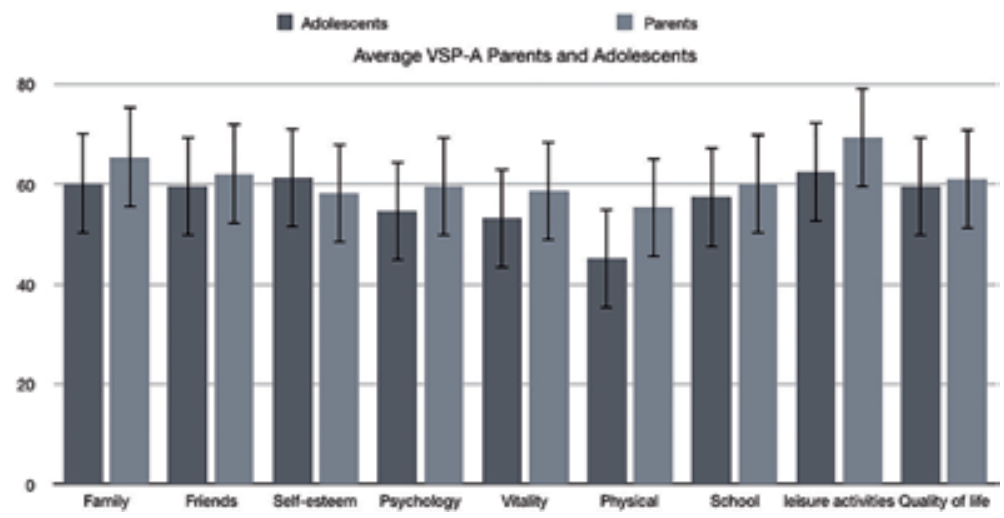

Figure 1.

Diagram of the averages of VSP-A parents and adolescents.

According to our results, between 32.5 and $42.5 \%$ of adolescents had selfconfidence. Fifty percent of adolescents lacked vitality and energy, and $50 \%$ of adolescents often went out to play with their friends; $72.5 \%$ were understood and reassured by their friends.

About $47.5 \%$ of adolescents were satisfied with their academic performance, while $15 \%$ thought they were very well understood by their parents about their schooling. About $67.5 \%$ are complexed by their physical appearance.

Psychologically, only $2.5 \%$ of adolescents are self-confident with $47.5 \%$ tending to take life on the bright side.

The relationship with medical and nursing staff showed that $70 \%$ of adolescents found that they were understood, reassured, and respected by medical staff.

As far as parents of sick children are concerned, only $30 \%$ found that their children were too worried.

Fifteen percent of parents noticed signs of depression in their children, and $35 \%$ found that they were not at all revolted or shocked by what was happening 


\section{Adolescents}

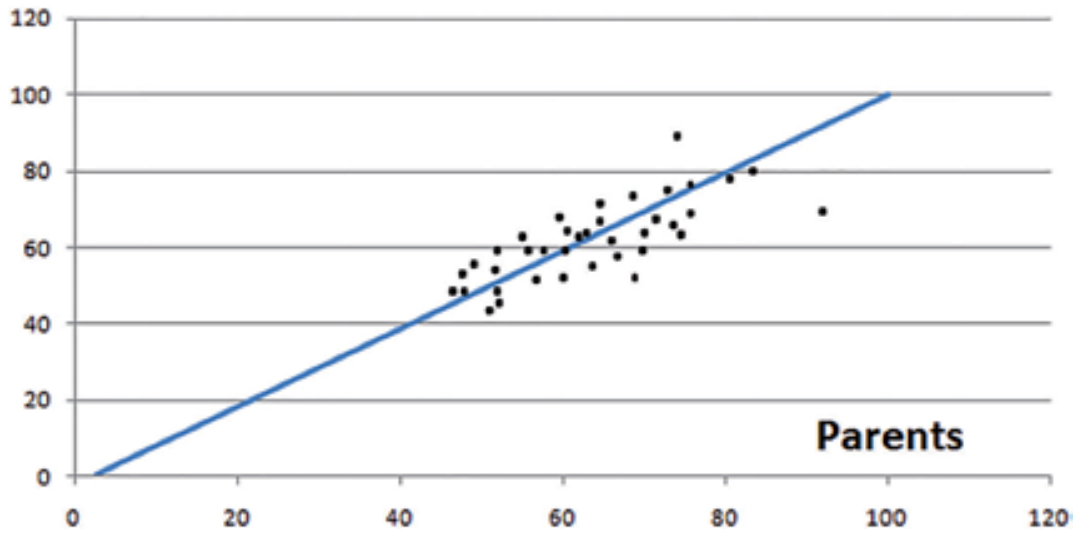

Figure 2.

Linear regression, overall quality of life index.

around them. Sixty percent of parents noted that their children were optimistic and confident about their future; only $10 \%$ thought that their children were extremely happy and satisfied with their lives.

With regard to the education component for adolescents, parents with an average of $31 \%$ were satisfied with their children's schooling and relationship with their children's teachers. Fifty-five percent of parents noted that their children were not at all complexed by their physical appearance.

On average, $45 \%$ of parents reported that their children lacked energy and vitality; $65 \%$ of parents reported that their children tended to take life on the right side; and $70 \%$ thought their children thought that everything was fine around them.

\section{Discussion}

\subsection{Quality of life instrument evaluation}

Our study was based on the administration of two questionnaires, VSP-A "Vécu et Santé Perçue par l'Adolescent" "Experienced and Perceived Health by the Adolescent" one for adolescents with CLP and the other for their parents.

These questionnaires were considered reliable by a test/retest with the first 10 patients interviewed. The questionnaire we used is in French [4].

Quality of life is defined by the World Health Organization (WHO) as "perception of people in terms of their situation in life, in the cultural context, and in values with whom they live according to their objectives, expectations, models, and concerns" [11].

When an individual is accepted into society, the sense of well-being or good quality of life is easier to achieve [12]. The overall quality of life index for adolescents with CLP was 59.61 and that of the parents of the children of was 60.58, which shows that the perceived quality of life is almost superimposable between parents/ children.

Recent studies show that reports of children on OHRQoL are reliable and valid. Instruments developed to measure the quality of life of children must also assess the impact of these problems on the quality of life of the family, as they are inseparable factors [13-16]. 


\subsection{Psychological aspect of quality of life perception}

The analysis of the quality of life in CL/CLP remains a difficult exercise. Family dynamics, education, and professional factors influence the social development and rehabilitation of these patients [17] .

Psychological problems, such as loss of self-esteem and difficulties in social interaction, are also encountered in patients with cleft lip or palate $[8,18-20]$.

In our study, the quality of life perceived by parents was close to that of their children, which was confirmed by the linear regression curves (Figure 2).

The literature on quality of life in cases of facial malformation (congenital or acquired) is disparate. The quality of life index is considered in the majority of cases to be equal to and, in some cases, lower than that of a control population.

François-Fiquet et al. [4], in his study, found that patients' quality of life was estimated by patients at an average of 65.1/100. This overall quality of life index was comparable $(P=0.66)$ to that of the control population. The perceived quality of life of patients by their parents was quite close to the quality of life described by patients $(66.5 / 100)$.

In our study, and during adolescence, problems of attractiveness, peer acceptance, and identity formation are particularly acute in populations and patients in general. With CLP, the results show that $67.5 \%$ of patients surveyed are complexed by their physical appearance.

Turner et al. [21] conducted a study in England that showed that a negative reaction from foreigners, real or perceived, can damage our own image. The links between physical attractiveness and the probability of success and social acceptability are well established. These links highlight the potential disadvantages for people affected by CLP because they may have an abnormal facial appearance [22-24].

Broder et al. [7] mainly showed higher levels of dissatisfaction with body image associated with an increase in apparent anxiety in patients related to their CLP.

Similarly, our psychological study revealed that only $2.5 \%$ of adolescents have self-confidence and $47.5 \%$ tend to take life on the bright side.

Several studies have reported that the majority of patients and their parents report that self-confidence has been affected or "very affected" by the cleft. Lower levels of self-esteem have also been observed in adults with CLP [25-28].

\subsection{CLP and social aspect}

In our study, socially, more than $60 \%$ of adolescents reported a better quality of life in their relationships with friends and $72.5 \%$ found that they are understood and reassured by their friends with only $27.5 \%$ of adolescents worried about their future. The highest index in this field explains our patients by the fact that they have developed a privileged relationship with their "best friend," integrating almost total trust, a greater complicity than between classmates without a surgical background.

These results disagree with those observed in several studies, in particular that of Antoun et al. [29] who found that children with facial malformations may have specific attitudes that influence or even interfere with interactions with others. Facial malformations are not the most accepted physical abnormality in the population with a higher incidence of facial mockery; another factor that affects the social life of their children is the visible deficiency, nose and lips by this abnormality having a negative impact on peer interactions or even in the field of marriage.

Stock et al. [28] conducted a study in which they found that children with CLP were less socially motivated, less competent, and less effective in overall social functioning than their peers without CLP. 
The study by François-Fiquet et al. [4] is consistent with our study which shows that these patients have achieved better results in the areas of friendship.

On the other hand, concerning the fields of schooling showed that the quality of life index was proportionally lower than that of the other fields [4]. Another study by Turner et al. [21] indicates that social anxiety was associated with poor academic performance, in addition to communication difficulties and words encountered in patients. The study by Broder et al. [7] found that patients with CLP requiring multiple surgical procedures had lower school scores.

\subsection{Parent's relationship and quality of life}

In our study, $75 \%$ of parents thought that their children spoke freely with them and $45 \%$ thought that their children spoke well with other family members as well.

The highest scores in the literature on parent-child relationships are partly explained by the importance of parents' investment in care over many years and also by daily concerns about the mockery and stigma that could affect their child [30].

The study by François-Fiquet et al. [4] confirmed the presence of a fusional and overprotective parental relationship that can be established, leading in some cases to an increased dependence of adolescents on their parents. This may even lead to a later departure from the family unit.

Parents' feelings about their children's facial anomaly are expected to be critical to their well-being in developing the child's self-esteem, although at the birth of their babies, they may experience feelings of uneasiness, shock, confusion, pain, and guilt; over time, they seek to adapt and better understand it to ensure maximum comfort and social integration.

The announcement of a facial malformation affecting their child is a major psychological test for parents. Other studies [10, 31-33] have found that parents' first relationships with their children are based on conscious and unconscious emotions, which essentially involve touch, sound of voice, gaze, and facial expression.

When the newborn is carrying a CLP, parents are brutally confronted with their child's "spoiled, open, cracked" face, and the emotional overload of this event can slow down their emotional investment. Thus, the parent-child relationship can be affected from birth [34]. The mother's attachment to her child during childhood does not seem to be a problem, quite the contrary. This is because a mother protects her child more when he or she has an unsightly face $[8,35]$.

Aslan et al. [36] identified in their study the multiple variables affecting family functions and life quality of parents with cleft lip and/or palate children. In fact, the parents of CLP children need to be strengthened in behavioral control, roles, and the required attention areas of family functions at early childhood and at required attention area in all age groups of children. In addition, families need to be supportive for social, physical, and the psychological fields of QoL when their children are in adolescence growth period. Therefore, concepts of psychological services in cleft centers should be developed, and a family-centered approach should be applied caring the psychosocial needs of parents, children, and their families.

\subsection{Orofacial functions and quality of life}

In our study, $50 \%$ of adolescents lacked vitality and energy according to them and $45 \%$, according to their parents.

Grollemund et al. [9] and François-Fiquet et al. [4] confirmed that although patients with bilateral FLP are functionally satisfied with their speech, swallowing, and hearing, they are significantly dissatisfied with their appearance, particularly 
in the upper lip and nose. This dissatisfaction with the esthetic result may even be an early sign of depression [37].

People with CLP can suffer from a variety of disorders: behavioral disorders, anxiety, depression, and facial esthetic dissatisfaction in both children and adults. The difficulty in interpreting these disorders lies in the multiplicity of factors that can influence the quality of life of these people.

A retrospective cohort study including 220 child born with unilateral CL+A, concluded that the findings of this study provide a reference for morphologic variations in $\mathrm{CL}+\mathrm{A}$ and insight into the surgical burden of care until the age of 18 years. These results are consistent with the results of our study on the influence of the management of cleft lip and palate on the quality of life of children and adolescents [38].

\subsection{Limitation of this study}

Our study was a retrospective monocentric study for the evaluation of the quality of life in patients with cleft lip or labial palate and their parents. This is justified by the difficulty of accessing this particular population; in general, these anomalies affect with disparity a population with an unfavorable socio-economic and cultural context. On the other hand, a prospective longitudinal study with an evaluation at the beginning and at the end of treatment and long-term follow-up with a comparison group of children without CL and CLP would have been more relevant.

\section{Conclusion}

At the end of this work, we concluded that patients' and their parents' perceptions of quality of life remain average, with satisfaction rates of 59.61 for the former and 60.58 for the latter.

Teenagers had the lowest quality of life rates in the items: physical appearance and self-esteem, while their parents did not like the fact that their children were dissatisfied with their lives.

Multidisciplinary management is the rule in the treatment of the after-effects of cleft lip and palate. However, it will be necessary to strengthen the role of the psychologist in the therapeutic chain of these patients, as they are currently still neglected at the expense of surgeons and orthodontists.

\section{Conflict of interest}

The authors declare no conflict of interest in relation to this chapter. 


\section{Author details}

Latifa Elmouden $^{1 *}$, Fatima Zahra Elgasmi ${ }^{2}$ and Lahcen Ousehal ${ }^{1}$

1 Faculty of Dentistry, Department of Orthodontics and Dentofacial Orthopedics, Hassan II University, Casablanca, Morocco

2 Faculty of Dentistry, Department of Pediatric Dentistry, Hassan II University, Casablanca, Morocco

*Address all correspondence to: latifaelmouden11@gmail.com

\section{IntechOpen}

(C) 2020 The Author(s). Licensee IntechOpen. This chapter is distributed under the terms of the Creative Commons Attribution License (http://creativecommons.org/licenses/ by/3.0), which permits unrestricted use, distribution, and reproduction in any medium, provided the original work is properly cited. (cc) BY 


\section{References}

[1] Centers for Disease Control and Prevention (CDC). Improved national prevalence estimates for 18 selected major birth defects--United States, 1999-2001. Morbidity and Mortality Weekly Report. 2006;54:1301-1305

[2] Peterson LJ, Ellis E, Hupp JR, Tucker MR. Contemporary Oral \& Maxillofacial Surgery. 5th ed. St. Louis (USA): Mosby; 2008

[3] Veau V, Récamier J. Bec-de-lièvre: Clinical Forms, Surgery. Paris: Masson; 1938. p. 342

[4] François-Fiquet C, Dupouy M, Daoud S, Poli-Merol M-L. Cleft lip and palate: Health-related quality of life (French VSP-A scale) for patients and their family. About 51 families. Annales de Chirurgie Plastique et Esthétique. 2015;60:192-200. DOI: 10.1016/j. anplas.2014.08.008

[5] Elmouden L, Ousehal L. Assessment of the quality of life in Moroccan patients undergoing Orthognathic surgery. Turkish Journal of Orthodontics. 2018;31(3):79-85. DOI: 10.5152/TurkJOrthod.2018.17040

[6] Mani M, Carlsson M, Agneta M. Quality of life varies with gender and age among adults treated for unilateral cleft lip and palate. The Cleft PalateCraniofacial Journal. 2010;47(5): 491-498. DOI: 10.1597/08-281

[7] Broder HL, Maureen W-G, Lacey S, Robert GN. Examining factors associated with Oral health-related quality of life for youth with cleft. Plastic and Reconstructive Surgery. 2014;133(6):828e-834e. DOI: $10.1097 /$ PRS.0000000000000221

[8] Eckstein DA, Wu RL, Akinbiyi T, Silver L, Taub PJ. Measuring quality of life in cleft lip and palate patients: Currently available patient-reported outcomes measures. Plastic and Reconstructive Surgery. 2011;128(5):518e-526e. DOI: 10.1097/ PRS.0b013e31822b6a67

[9] Eslami N, Majidi MR, Aliakbarian M, Hasanzadeh N. Oral health-related quality of life in children with cleft lip and palate. The Journal of Craniofacial Surgery. 2013;24(4):e340-e343. DOI: 10.1097/SCS.0b013e31828b743b

[10] Grollemund B, Galliani E, Soupre V, Vazquez MP, Guedeney A, Danion A. The impact of cleft lip and palate on the parent-child relationships. Archives de Pédiatrie. 2010;17:13801385. DOI: 10.1016/j.arcped.2010.06.026

[11] WHOQOL Group of the World Health Organization. Study protocol for the World Health Organization project to develop a quality of life assessment instrument (WHOQOL). Quality of Life Research. 1993;2:153-159. DOI: 10.1007/ BF00435734

[12] Charlotte P, Craniofacial P-AB. Anomalies and quality of life. Seminars in Orthodontics. 2007;13:116-121. DOI: 10.1053/j.sodo.2007.03.007

[13] Rando GM, Jorge PK, Vitor LLR, Carrara CFC, Soares S, Silva TC, et al. Oral health-related quality of life of children with oral clefts and their families. Journal of Applied Oral Science. 2018;26:e20170106. DOI: 10.1590/1678-7757-2017-0106

[14] Vuletić M, Marčinko D, Vražić D, Milošević M, Dediol E, Knežević P. Development of a valid and reliable instrument for the assessment of quality of life in adolescents with clefts - detection of potential mental health issues. Psychiatria Danubina. 2017;29:360-368. DOI: 10.24869/ psyd. 2017.360

[15] Sischo L, Wilson-Genderson M, Broder HL. Quality-of-life in children 
with orofacial clefts and caregiver well-being. Journal of Dental Research. 2017;96:1474-1481. DOI: 10.1177/0022034517725707

[16] Sundell AL, Törnhage CJ, Marcusson A. A comparison of healthrelated quality of life in 5 - and 10 -yearold Swedish children with and without cleft lip and/or palate. International Journal of Paediatric Dentistry. 2017;27:238-246. DOI: 10.1111/ipd.12253

[17] Pisek A, Waranuch P, Bowornsilp C, Suteera P. Oral health status and oral impacts on quality of life in early adolescent cleft patients. Journal of the Medical Association of Thailand. 2014;97(10):S7-S16

[18] Kramer FJ, Baethge C, Sinikovic B, Schliephake H. An analysis of quality of life in 130 families having small children with cleft lip/palate using the impact on family scale. International Journal of Oral and Maxillofacial Surgery. 2007;36(12):1146-1152. DOI: 10.1016/j. ijom.2007.06.009

[19] Konan P, Manosudprasit M, Pisek P, Pisek A, Wangsrimongkol T. Oral health-related quality of life in children and young adolescent orthodontic cleft patients. Journal of the Medical Association of Thailand. 2015;98(7):S84-S91

[20] Srinivas GR et al. Health related quality of life of patients with nonsyndromic orofacial clefts. Journal of Oral and Maxillofacial Surgery, Medicine, and Pathology. 2012;24:6-10. DOI: 10.1016/j.ajoms.2011.08.004

[21] Turner SR, Rumsey N, Sandy JR. Psychological aspects of cleft lip and palate. European Journal of Orthodontics. 1998;20(4):407-415. DOI: 10.1093/ejo/20.4.407

[22] Awoyale T, Onalaje AT, Ogunnowo BE, Adeyemo WL, Wanyonyi KL, Butali A. Quality of life of family caregivers of children with orofacial clefts in Nigeria: A mixed - Method study. Oral Diseases. 2016;22(2):116-122. DOI: 10.1111/ odi.12379

[23] Sinko K, Jagsch R, Prechtl V, Watzinger F, Hollmann K,

Baumann A. Evaluation of esthetic, functional, and quality-of-life outcome in adult cleft lip and palate patients. The Cleft Palate-Craniofacial Journal. 2005;42:355-361. DOI: 10.1597/03-142.1

[24] Raghavan S, Philip K, Batra P, Marcusson A. Aesthetic perceptions and psychosocial impact of malocclusion: Comparison between cleft and non-cleft patients and their parents. European Journal of Orthodontics. 2018;41(1): 38-45. DOI: 10.1093/ejo/cjy022

[25] Kapp-Simon KA, McGuire DE. Observed social interaction patterns in adolescents with and without craniofacial conditions. The Cleft Palate-Craniofacial Journal. 1997;34:380-384. DOI: 10.1597/15451569_1997_034_0380_osipia_2.3.co_2

[26] Lorot-Marchand A, Guerreschi P, Pellerin P, Martinot V, Gbaguidi CC, Neiva C, et al. Frequency and sociopsychological impact of taunting in school-age patients with cleft lip-palate surgical repair. International Journal of Pediatric Otorhinolaryngology. 2015;79(7):1041-1048. DOI: 10.1016/j. ijporl.2015.04.024

[27] Piombino P, Ruggiero F, Dell'Aversana Orabona G, Scopelliti D, Bianchi A, De Simone F, et al. Development and validation of the quality-of-life adolescent cleft questionnaire in patients with cleft lip and palate. The Journal of Craniofacial Surgery. 2014;25(5):1757-1761. DOI: 10.1097/SCS.0000000000001033

[28] Stock NM, Feragen KB. Psychological adjustment to cleft lip and/or palate: A narrative review 
of the literature. Psychology \& Health. 2016;31:777-813. DOI: 10.1080/08870446.2016.1143944

[29] Antoun JS, Fowler PV, Jack HC, et al. Oral health-related quality of life changes in standard, cleft, and surgery patients after orthodontic treatment. American Journal of Orthodontics and Dentofacial Orthopedics. 2015;148:568575. DOI: 10.1016/j.ajodo.2015.03.028

[30] Warschausky S, Kay JB, Buchman S, Halberg A, Berger M. Health-related quality of life in children with craniofacial anomalies. Plastic and Reconstructive Surgery. 2002;110:409414 , discussion 415-406. DOI: 10.1097/00006534-200208000-00004

[31] Kortelainen T, Tolvanen M, Luoto A, Ylikontiola LP, Sandor GK, Lahti S. Oral health-related quality of life among cleft lip and/or palate and school children. The Cleft Palate-Craniofacial Journal. 2016;53:172-176. DOI: 10.1597/14-180

[32] Munz SM, Edwards SP, Inglehart MR. Oral health-related quality of life and satisfaction with treatment and treatment and treatment outcomes of adolescents/young adults with cleft lip/palate: An exploration. International Journal of Oral and Maxillofacial Surgery. 2011;40:790-796. DOI: 10.1016/j.ijom.2011.03.002

[33] Thomas PT, Turner SR, Rumsey N, Dowell T, Sandy JR. Satisfaction with facial appearance among subjects affected by a cleft. The Cleft Palate-Craniofacial Journal. 1997;34:226-231. DOI: 10.1597/15451569_1997_034_0226_swfaas_2.3.co_2

[34] Marcusson A, Akerlind I, Paulin G. Quality of life in adults with repaired complete cleft lip and palate. The Cleft Palate-Craniofacial Journal. 2001;38:379-385. DOI: 10.1597/15451569_2001_038_0379_qoliaw_2.0.co_2

[35] Oosterkamp BC, Dijkstra PU, Remmelink HJ, et al. Satisfaction with treatment outcome in bilateral cleft lip and palate patients. International Journal of Oral and Maxillofacial Surgery. 2007;36:890-895. DOI: 10.1016/j.ijom.2007.07.008

[36] Aslan BI et al. Family functions and life quality of parents of children with cleft lip and palate. The Journal of Craniofacial Surgery. 2018;29(6):1614-1618. DOI: 10.1097/ SCS.0000000000004611

[37] Hunt O, Burden D, Hepper P, Johnston C. The psychosocial effects of cleft lip and palate: A systematic review. European Journal of Orthodontics. 2005;27:274-285. DOI: 10.1093/ejo/ cji004

[38] Mandal E et al. Eighteen-year follow-up of 160 consecutive individuals born with unilateral cleft lip or cleft lip and alveolus treated by the Oslo cleft lip and palate team. The Cleft PalateCraniofacial Journal. 2019;56(7):853-859 DOI: $10.1177 / 1055665618820753$ 


\section{Edited by Ayşe Gülşen}

Non-syndromic cleft lip and palate patients have the most common congenital anomalies that affect the middle and lower part of the face, and which impair aesthetic integrity. These anomalies also affect basic functions such as hearing, speaking, chewing, and breathing. Treatment of patients with cleft lip and palate requires multidisciplinary teamwork. The cleft child should be followed and treated by a team of experts from different disciplines who work well together. Although cleft surgery, orthodontic treatment, and speech therapy are the main disciplines, each of the other branches (maxilla-facial-surgeon, otolaryngologist, speech therapist, pediatric dentist, psychologist, nurse etc.) are also very important. In this book, we wanted to present the reader with the experiences and knowledge of some of these disciplines. This book

also includes information on the quality of life of children with this anomaly and anesthesia evaluation, which is very important for the cleft surgery. 